\title{
Modeling and Cold Start in Alcohol-Fueled Engines
}

\author{
A. J. Markel and B. K. Bailey \\ National Renewable Energy Laboratory \\ Golden, Colorado
}

RECEIVED

MAY 261998

OSTI

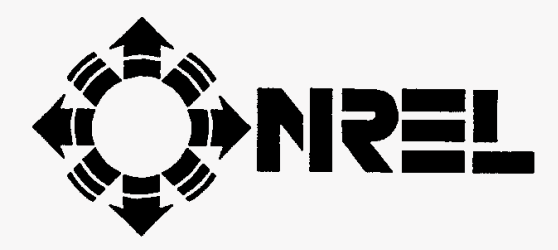

Alternative Fuels Hotline: 1-800-423-1DOE

Alternative Fuels Data Center World Wide Web Site: http://www.afdc.doe.gov

National Renewable Energy Laboratory

1617 Cole Boulevard

Golden, Colorado 80401-3393

A national laboratory of the

U.S. Department of Energy

Managed by the Midwest Research Institute

For the U.S. Department of Energy

Under Contract No. DE-AC36-83CH10093

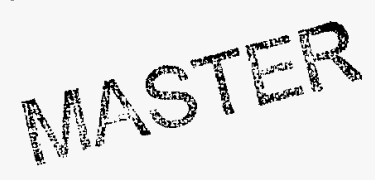




\title{
Modeling and Cold Start in Alcohol-Fueled Engines
}

\author{
A. J. Markel and B. K. Bailey \\ National Renewable Energy Laboratory \\ Golden, Colorado
}

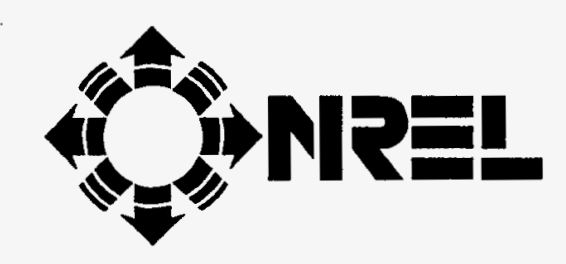

Alternative Fuels Hotline: 1-800-423-1DOE

Alternative Fuels Data Center World Wide Web Site: http://www.afdc.doe.gov

National Renewable Energy Laboratory

1617 Cole Boulevard

Golden, Colorado 80401-3393

A national laboratory of the

U.S. Department of Energy

Managed by the Midwest Research Institute

For the U.S. Department of Energy

Under Contract No. DE-AC36-83CH10093

Prepared under Task Number FU702130

May 1998 


\section{NOTICE}

This report was prepared as an account of work sponsored by an agency of the United States government. Neither the United States government nor any agency thereof, nor any of their employees, makes any warranty, express or implied, or assumes any legal liability or responsibility for the accuracy, completeness, or usefulness of any information, apparatus, product, or process disclosed, or represents that its use would not infringe privately owned rights. Reference herein to any specific commercial product, process, or service by trade name, trademark, manufacturer, or otherwise does not necessarily constitute or imply its endorsement, recommendation, or favoring by the United States govemment or any agency thereof. The views and opinions of authors expressed herein do not necessarily state or reflect those of the United States government or any agency thereof.

Available to DOE and DOE contractors from:

Office of Scientific and Technical Information (OSTI)

P.O. Box 62

Oak Ridge, TN 37831

Prices available by calling (423) $576-8401$

Available to the public from:

National Technical Information Service (NTIS)

U.S. Department of Commerce

5285 Port Royal Road

Springfield, VA 22161

(703) $487-4650$ 


\begin{abstract}
Neat alcohol fuels offer several benefits over conventional gasoline in automotive applications. However, their low vapor pressure and high heat of vaporization make it difficult to produce a flammable vapor composition from a neat alcohol fuel during a start under cold ambient conditions. Various methods have been introduced to compensate for this deficiency. In this study, we applied computer modeling and simulation to evaluate the potential of four cold-start technologies for engines fueled by near-neat alcohol. The four cold-start technologies included a rich combustor device, a partial oxidation reactor, a catalytic reformer, and an enhanced ignition system. For comparison purposes, we also simulated the cold-start performance of several fuel blends. We ranked the competing technologies by their ability to meet two primary criteria for cold starting an engine at $-25^{\circ} \mathrm{C}$ and also by several secondary parameters related to commercialization. First, an acceptable cold-start technology approach must be able to provide a vapor phase equivalence ratio (VPER) greater than approximately 0.50 to begin the ignition process. Second, the supplied mixture must have an energy density greater than approximately 2500 Joules/Liter $(\mathrm{J} / \mathrm{L})$ to overcome the high friction loads present in a cold-cranking engine and to accelerate the engine to a stable idle speed. Both the catalytic reformer and the enhanced ignition system cold-start technologies exceeded the performance criteria. However, the enhanced ignition system seems more commercially viable. Our analysis suggests that of the four technologies evaluated, the enhanced ignition system is the best option for further development.
\end{abstract}




\section{Executive Summary}

Using alcohol fuels in automotive applications can result in decreased greenhouse gas emissions, lessened dependence on foreign petroleum, and improved engine efficiency. However, because alcohol-fueled engines are difficult to start under cold ambient conditions, several cold-start technologies have been developed to assist with engine starting.

This report describes work performed by the National Renewable Energy Laboratory (NREL) to evaluate four cold-start technologies for alcohol-fueled engines. These four technologies were developed concurrently under separate NREL subcontracts, with funding from the U.S.

Department of Energy (DOE). The project was designed to provide insight and recommendations for future research and development paths related to these four technologies.

We evaluated a rich combustor device, a partial oxidation reactor, a catalytic reformer, and an enhanced ignition system. We have included in this report basic descriptions of each technology, based on information provided by the principal investigators for each subcontract.

The evaluation process was composed of several steps. First, we performed a literature review to provide background information on cold-start technologies and computer modeling applications. As a result, we compiled a summary report including a detailed bibliography of resources for future reference. Based on this information, we then selected the computer simulation tools to use in the evaluation-ASPEN Plus, a chemical process modeling software package, and SIS, an engine cycle simulation program. Then, we determined the parameters for comparison. The primary comparison was based on performance. The primary comparison parameters included the supplied vapor phase equivalence ratio (VPER) and the energy density. An acceptable technology must be able to provide an average VPER greater than 0.50 and an energy density greater than 2500 Joules/Liter (J/L). The selection of these values was based on a combination of published, experimental, and simulation-generated data. The secondary parameters were related to commercialization and included cost, durability, pre-heating or delay period, and ease of implementation. We based the secondary rankings of each technology on the evaluation of information presented in subcontract reports and other publications.

Because the current approach for cold-starting alcohol-fueled engines is to use a blended fuel, such as M85 (85\% methanol plus 15\% primer), we also evaluated several fuel blends against the primary acceptance standards. We created an ASPEN Plus model for the fuel blends and derived a multi-component pseudo-gasoline blend for the evaluation.

The averaged results of the fuel blends analysis showed that it is unlikely that fuel blending will satisfy the cold-start requirements at $-25^{\circ} \mathrm{C}$. Only the baseline gasoline and a high vapor pressure gasoline were able to meet the primary acceptance standards. The alcohol fuel blends were unable to provide a sufficient VPER. However, two cold-start technologies were able to meet the acceptance standards: the catalytic reformer and the enhanced ignition system. In addition, because the enhanced ignition system ranked highest in the secondary comparison, it should be more commercially viable. 
Based on this analysis, we recommend that further research and development toward commercialization be performed on the enhanced ignition system for application to cold starting of alcohol-fueled engines. 


\section{Contents}

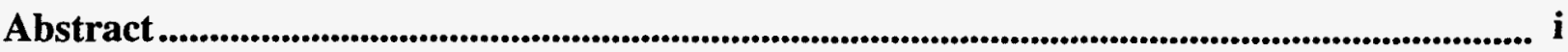

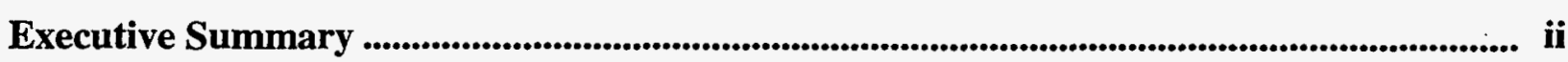

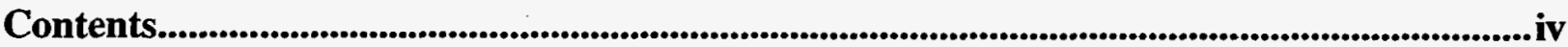

List of Tables ...................................................................................................................................................... v

List of Figures ....................................................................................................................................................

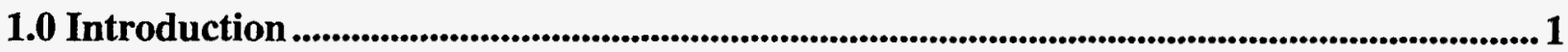

1.1 Background

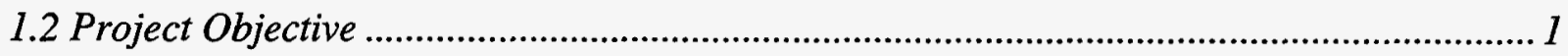

2.0 Description of Alcohol Cold-Start Technologies Evaluated......................................................2

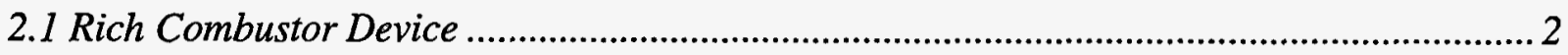

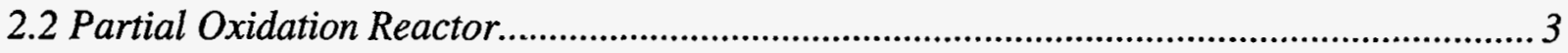

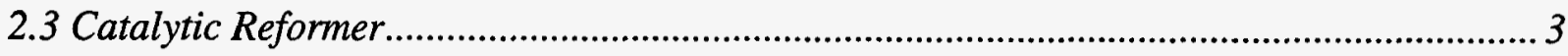

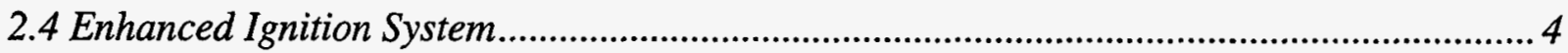

3.0 Evaluation Process .............................................................................................................................6 6

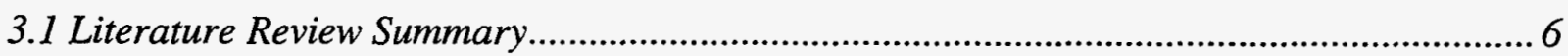

3.2 Application of Computer Modeling and Simulation Tools ................................................ 6

3.3 Description of the Comparison Parameters ...................................................................... 7

3.3.1 Primary Comparison Parameters …………...........................................................

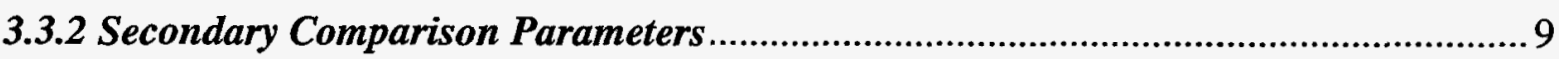

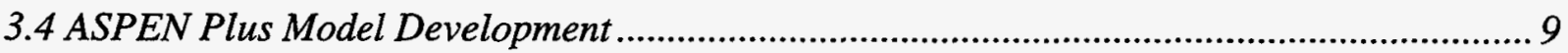

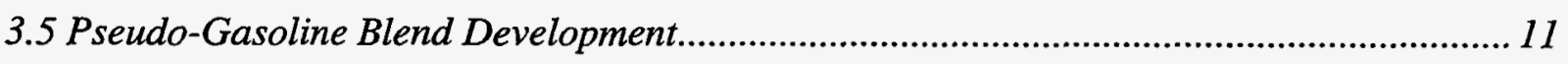

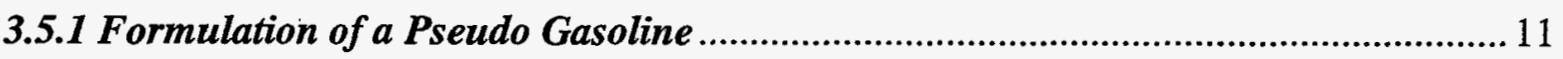

4.0 Fuel Blends Results and Discussion...............................................................................13

5.0 Cold-Start Technologies Results and Discussion ..................................................................... 16

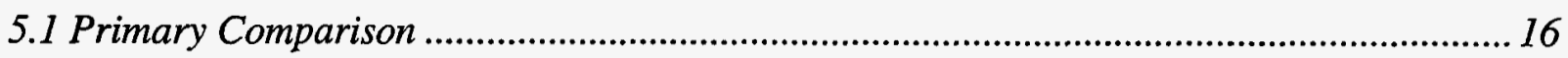

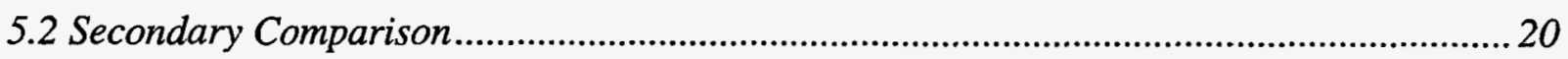

6.0 Summary, Conclusions, and Recommendations ..........................................................................22

7.0 Acknowledgments......................................................................................................................... 22

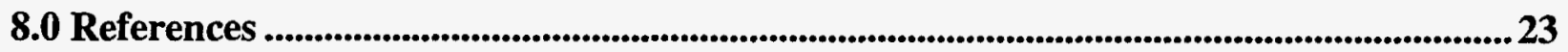

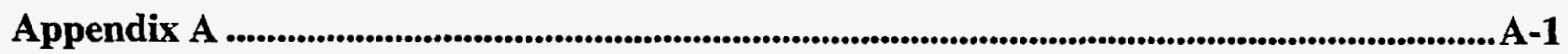

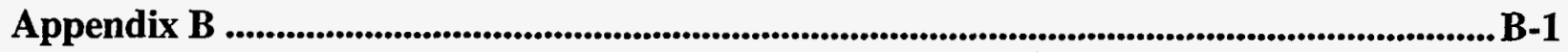

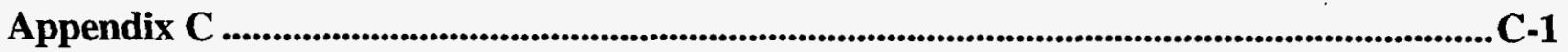




\section{List of Tables}

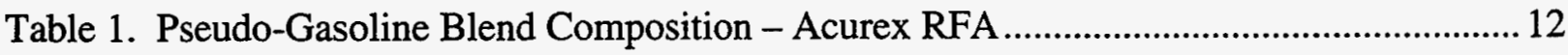

Table 2. Pseudo-Gasoline Blend Composition - Winter Blend ................................................... 13

Table 3. Model Operating Conditions Validation Results ............................................................ 14

Table 4. Fuel Blends Simulation Results - Summary ................................................................ 14

Table 5. Cold-Start Technology Simulation Parameters............................................................ 16

Table 6. Simulation Results - Rich Combustor Device................................................................. 17

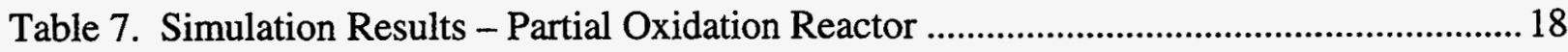

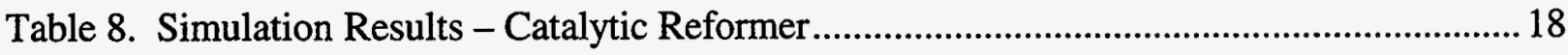

Table 9. Simulation Results - Enhanced Ignition System ........................................................... 19

Table 10. Summary of Cold-Start Technology Simulation Results ............................................... 19

Table 11. Secondary Comparison of Cold-Start Technologies .......................................................2

\section{List of Figures}

Figure 1. Alcohol Fuel Equilibrium Vapor Phase Equivalence Ratios ....................................... 2

Figure 2. Rich Combustor Device Schematic ..................................................................... 3

Figure 3. Partial Oxidation Reactor Schematic ................................................................. 4

Figure 4. Catalytic Reformer Schematic ............................................................................

Figure 5. Enhanced Ignition System Schematic ..................................................................... 5

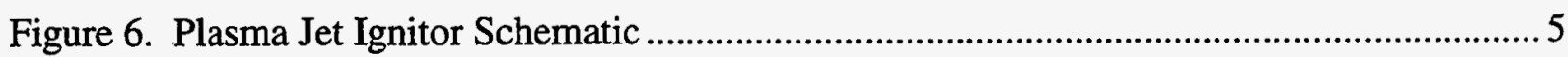

Figure 7. Vapor Phase Equivalence Ratios of Various Fuels and Fuel Components...................... 7

Figure 8. ASPEN Plus Simulation Flow Sheet - Rich Combustor Model .................................. 10

Figure 9. ASPEN Plus Simulation Flow Sheet - Fuel Blends Model........................................... 11

Figure 10. Fuel Blends Cold-Start Performance Prediction - Averaged Results.......................... 15

Figure 11. Fuel Blends Cold-Start Performance Predictions - Full Results ................................ 15

Figure 12. Cold Start Technology Simulation Results - Averaged ............................................... 20

Figure 13. Cold-Start Technology Simulation Results - Full........................................................ 20

Figure 14. Secondary Comparison of Cold-Start Technologies.....................................................2 21

Figure 15. Secondary Comparison of Cold-Start Technologies - Average Combined Index......22 


\subsection{Introduction}

\subsection{Background}

Using alcohol fuels offers several benefits over using petroleum fuels in automobiles. Both methanol and ethanol have lower vapor pressures than gasoline, which means that they produce fewer evaporative emissions. Furthermore, the emissions from combustion of ethanol and methanol are less reactive in the atmosphere than those of gasoline $[1,2]$. In addition, alcohol fuels can help to reduce our dependence on petroleum imports and reduce greenhouse gas emissions because they can be derived from renewable and domestic resources. Finally, alcohols typically have high octane ratings, which allow the use of higher engine compression ratios, leading to improved efficiency [3].

On the other hand, alcohols do have a few disadvantages compared to gasoline. They have lower heating values, so they require more fuel mass to release the same amount of energy. In addition, they have higher heats of vaporization, so they require more energy to convert the same mass of liquid fuel to a vapor state. In addition, the lower flammability limits of methanol $(6.7 \%$ by volume) and ethanol (3.3\%) are higher than that of a typical gasoline (1.3\%) [4]. As a result, a larger concentration (by volume) of the alcohol fuel vapor must be present for the mixture to ignite compared to gasoline.

The low vapor pressure, the high heat of vaporization, and the higher lean flammability limit of alcohol fuels make them inherently difficult to ignite under cold ambient conditions. Figure 1 shows that the vapor phase equivalence ratio of equilibrium mixtures of neat methanol and neat ethanol in air drops below 0.50 at approximately $8.3^{\circ} \mathrm{C}$ and $11.2^{\circ} \mathrm{C}$, respectively. In general, below these temperatures, it is unlikely that a flammable mixture will be produced without assistance.

Various approaches to improving the cold startability of alcohol-fueled engines have been investigated. Many of these are discussed in more detail in Appendix A, Task 1: Review of Industry and Literature Resources. This report includes a summary of our literature review and a bibliography organized by topic. In general, the cold-start approaches can be grouped into fuelrelated and engine-related technologies. Fuel-related solutions include blending, fuel reforming, fuel heating, and improved atomization. Engine-related approaches include ignition system modifications, increased cranking speed, and direct injection technology. In this report, we present our evaluation of three fuel-related technologies (a rich combustor device, a partial oxidation reactor, and a catalytic reformer) and one engine-related technology (an enhanced ignition system).

\subsection{Project Objective}

The purpose of this project was to evaluate the potential of the four cold-start technologies mentioned above. Because these technologies are under development, limited experimental data were available. In addition, the technologies have been tested on different engines under different operating conditions. Still, no one technology emerges as the clear leader-each has 
advantages and disadvantages. To compare the technologies on a relative basis for potential cold-start assistance, we used computer modeling and simulation. We generated performance predictions to assist in selecting a cold-start technology that would improve the cold startability of alcohol-fueled engines at $-25^{\circ} \mathrm{C}$.

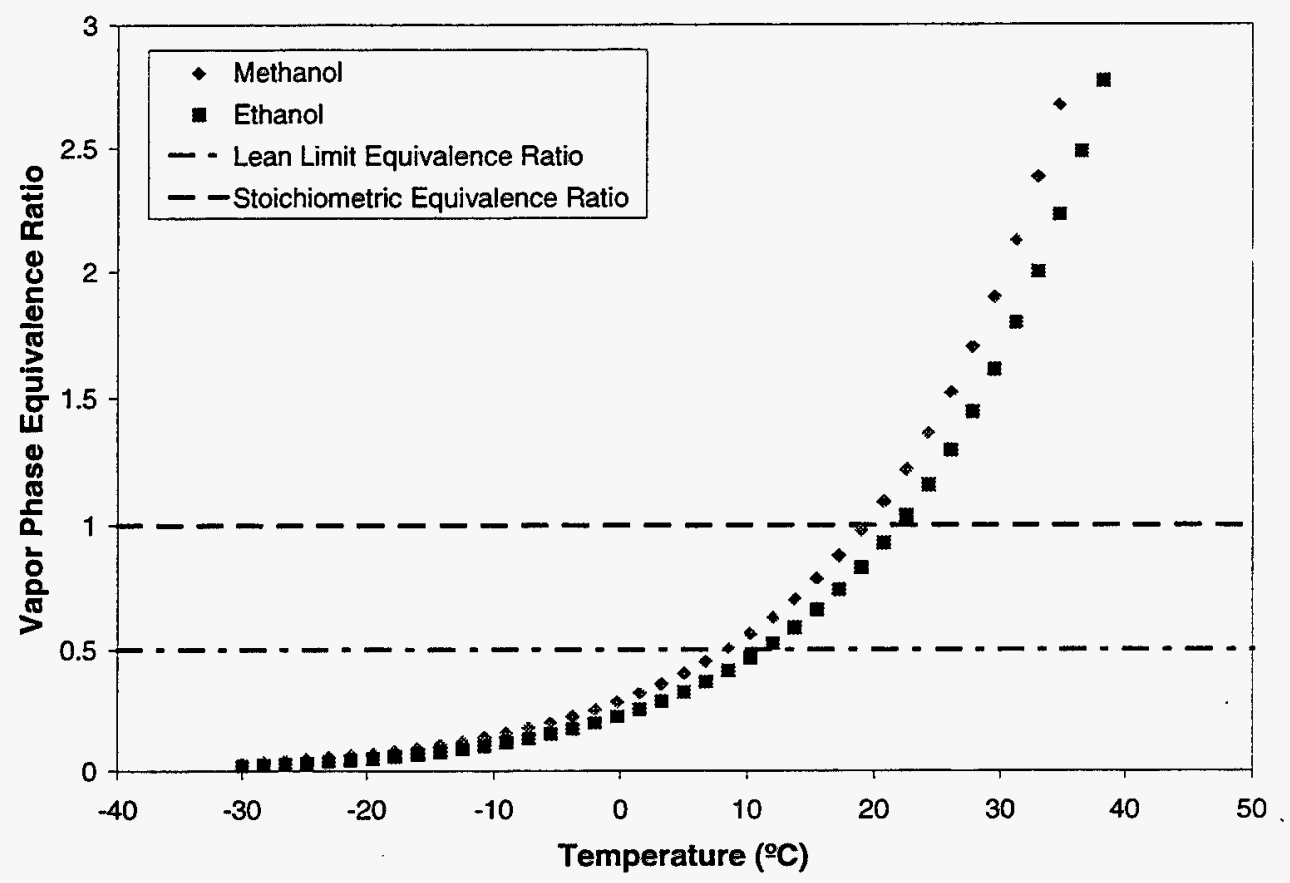

Figure 1. Alcohol Fuel Equilibrium Vapor Phase Equivalence Ratios

\subsection{Description of Alcohol Cold-Start Technologies Evaluated}

The four cold-start technologies evaluated, along with the names of the principal investigator for each include: a rich combustor device (Jeffery Hogdson, University of Tennessee), a partial oxidation reactor (Peter Loftus, Arthur D. Little, Inc.), a catalytic reformer (Scott Cowley, Colorado School of Mines), and an enhanced ignition system (David Gardiner, Thermotech Engineering). Each technology is described in more detail below.

\subsection{Rich Combustor Device}

Figure 2 is a schematic of the rich combustor device. The device uses a set of two ignitors to partially combust a fuel-rich mixture (fuel/air equivalence ratio of approximately 2.0 ) prior to induction into the cylinder. The products of this process have a high concentration of carbon monoxide $(\mathrm{CO})$ and hydrogen $\left(\mathrm{H}_{2}\right)$. The combustion products are mixed with air and/or additional liquid fuel and inducted into the cylinder. $\mathrm{CO}$ and $\mathrm{H}_{2}$ will remain in a gaseous phase at extremely low temperatures and will alleviate the problem of alcohol fuel vapor condensing on the cold cylinder walls. In addition, the ignition of $\mathrm{CO}$ and $\mathrm{H}_{2}$ is less dependent on mixture concentration because both have very wide flammability ranges. The device attaches between the throttle body and the intake plenum. The primary throttle plate is used to control the overall 
equivalence ratio provided to the engine. A secondary throttle plate controls the combustor equivalence ratio by dividing the intake air between the bypass section and the combustor section. The bypass air is recombined with the combustor products prior to induction into the cylinder [5].

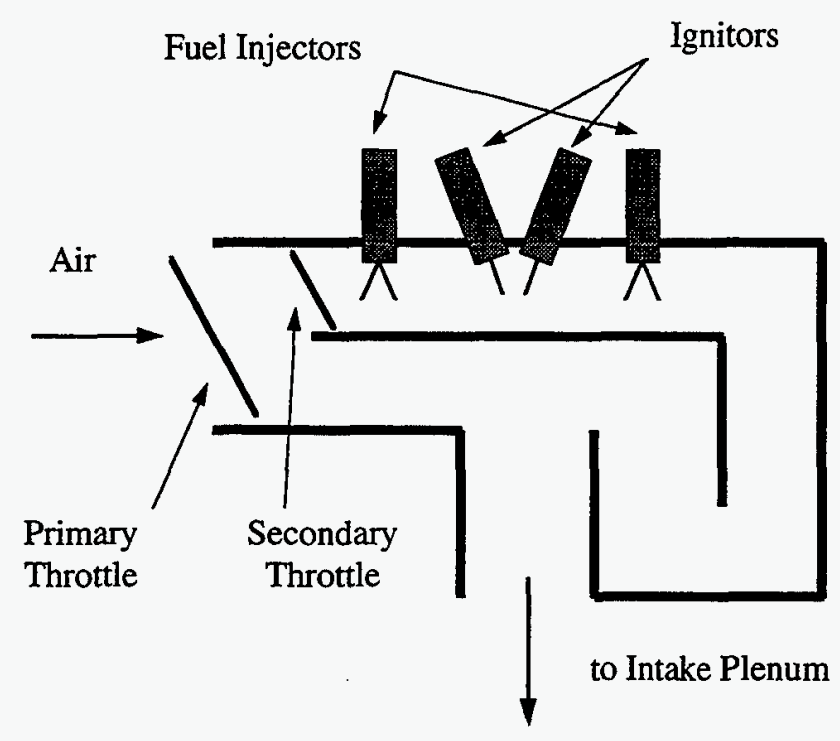

Figure 2. Rich Combustor Device Schematic

\subsection{Partial Oxidation Reactor}

Similar to the rich combustor device, the partial oxidation reactor (see schematic in Figure 3) also provides a fuel mixture rich in $\mathrm{CO}$ and $\mathrm{H}_{2}$ to the engine. The reactor itself is somewhat smaller than the rich combustor device because it uses a swirling flow pattern rather than the linear flow pattern of the rich combustor device. The swirling motion is caused by air entering the cylindrical reactor tangentially. A hot surface ignitor partially oxidizes the swirling fuel-rich mixture. The products of this process pass through a heat exchanger and are then combined with air and/or additional liquid fuel prior to induction into the cylinder. Many of the same benefits associated with the rich combustor device apply to the partial oxidation reactor [6].

\subsection{Catalytic Reformer}

The catalytic reformer passes vaporized fuel over a heated catalyst bed to dehydrate the alcohol fuel and produce either dimethyl ether from methanol or diethyl ether from ethanol. Figure 4 is a schematic of this system. The catalyst lowers the activation energy of the dehydration reaction, promoting the generation of ether. Dimethyl ether and diethyl ether both have high vapor pressures and wide flammability limits, which give them excellent cold-starting properties. With this system, only a fraction of the alcohol fuel is reformed to produce a sufficient amount of ether to improve cold startability. The reformer attaches to the intake manifold between the throttle body and the intake valve. In the current system, the fuel is heated and vaporized with electric heaters. It may be possible, however, to use exhaust energy for this task by passing hot exhaust 
gases over the reformer. In this case, ether could be produced during vehicle operation and stored on board for future starts [7].

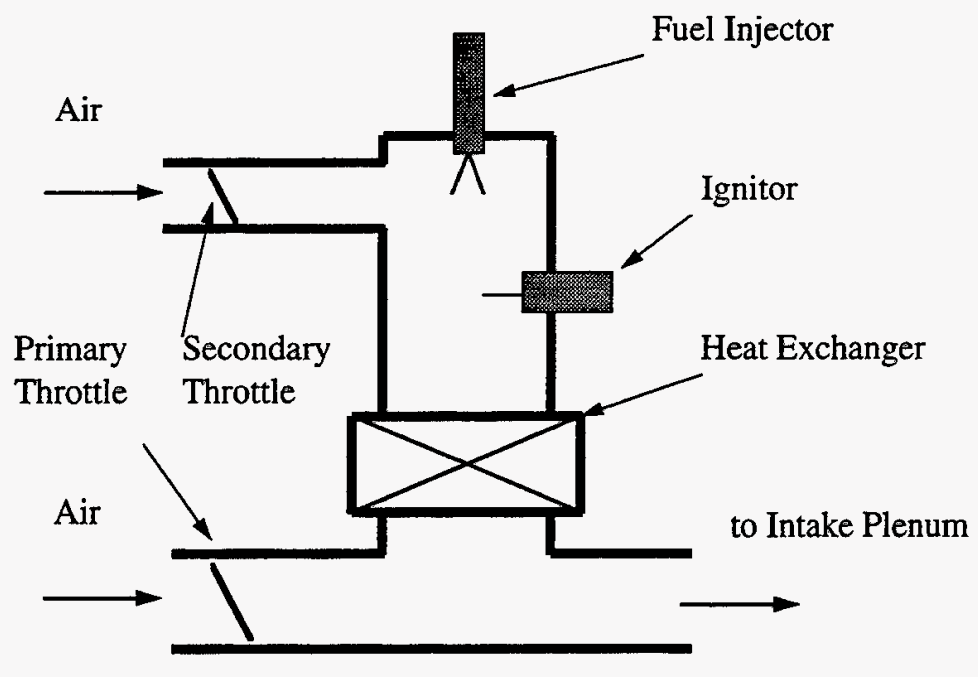

Figure 3. Partial Oxidation Reactor Schematic

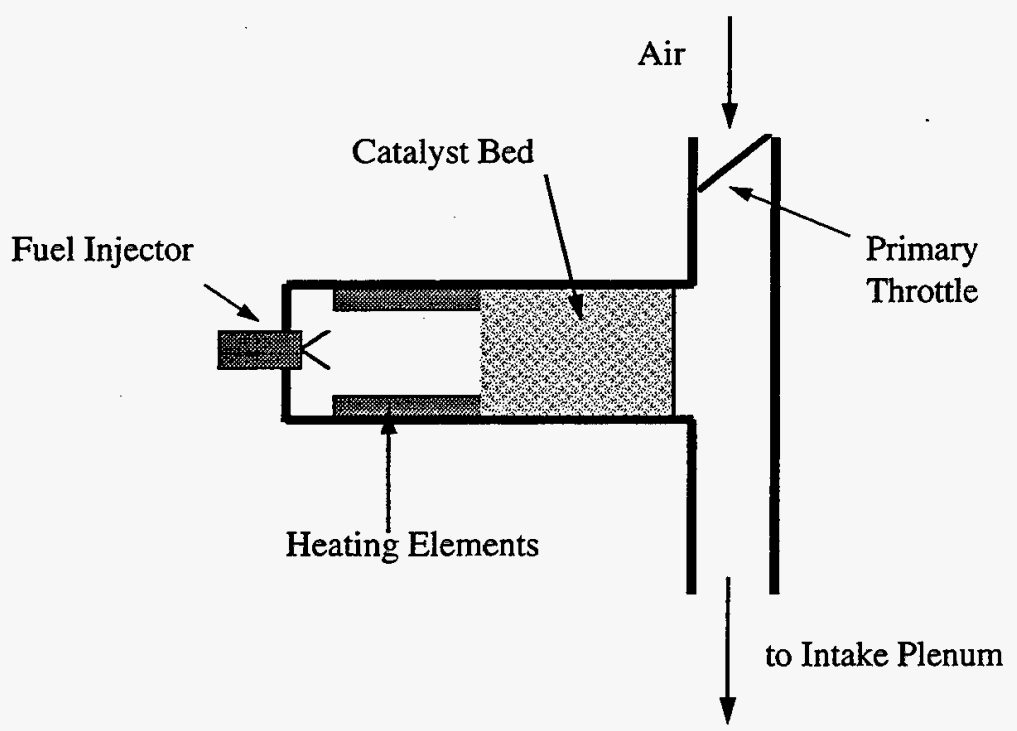

Figure 4. Catalytic Reformer Schematic

\subsection{Enhanced Ignition System}

The enhanced ignition system improves the cold startability of an alcohol-fueled engine by effectively using the ignition energy. Figure 5 provides a schematic representation of this system. A recessed gap ignitor (shown in Figure 6) is used to produce a plasma jet that disperses ignition energy over a large area within the cylinder. The jetting action is the result of hot gases 
expanding rapidly from the ignitor cavity. The spark energy is then transferred to the liquid fuel droplets near the ignition source. A vapor cloud surrounding the droplet is produced, in which ignition is probable. Thus the system does not rely solely on the presence of fuel vapor near the ignition source but can instead take advantage of the liquid fuel droplets present near the ignition source to initiate that combustion process. Through the use of additional circuitry, the enhanced ignition system energy discharge can be pulsed and usually spans a shorter time period while delivering more current than the standard ignition system. The enhanced ignition system replaces the standard ignition system components $[8,9]$.

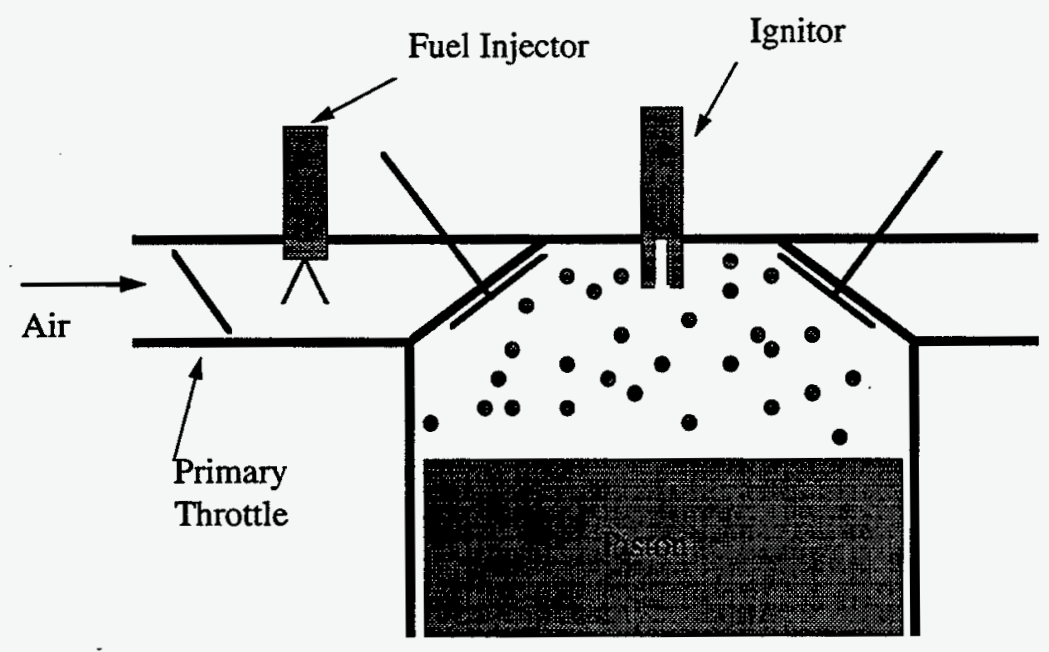

Figure 5. Enhanced Ignition System Schematic

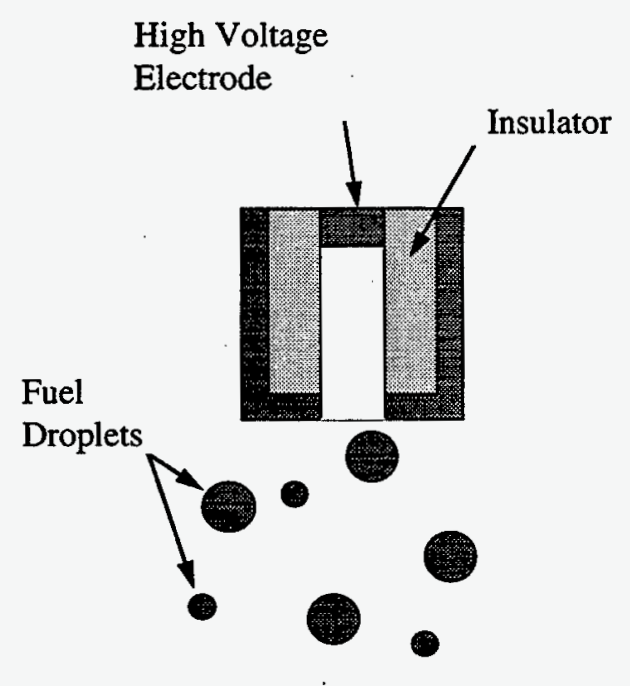

Recessed Gap Ignitor

Figure 6. Plasma Jet Ignitor Schematic 


\subsection{Evaluation Process}

\subsection{Literature Review Summary}

We performed a literature review on a variety of topics related to this project, including cold starting in general, cold starting with alcohol fuels, engine modeling and simulation, and fuel properties. We compiled a summary of the information collected in "Task 1: Review of Industry and Literature Resources," which can be found in Appendix A.

From the literature review, we drew the following conclusions:

- Experimental testing of cold-start approaches varies in both conditions and objectives.

- Computer modeling and simulation provides a common arena in which technologies can be compared.

- Although a variety of engine models exist, few attempt to simulate the initial startup phase. Instead, most are based on and thus best simulate steady-state, fully warmed operation.

- Independent of the fuel used, two primary conditions must be satisfied for an engine to start and attain a stable idle.

1. First, a flammable mixture of fuel vapor and air must be present near the ignition source at the time of ignition.

2. Second, sufficient fuel must be provided and combust such that enough energy is released to overcome friction and rotate the crankshaft.

\subsection{Application of Computer Modeling and Simulation Tools}

We used two primary simulation and evaluation tools-ASPEN Plus and SIS. ASPEN Plus is a chemical process modeling software package available from ASPEN Technology, Inc. We used it to simulate the cold-start technologies and predict the chemical composition of the fuel mixture delivered to the cylinders by the cold-start technologies. This package has and extensive databank of physical and chemical properties of numerous components and is able to quickly resolve the properties and states of complex non-ideal mixtures. It provides a selection of predefined process models, including reactors, heat exchangers and phase separators that can be combined on a flow sheet to represent a complete process. Although this package is unable to model the actual ignition event, it is useful for determining the composition and the state of components of the fuel mixtures provided by the various cold-start technologies and fuel blends. In addition, it allows the simulation of a variety of cases easily and quickly. Experimentation to achieve the same results would be costly and time-consuming.

SIS is a steady-state engine cycle simulation program developed by Dennis Assanis of the University of Michigan. With this program, an engine can be defined through a variety of parameters and its performance simulated under specific operating conditions. Inputs to the model include the number of cylinders, bore, stroke, and engine speed to name a few while the output provides information on fuel use, emissions, and efficiency. This tool was used to determine reasonable estimates for the energy requirements of a cold-cranking engine. 


\subsection{Description of the Comparison Parameters}

To evaluate the four technologies, we first determined the relevant comparison parameters. The two primary evaluation parameters used were the vapor phase equivalence ratio (VPER) and the energy density of the fuel mixture. Because the VPER relates to the presence of a combustible mixture at the time of ignition, it is a good indicator of the probability of ignition. The energy density is a measure of available energy per unit volume. It correlates to whether enough energy exists within a specific volume of fuel/air mixture to rotate the engine. In addition to the primary comparison parameters, we also used four secondary parameters related to commercialization for comparison. The secondary parameters include cost, durability, pre-heating/delay period, and ease of implementation. We determined comparative values for the primary parameters through computer modeling and simulation. We based the comparative values for the secondary parameters on the evaluation of published and presented information.

\subsubsection{Primary Comparison Parameters}

Vapor Phase Equivalence Ratio. We calculated the VPER based on the fuel/air mixture composition provided to the engine. The VPER was defined as

$$
\text { VPER }=\frac{(\text { Mass of Fuel Vapor } / \text { Mass of Air })}{(\text { Mass of Fuel } / \text { Mass of Air })_{\text {Stoichiometric }}} .
$$

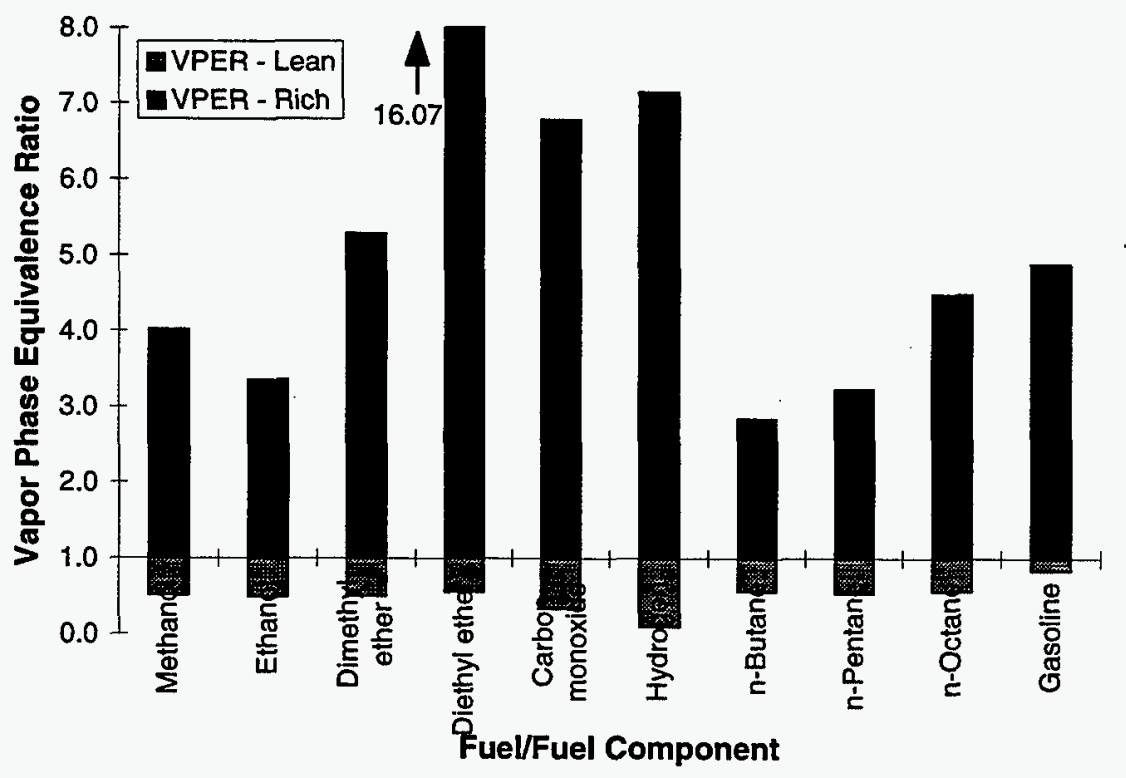

Figure 7. Vapor Phase Equivalence Ratios of Various Fuels and Fuel Components

Figure 7 compares VPER lean and rich limits for various fuels and common fuel components based on the flammability limits reported by Zabetakis at $25^{\circ} \mathrm{C}$ and 1 atmosphere (atm) [4].

Based on this information, pure methanol has a lean VPER limit of 0.51 and a rich limit of 4.02. 
Likewise, a pure ethanol mixture should be flammable with a VPER between 0.49 and 3.35 . In comparison, the VPER range for a typical gasoline is 0.84 to 4.87 . The average lean VPER limit of the fuels shown is 0.50 ; the average rich VPER limit is 5.81. Although a mixture with a VPER within these average limits will not guarantee ignition, the conditions will favor an ignition event.

From Figure 7 we can see that mixtures containing dimethyl ether, diethyl ether, carbon monoxide, or hydrogen should be relatively easy to ignite. These components have very wide ranges of flammability and corresponding wide ranges of acceptable VPERs. Therefore, the probability of ignition is less dependent on the vapor concentration. For example, a mixture of air and hydrogen will be flammable under both very lean and very rich conditions.

It may also be noted that the rich VPER of diethyl ether seems excessively high. Note that the values calculated are based on tabulated data of Zabetakis and that these data were collected from a variety of sources. Some values reported may include a safety margin, depending on the purpose of the experiments. For example, those conducted for relevance to engine applications may be different from those applied to hazardous concentrations in a building.

Energy Density. We calculated the energy density based on the available energy of the fuel/air mixture and its density. The energy density is defined as

$$
\text { Energy Density }=(\text { Lower Heating Value }[\mathrm{J} / \mathrm{kg}]) *(\text { Fuel / Air Mixture Density }[\mathrm{kg} / \mathrm{L}]) \text {. }
$$

We calculated the lower heating value (LHV) at standard conditions of $25^{\circ} \mathrm{C}$ and $1 \mathrm{~atm}$. The actual heating value may be slightly different because the final state of the products of combustion may not be at standard conditions. However, if this standard value is used then the results provide a good relative comparison.

Using a combination of experimental data and simulation results, we determined the acceptance standard for energy density. The experimental data, provided by David Gardiner, included air flow and equivalence ratio measurements during successful cold starts. These cold starts were conducted at $-7^{\circ} \mathrm{C}$ in two different $2.2 \mathrm{~L}$ engines operating on gasoline. Based on this information, we calculated the supplied energy density in each case. The results showed that an energy density of approximately $3400 \mathrm{~J} / \mathrm{L}$ was provided during the cranking phase.

In comparison, we used SIS, an engine cycle simulation program described above, to predict the energy density requirements during operation under cold ambient conditions. The engine was operated at $-10^{\circ} \mathrm{C}$ in the range of 250-500 RPM and partial load conditions to simulate the cold start. Lower temperatures and slower speeds could not be simulated because the code would not converge. The air flow and fuel flow was recorded and the required energy was calculated. These results predicted that a typical engine would require an energy density of approximately $1800 \mathrm{~J} / \mathrm{L}$ under cold-start conditions.

The energy density predictions differ because the simulation is of the ideal case while the experimental results are non-ideal. During cold starts with gasoline, the engine uses an over- 
fueling strategy in order to produce sufficient vapor. The simulation program is based on fully warmed and stoichiometric operation. Thus, in the case of the experimental results, extra fuel enters the cylinder but may not contribute to the energy release. Therefore, we chose a value between the simulation prediction and the experimental value as an energy density acceptance standard, and set the standard at $2500 \mathrm{~J} / \mathrm{L}$.

\subsubsection{Secondary Comparison Parameters}

The secondary parameters, related to commercialization, were cost, durability, pre-heat or delay period, and ease of implementation.

Cost. If the device is to be used in a commercial vehicle, its cost must be low, and if the technology considered is in addition to the standard engine components, its cost will be crucial. However, if it replaces existing components, the specific cost may be less important and the differential cost will be more important.

Durability. The device must have a reasonable service life under normal operation, which will typically be intermittent use for cold-start devices. However, when the device is needed, the conditions will be extreme. Ambient temperatures will be very low, but once combustion occurs, the engine will warm up fairly quickly. In addition, service will be cyclic with rapid heating and cooling.

Pre-Heating or Delay Period. Few consumers will accept any pre-heating or delay period. Based on our discussions with various auto industry contacts, it is clear that the operator should perceive little, if any, difference between the operation of a alcohol-fueled vehicle and a conventional gasoline vehicle. In general, the engine will be expected to start within 5-10 seconds from the time the ignition key is turned at approximately $-25^{\circ} \mathrm{C}$.

Implementation. Integration of the technology into the current vehicle design is also key to acceptance by the automotive industry. An acceptable technology should not cause inconveniences during vehicle service and maintenance, and it should use existing components and controls as much as possible.

\subsection{ASPEN Plus Model Development}

We created a simulation model for each of the cold-start technologies in ASPEN Plus. ASPEN Plus provides a graphical user interface to guide the generation of simulation flow sheets. By connecting process blocks on a workspace, a simulation flow sheet is created. The flow sheet defines how the process blocks and the simulation will be executed. Each block in the workspace performs a pre-defined function. Other information, such as component definition and operating conditions, is specified in various input windows. Once all the necessary input information has been defined, the simulation can be run and select results are displayed in a control panel window.

Figure 8 is a sample of an ASPEN Plus flow sheet diagram, specifically for the rich combustor device simulation model. In this model, we first specify the fuel and air compositions, then 
specify the desired overall equivalence ratio. The simulation adjusts the air flow rate accordingly so that all calculations can be performed on a unit fuel basis. The AIR and FUEL streams are then split (Blocks B1 and B2) into two streams based on the fuel fraction to the combustor and the combustor equivalence ratio that we specified. The fuel fraction to the combuster value indicates what fraction of the supplied fuel enters the combustor (Stream 2) while the remaining fraction bypasses the combustor (Stream 5 ). The combustor equivalence ratio value controls the amount of air entering the combustor (Stream 1) based on the amount of fuel entering the combustor (Stream 2) while the rest of the air bypasses the combustor (Stream 5). The fuel and air streams are then blended together in Block B3 and supplied to the reactor (Block B4). The reactor performs a Gibbs free energy adiabatic combustion process on the supplied mixture. The reactor products (Stream 6) are recombined with any bypass air (Stream 5) and/or fuel (Stream 4) in Block B5. Block B6 adjusts the temperature of the mixture to simulate heat loss to the atmosphere. In Block B7 the mixture is separated into a liquid stream (Stream 9) and a vapor stream (Stream 10). In Block B7 we can specify that a fraction of the liquid present is entrained into the vapor stream (Stream 10). We refer to this value as the liquid entrainment fraction. The liquid entrainment simulates liquid fuel entering the cylinder with vapor, as is the case in a real intake manifold. Stream 10 then represents the mixture that enters the engine cylinder. Block B8 and Block B9 simply separate and recombine the vapor and liquid in Stream 10 to aid in calculation of the VPER and the in-cylinder equivalence ratio. Block B10 then performs a second adiabatic combustion process and $\mathrm{B} 11 \mathrm{cools}$ the products to $25^{\circ} \mathrm{C}$ and $1 \mathrm{~atm}$. We then calculated the energy density of the supplied fuel mixture by dividing Stream 16 (the energy released when the combustion products, Stream 14, are cooled to standard conditions) by the mixture density of Stream 10.

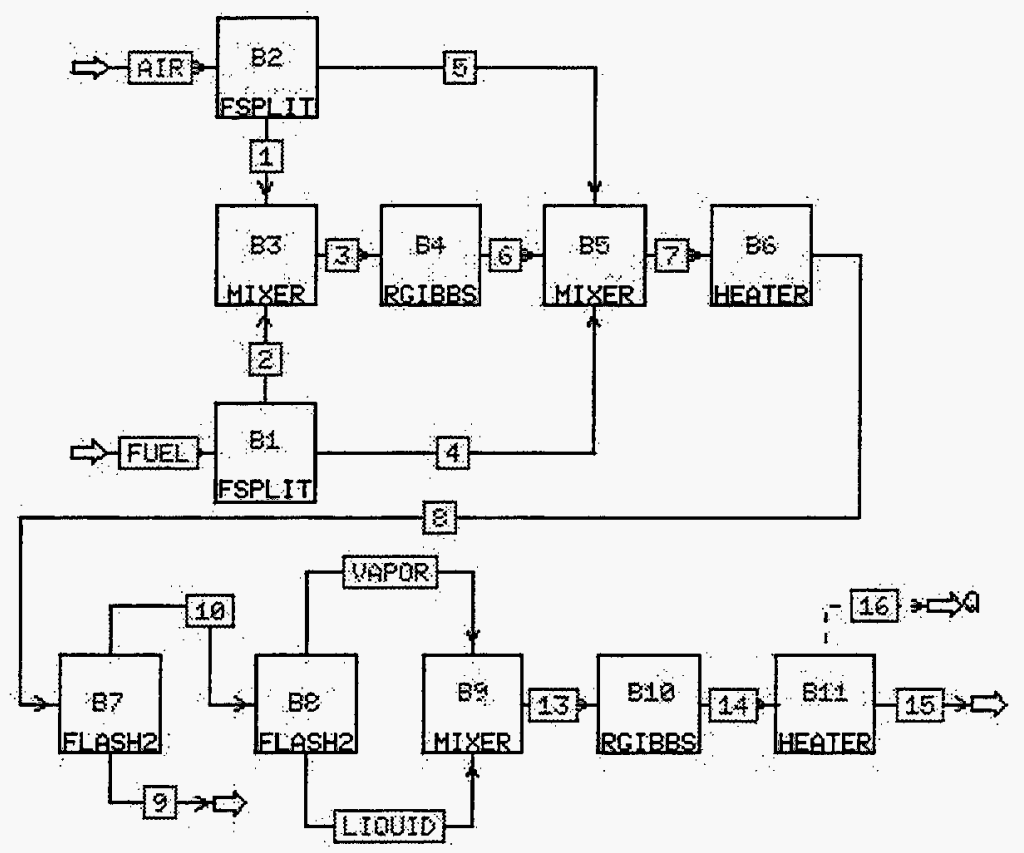

Figure 8. ASPEN Plus Simulation Flow Sheet - Rich Combustor Model

We created similar ASPEN Plus flow sheets for each of the four cold-start technologies. There were only minor differences between the four simulation flow sheets. The major differences were in the input parameters. However, in the case of the catalytic reformer, a specified yield 
reactor was used in place of the Gibbs free energy reactor. The yield reactor allowed us to specify the reaction product yields. The catalytic reaction was not simulated but was instead based on experimental data. Also, in the case of the rich combustor device, the outlet temperature of Block B6 was set at $-10^{\circ} \mathrm{C}$. This value was set based on experimental data but realistically could fluctuate with respect to the combustor operating conditions. For the partial oxidation reactor, Block B6 was placed prior to Block B5 and the outlet temperature was limited to a maximum of $95^{\circ} \mathrm{C}$. This modification was made to more closely represent the actual device. Block B6 was not applicable for the enhanced ignition system and the catalytic reformer, thus the heat loss was set to zero for these simulation models. These systems operate at much lower temperatures and therefore release less heat to the atmosphere.

An additional flow sheet for fuel blends cold-start analysis was created. Figure 9 shows the flow sheet diagram for the fuel blends model. We omitted some process blocks from the fuel blends model because they were not applicable while retaining others such as Blocks B3 and B4 to aid in results calculation. This flow sheet allowed us to predict the cold start performance of different fuels as a function of fuel composition, supplied equivalence ratio, liquid entrainment fraction, and ambient temperature.

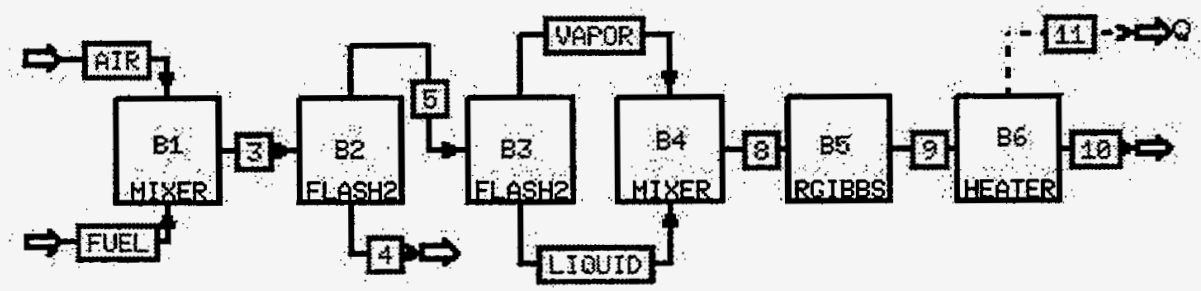

Figure 9. ASPEN Plus Simulation Flow Sheet - Fuel Blends Model

\subsection{Pseudo-Gasoline Blend Development}

Using alcohol fuel blended with gasoline, which acts as a priming agent, is the current method for improving cold startability. The amount of gasoline in the blend can be as high as $40 \%$ during winter months. This is necessary to provide sufficient vapor to ignite within the cylinder because little alcohol vapor will be formed below $5^{\circ}-10^{\circ} \mathrm{C}$. In addition, excessive over-fueling is necessary to provide sufficient gasoline vapor to initiate the combustion process. It is useful to compare the current cold-starting approach, fuel blending, with the proposed technologies. To do this accurately, we derived a pseudo-gasoline blend and used it in an ASPEN Plus simulation. The pseudo gasoline was created by mixing various individual components that together exhibit properties similar to gasoline. Through ASPEN Plus simulations, we could then determine the cold-start performance of this blend and any derivatives of it, then compare these results to those derived for the cold-start technologies.

\subsubsection{Formulation of a Pseudo Gasoline}

We derived the pseudo-gasoline blend based on speciation data (Appendix B) provided by Acurex Environmental. The speciation was performed on an M85 blend called M85 RFA (85\% 
methanol/15\% Coordinating Research Council [CRC] national average gasoline). The blend included 75 individual components and had a measured Reid Vapor Pressure (RVP) of 8.8 psia.

First, we removed the methanol mass percent from this blend by adjusting the reported mass percents for the other components to represent just the gasoline portion of the blend. This was accomplished by dividing each component mass percent by 0.8493 (the measured methanol mass fraction). The resulting blend is a 74-component blend representing gasoline.

We then arranged the components according to their carbon and hydrogen numbers. Many of the components had quite similar chemical structures such as 2-methyl pentane and 3-methyl pentane. Next, we grouped components with similar chemical structures together and assigned the combined mass percent of the group to the component with the largest mass percent. The resulting pseudo-gasoline blend was composed of 19 components; Table 1 shows its composition. This blend, referred to as Acurex RFA, was predicted by an ASPEN Plus simulation to have a vapor pressure of $9.8 \mathrm{psia}$ at $100^{\circ} \mathrm{F}$. ASPEN Plus predicted the original M85 RFA blend to have a vapor pressure of $8.7 \mathrm{psia}$ at $100^{\circ} \mathrm{F}$ compared to the experimental RVP of 8.8 psia. RVP and vapor pressure at $100^{\circ} \mathrm{F}$ are not exactly comparable however this exercise does show that ASPEN Plus can predict vapor pressures of complex mixtures reasonably well.

Table 1. Pseudo-Gasoline Blend Composition - Acurex RFA

\begin{tabular}{|l|r|r|r|}
\hline \multicolumn{4}{|c|}{ Pseudo Gasoline Blend - Acurex RFA } \\
\hline Component & \multicolumn{1}{|c|}{ C } & \multicolumn{1}{|c|}{ H } & Mass \% \\
\hline n-butane & 4 & 10 & 7.44 \\
\hline 2-methyl-2-butene & 5 & 10 & 2.81 \\
\hline i-pentane & 5 & 12 & 6.45 \\
\hline n-pentane & 5 & 12 & 1.67 \\
\hline benzene & 6 & 6 & 2.28 \\
\hline methylcyclopentane & 6 & 12 & 2.50 \\
\hline 2-methyl pentane & 6 & 14 & 13.35 \\
\hline toluene & 7 & 8 & 10.70 \\
\hline methylcyclohexane & 7 & 14 & 1.67 \\
\hline 3-methyl hexane & 7 & 16 & 13.13 \\
\hline ethyl benzene & 8 & 10 & 3.64 \\
\hline m-xylene & 8 & 10 & 12.06 \\
\hline 2,2,4-trimethyl pentane & 8 & 18 & 7.51 \\
\hline 1,2,4-trimethyl benzene & 9 & 12 & 10.09 \\
\hline 2-methyl octane & 9 & 20 & 0.68 \\
\hline naphthalene & 10 & 8 & 0.61 \\
\hline 1,2 -dimethyl-4-ethyl benzene & 10 & 14 & 2.12 \\
\hline 3,3-dimethyl octane & 10 & 22 & 0.76 \\
\hline 2,4,6-trimethyl octane & 11 & 24 & 0.53 \\
\hline Total & & & 100 \\
\hline
\end{tabular}

For cold starting purposes, it is common to use a fuel with an RVP as high as $15 \mathrm{psia}$. We created a pseudo-gasoline blend with a vapor pressure of 14.3 psia at $100^{\circ} \mathrm{F}$ (predicted by ASPEN Plus) by doubling the mass percent of $n$-butane and i-pentane without adjusting the other components. This blend was referred to as "winter blend" and Table 2 gives its composition. 
Table 2. Pseudo-Gasoline Blend Composition - Winter Blend

\begin{tabular}{|l|r|r|r|}
\hline \multicolumn{3}{|c|}{ Pseudo Gasoline Blend - Winter Blend } \\
\hline Component & \multicolumn{1}{c|}{ C } & \multicolumn{1}{c|}{ H } & Mass \% \\
\hline n-butane & 4 & 10 & 13.06 \\
\hline 2-methyl-2-butene & 5 & 10 & 2.46 \\
\hline i-pentane & 5 & 12 & 11.33 \\
\hline n-pentane & 5 & 12 & 1.47 \\
\hline benzene & 6 & 6 & 2.00 \\
\hline methylcyclopentane & 6 & 12 & 2.20 \\
\hline 2-methyl pentane & 6 & 14 & 11.72 \\
\hline toluene & 7 & 8 & 9.39 \\
\hline methylcyclohexane & 7 & 14 & 1.47 \\
\hline 3 -methyl hexane & 7 & 16 & 11.52 \\
\hline ethyl benzene & 8 & 10 & 3.20 \\
\hline m-xylene & 8 & 10 & 10.59 \\
\hline 2,2,4-trimethyl pentane & 8 & 18 & 6.59 \\
\hline $1,2,4-$-trimethyl benzene & 9 & 12 & 8.86 \\
\hline 2-methyl octane & 9 & 20 & 0.60 \\
\hline naphthalene & 10 & 8 & 0.53 \\
\hline 1,2-dimethyl-4-ethyl benzene & 10 & 14 & 1.87 \\
\hline 3,3-dimethyl octane & 10 & 22 & 0.67 \\
\hline 2,4,6-trimethyl octane & 11 & 24 & 0.47 \\
\hline Total & & & 100 \\
\hline
\end{tabular}

\subsection{Fuel Blends Results and Discussion}

Using the pseudo-gasoline blends described above, we formulated various alcohol blends and evaluated their cold-start performance using ASPEN Plus. Baseline results were calculated at a supplied equivalence ratio of 3.0,20\% liquid entrainment into the vapor stream, and an ambient temperature of $-25^{\circ} \mathrm{C}$. The baseline conditions we selected would be typical during a cold start. In addition, we collected results over a range of conditions. These include an equivalence ratio from 1.0 to 6.0 and a liquid entrainment fraction from 0.0 to 0.5 . These should represent fairly typical ranges of operation.

Using experimental cold-start results reported by Acurex, we validated the baseline and range of operation values selected. Acurex reported that the test vehicles fueled with M85 RFA started at temperatures as low as $-8^{\circ} \mathrm{C}$. We used the fuel blends model (Figure 9) to determine the input conditions that would lead to successful starts (i.e., a VPER greater than 0.50 and an energy density greater than $2500 \mathrm{~J} / \mathrm{L}$ ) under these conditions. With the ambient temperature set at $-8^{\circ} \mathrm{C}$, the supplied equivalence ratio was adjusted until the desired VPER of at least 0.50 was achieved. The VPER is directly related to the temperature and the supplied equivalence ratio and is a function of the fuel composition. Thus with the temperature and fuel composition fixed, the supplied equivalence ratio is the only variable affecting the VPER. Then while holding the temperature, the supplied equivalence ratio, and the fuel composition fixed we adjusted the liquid entrainment fraction. This resulted in a range of energy density values for the specified conditions. For M85 RFA, a supplied equivalence ratio of 5.5 was required to provide a VPER greater than 0.50 and a liquid entrainment fraction between 0.05 and 0.40 was needed to provide an energy density greater than $2500 \mathrm{~J} / \mathrm{L}$. A similar validation process was performed for all of the fuels for which we obtained experimental data. The results have been summarized in Table 3. 
Table 3. Model Operating Conditions Validation Results

\begin{tabular}{|c|c|c|c|c|c|}
\hline \multicolumn{6}{|c|}{ Validation of Model Operating Condition Selections } \\
\hline \multirow[t]{2}{*}{ Fuel } & $\begin{array}{l}\text { Minimum Start } \\
\text { Temperature }\end{array}$ & $\begin{array}{c}\text { Supplied } \\
\text { Equivalence } \\
\text { Ratio }\end{array}$ & $\begin{array}{c}\text { Liquid } \\
\text { Entrainment } \\
\text { Fraction }\end{array}$ & $\begin{array}{c}\text { Vapor Phase } \\
\text { Equivalence } \\
\text { Ratio }\end{array}$ & $\begin{array}{l}\text { Energy } \\
\text { Density }\end{array}$ \\
\hline & ${ }^{\circ} \mathrm{C}$ & -- & -- & - & $\mathrm{J} / \mathrm{L}$ \\
\hline $\mathrm{M100}$ & 13 & 1.0 & $0.10-0.30$ & 0.676 & $2581-2804$ \\
\hline IP M95 & 3 & 1.0 & $0.15-0.70$ & 0.520 & $2521-3750$ \\
\hline RFA M92 & 0 & 4.0 & $0.05-0.50$ & 0.501 & $2580-3582$ \\
\hline RFA M85 & -8 & 5.5 & $0.05-0.40$ & 0.510 & $2499-3868$ \\
\hline RFA & -25 & 2.0 & $0.10-0.60$ & 0.504 & $2644-3945$ \\
\hline Winter & -40 & 3.0 & $0.05-0.40$ & 0.538 & $2813-4267$ \\
\hline
\end{tabular}

We then collected the VPER and energy density values over the range of operating conditions listed above for each of the fuel blends. The complete simulation results have been provided in Tables 1-9 in Appendix C. Table 4 provides a summary of the averaged results. Figure 10 shows that only the two gasoline blends (Acurex RFA and the Winter Blend) were able to meet the acceptance criteria when the data sets are averaged. The other fuel blends have difficulty in providing a sufficient VPER. The VPER for the fuel blends is directly related to the amount of primer in the blend and the supplied equivalence ratio because the primer is typically the only component in the vapor phase at $-25^{\circ} \mathrm{C}$. Thus, in order to provide a sufficient VPER, either the fraction of primer in the fuel can be increased or the supplied equivalence ratio can be increased. These are the common approaches for cold-starting alcohol-fueled engines. Increasing the supplied equivalence ratio of pure component fuels, such as neat methanol (M100) and neat ethanol (E100), has no effect on VPER.

\section{Table 4. Fuel Blends Simulation Results - Summary}

\begin{tabular}{|c|c|c|}
\hline \multicolumn{3}{|c|}{ Fuel Blends Simulation Results Summary } \\
\hline \multirow[b]{2}{*}{ Blend Name } & \multicolumn{2}{|c|}{ Average Results } \\
\hline & $\begin{array}{l}\text { Vapor Phase } \\
\text { Equivalence } \\
\text { Ratio }\end{array}$ & Energy Density \\
\hline & - & $\mathrm{J} / \mathrm{L}$ \\
\hline Acurex RFA & 0.629 & 3167 \\
\hline M85/RFA & 0.217 & 3018 \\
\hline E85/RFA & 0.127 & 2758 \\
\hline M100 & 0.047 & 2779 \\
\hline E100 & 0.031 & 2645 \\
\hline Winter Blend & 0.880 & 3200 \\
\hline M85/Winter & 0.298 & 3084 \\
\hline E85/Winter & 0.163 & 2782 \\
\hline E60/Winter & 0.362 & 2920 \\
\hline
\end{tabular}

Figure 10 seems to say that fuel blending will not work at $-25^{\circ} \mathrm{C}$. However, Figure 11 shows that some fuel blends do have operating points that satisfy the performance criteria under specific operating conditions. In the real world, some of the operating conditions evaluated may be more prominent than others. The equally-weighted averaging procedure used to generate the data presented in Table 4 and Figure 10 may under predict the performance of some fuel blends. 
However, this process allows us to make fair generalized comparisons between the fuel blends results and the cold-start technology results.

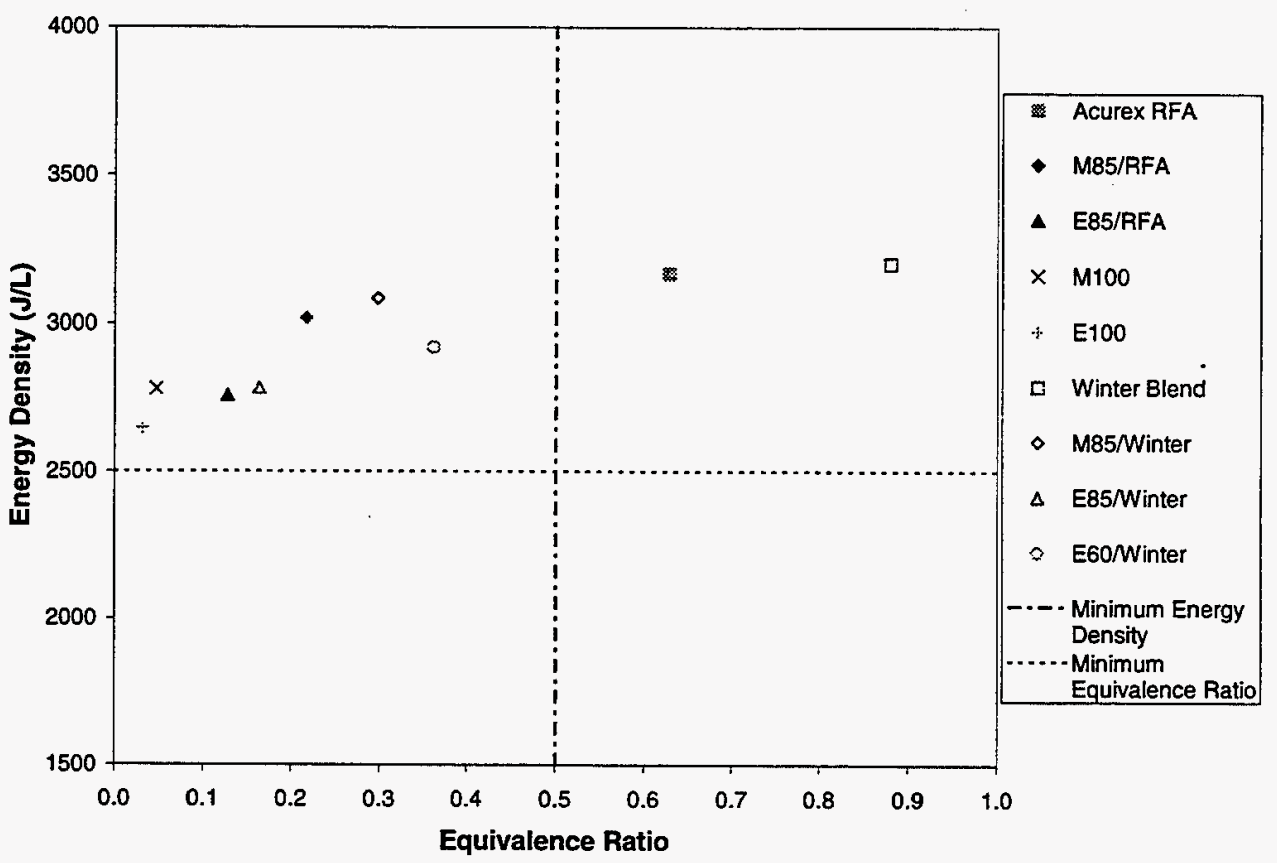

Figure 10. Fuel Blends Cold-Start Performance Prediction - Averaged Results

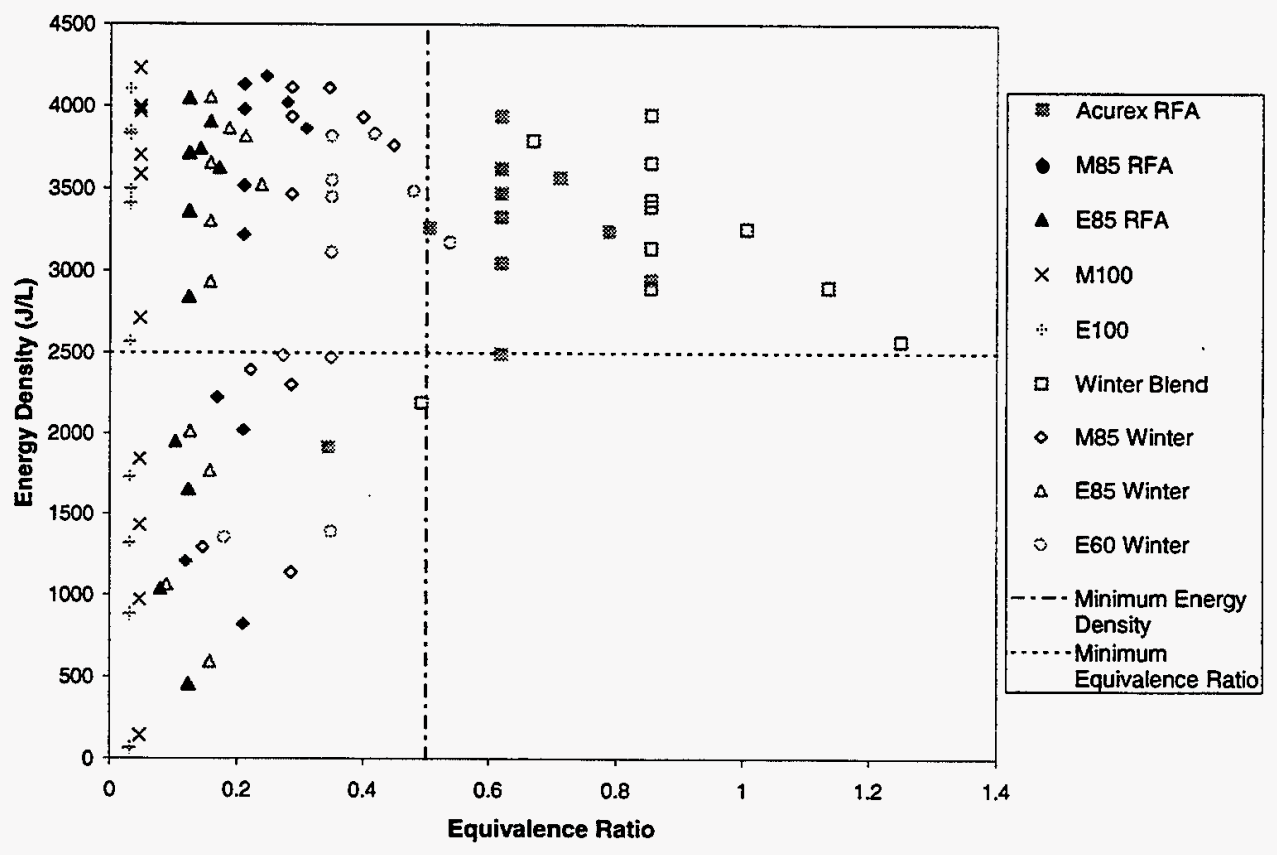

Figure 11. Fuel Blends Cold-Start Performance Predictions - Full Results 


\subsection{Cold-Start Technologies Results and Discussion}

\subsection{Primary Comparison}

Each cold-start technology is evaluated below based on the primary evaluation parameters described in Section 3.3.1. Over their operating range, each of the technologies should be able to provide a VPER greater than 0.50 and an energy density greater than $2500 \mathrm{~J} / \mathrm{L}$. These required values will certainly vary depending on the engine and conditions but provide relative hurdles for all of the technologies to overcome. The acceptable VPER range was based on an interpretation of the information in Figure 7. The energy density standard was based on a combination of experimental data and simulation results, as discussed previously.

We simulated the four cold-start technologies over a set of operating conditions. The simulation runs entailed adjusting one parameter at a time while all other parameters were maintained at their baseline conditions. We set the baseline conditions for each technology on information in reports submitted by the subcontractors related to their specific technology. Table 5 summarizes the baseline conditions and the range of conditions evaluated for each technology.

Table 5. Cold-Start Technology Simulation Parameters

\begin{tabular}{|c|l|c|c|}
\hline Cold-Start Technology Simulation Conditions \\
\hline Cold-Start Technology & \multicolumn{1}{|c|}{ Parameter Description } & Baseline & Range \\
\hline \multirow{4}{*}{ Rich Combustor Device } & Supplied Equivalence Ratio & 1.0 & $0.9-2.5$ \\
\cline { 2 - 4 } & Liquid Fuel Fraction to Combustor & 1.0 & $0.4-1.0$ \\
\cline { 2 - 4 } & Rich Combustor Device Equivalence Ratio & 2.0 & $1.5-4.0$ \\
\cline { 2 - 4 } & Liquid Entrainment Fraction & 0.3 & $0.3-0.6$ \\
\hline \multirow{3}{*}{$\begin{array}{c}\text { Partial Oxidation } \\
\text { Reactor }\end{array}$} & Supplied Equivalence Ratio & 1.0 & $0.9-2.5$ \\
\cline { 2 - 4 } & Liquid Fuel Fraction to Reactor & 1.0 & $0.4-1.0$ \\
\cline { 2 - 4 } & Partial Oxidation Reactor Equivalence Ratio & 3.0 & $2.0-5.0$ \\
\cline { 2 - 4 } Catalytic Reformer & Liquid Entrainment Fraction & 0.3 & $0.3-0.6$ \\
\hline \multirow{3}{*}{$\begin{array}{c}\text { Enhanced Ignition } \\
\text { System }\end{array}$} & Supplied Equivalence Ratio & 1.0 & $1.0-4.0$ \\
\cline { 2 - 4 } & Liquid Fuel Fraction to Reformer & 0.25 & $0.25-0.8$ \\
\cline { 2 - 4 } & Liquid Entrainment Fraction & 0.3 & $0.3-0.6$ \\
\hline & Supplied Equivalence Ratio & 1.0 & $1.0-4.0$ \\
\cline { 2 - 4 } & Liquid Entrainment Fraction & 0.3 & $0.3-0.6$ \\
\hline
\end{tabular}

The parameter descriptions in Table 4 merit some explanation. The supplied equivalence ratio considers all of the fuel and air supplied to the engine. The liquid fuel fraction to the device (rich combustor device, partial oxidation reactor, and catalytic reformer only) specifies the portion of the supplied liquid fuel that is provided to the device. The remainder of the supplied fuel bypasses the device and recombines with the device products prior to induction into the cylinder. The device specific equivalence ratio (rich combustor device and partial oxidation reactor only) considers only the fuel and air supplied to the device. The liquid entrainment fraction represents the fraction of the liquid fuel present in the intake manifold that is carried with the fuel vapor and air into the cylinder.

Tables 6 through 9 provide the complete results of the simulation runs. In each table, the results at the baseline condition are highlighted at the top, followed by the data collected over the entire set of operating conditions. For both the VPER and the energy density, we averaged the entire 
set of results to provide a means of ranking the technologies. Again, as in the fuel blends analysis, the equally-weighted averaging technique used may downgrade the performance of these technologies. At the bottom of each table, the averaged results are highlighted. Any other specific operating conditions have also been specified at the bottom of the tables. In the notes section, methanol refers to neat methanol an ethanol refers to neat ethanol. Because neat alcohol fuels were used, these results correlate to the worst case scenario from a cold-start perspective. The use of denatured fuels and alcohol blends in conjunction with the cold-start technologies may improve performance. We summarized the average results in Table 10 and plotted them in Figure 12. In Figure 12, we plotted the combined vapor/liquid equivalence ratio in the case of the enhanced ignition system. We did this because the system will convert much of the liquid fuel to combustible vapor because of its high current pulsed ignition circuitry and plasma jet ignitor. Figure 12 shows that both the catalytic reformer and the enhanced ignition system are capable of meeting the performance criteria, but the rich combustor and the partial oxidation reactor are unable to provide sufficient energy density. However, note from the data presented in Tables 6 through 9 that each of the technologies are able to meet or exceed the acceptance criteria at some operating point. Figure 12 demonstrates only those that are more likely to be successful over a typical set of operating conditions.

Table 6. Simulation Results - Rich Combustor Device

\begin{tabular}{|c|c|c|c|c|c|c|c|}
\hline \multicolumn{8}{|c|}{ Simulation Results - Rich Combustor Device } \\
\hline \multirow[t]{2}{*}{$\begin{array}{c}\text { Test } \\
\text { Condition }\end{array}$} & $\begin{array}{c}\text { Supplied } \\
\text { Equivalence } \\
\text { Ratio } \\
\end{array}$ & $\begin{array}{l}\text { Rich Combustor } \\
\text { Equivalence Ratio }\end{array}$ & $\begin{array}{l}\text { Liquid } \\
\text { Entrainment } \\
\text { Fraction }\end{array}$ & $\begin{array}{l}\text { Liquid Fuel } \\
\text { Fraction to } \\
\text { Combustor }\end{array}$ & \begin{tabular}{c|} 
Vapor Phase \\
Equivalence \\
Ratio
\end{tabular} & $\begin{array}{c}\text { In-Cylinder } \\
\text { Equivalence } \\
\text { Ratio }\end{array}$ & $\begin{array}{l}\text { Energy } \\
\text { Density }\end{array}$ \\
\hline & - & -- & $=$ & -- & -- & -- & $J / L$ \\
\hline \multicolumn{8}{|c|}{ Baseline } \\
\hline \multirow{2}{*}{\multicolumn{8}{|c|}{$\begin{array}{l}\text { Supplied Equivalence Ratio } \\
\text { Suld }\end{array}$}} \\
\hline & & & & & & & \\
\hline \multicolumn{8}{|c|}{0.447} \\
\hline \multicolumn{8}{|c|}{1.118} \\
\hline & 2.0 & & & & 1.676 & 1.676 & 1259 \\
\hline \multicolumn{8}{|c|}{\begin{tabular}{|l|l|l|} 
& 2.5 \\
\end{tabular}} \\
\hline \multicolumn{8}{|c|}{ Rich Combustor Equivlance Ratio } \\
\hline \multicolumn{8}{|c|}{0.338} \\
\hline \multicolumn{8}{|c|}{0.655} \\
\hline \multirow{2}{*}{\multicolumn{8}{|c|}{$\begin{array}{l}0.717 \\
0.792\end{array}$}} \\
\hline & & & & & & 0.792 & 2711 \\
\hline \multicolumn{8}{|c|}{ Liquid Entrainment Fraction } \\
\hline \multicolumn{8}{|c|}{ 1 } \\
\hline & & & 0.5 & & 0.559 & 0.559 & 1989 \\
\hline & & & 0.6 & & 0.559 & 0.559 & 1961 \\
\hline \multicolumn{8}{|c|}{ Liquid Fuel Fraction to Combustor } \\
\hline & & & & 0.8 & 0.407 & 0.507 & 1934 \\
\hline & & & & 0.6 & 0.384 & 0.456 & 1779 \\
\hline & & & & 0.4 & 0.300 & 0.407 & 1615 \\
\hline \multirow{2}{*}{\multicolumn{8}{|c|}{ Average Results }} \\
\hline & & & & & 10.8754 & $6 \pi / 2$ & 1888 \\
\hline
\end{tabular}


Table 9. Simulation Results - Enhanced Ignition System

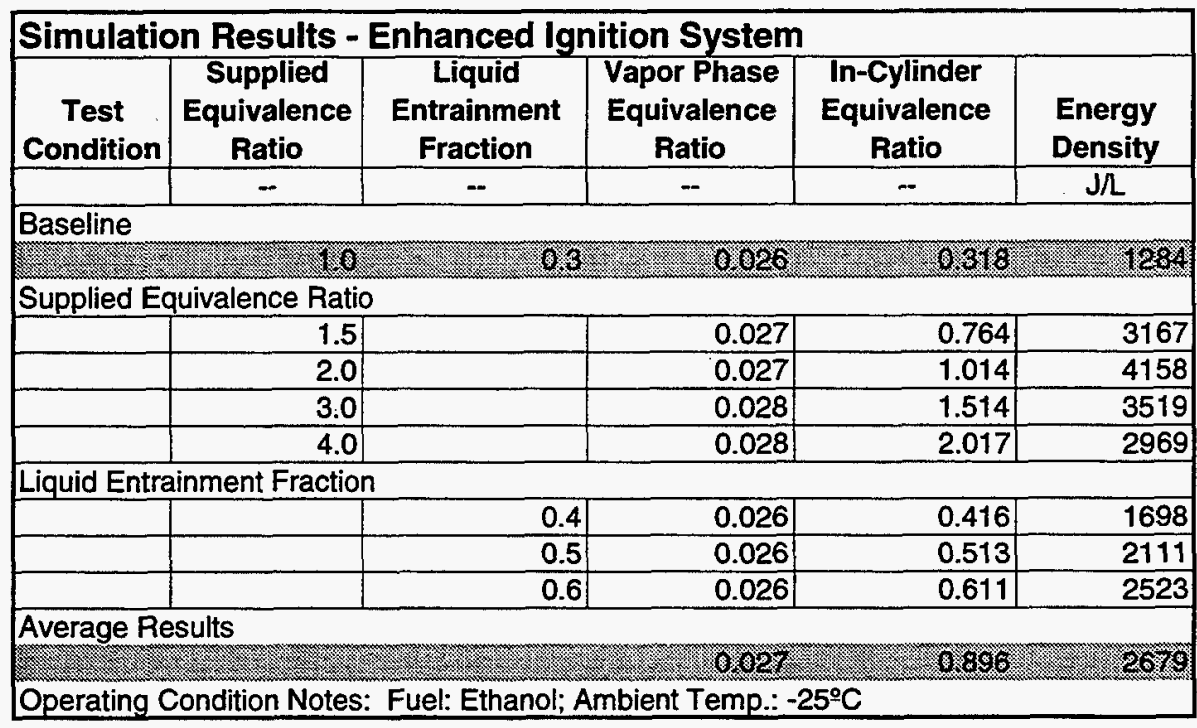

\section{Table 10. Summary of Cold-Start Technology Simulation Results}

\begin{tabular}{|c|c|c|c|}
\hline \multicolumn{4}{|c|}{ Summary of Cold-Start Technology Simulation Results } \\
\hline \multirow[b]{2}{*}{ Cold-Start Technology } & \multicolumn{3}{|c|}{ Average Results } \\
\hline & $\begin{array}{c}\text { Vapor Phase } \\
\text { Equivalence } \\
\text { Ratio }\end{array}$ & $\begin{array}{l}\text { In-Cylinder } \\
\text { Equivalence } \\
\text { Ratio }\end{array}$ & $\begin{array}{l}\text { Energy } \\
\text { Density }\end{array}$ \\
\hline & -- & $\ldots$ & $\mathrm{J} / \mathrm{L}$ \\
\hline Rich Combustor Device & 0.754 & 0.772 & 1868 \\
\hline Partial Oxidation Reactor & 0.896 & 0.904 & 2094 \\
\hline Catalytic Reformer & 0.594 & 0.861 & 2719 \\
\hline Enhanced Ignition System & 0.027 & 0.896 & 2679 \\
\hline
\end{tabular}

From this analysis, we saw that both the catalytic reformer and the enhanced ignition system exceeded the performance criteria. The partial oxidation reactor and the rich combustor device both have difficulty achieving the necessary energy density mainly because of the low density of the gaseous products provided to the engine. The results plotted in Figure 11 show that the catalytic reformer and the enhanced ignition system have the potential for successful cold starts at $-25^{\circ} \mathrm{C}$ over a range of operating conditions.

As with the fuel blends cold-start performance analysis, the equally-weighted averaging method used to generate Table 10 and Figure 12 may downgrade the performance of these technologies because some operating points may be more prominent than others. Therefore, Figure 13 has been included to show the full data sets plotted. This figure demonstrates that all of the technologies have some operating points that satisfy the acceptance criteria. 


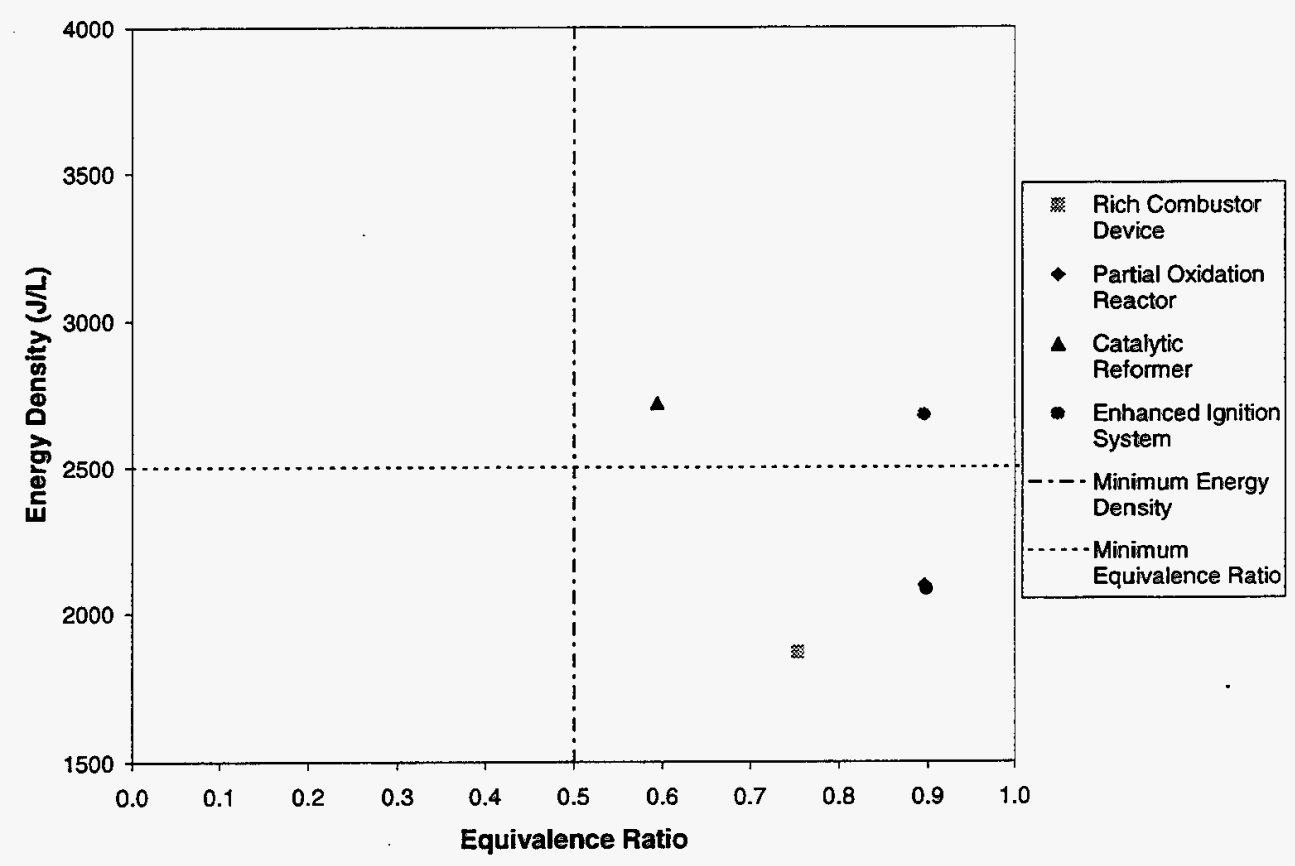

Figure 12. Cold Start Technology Simulation Results - Averaged

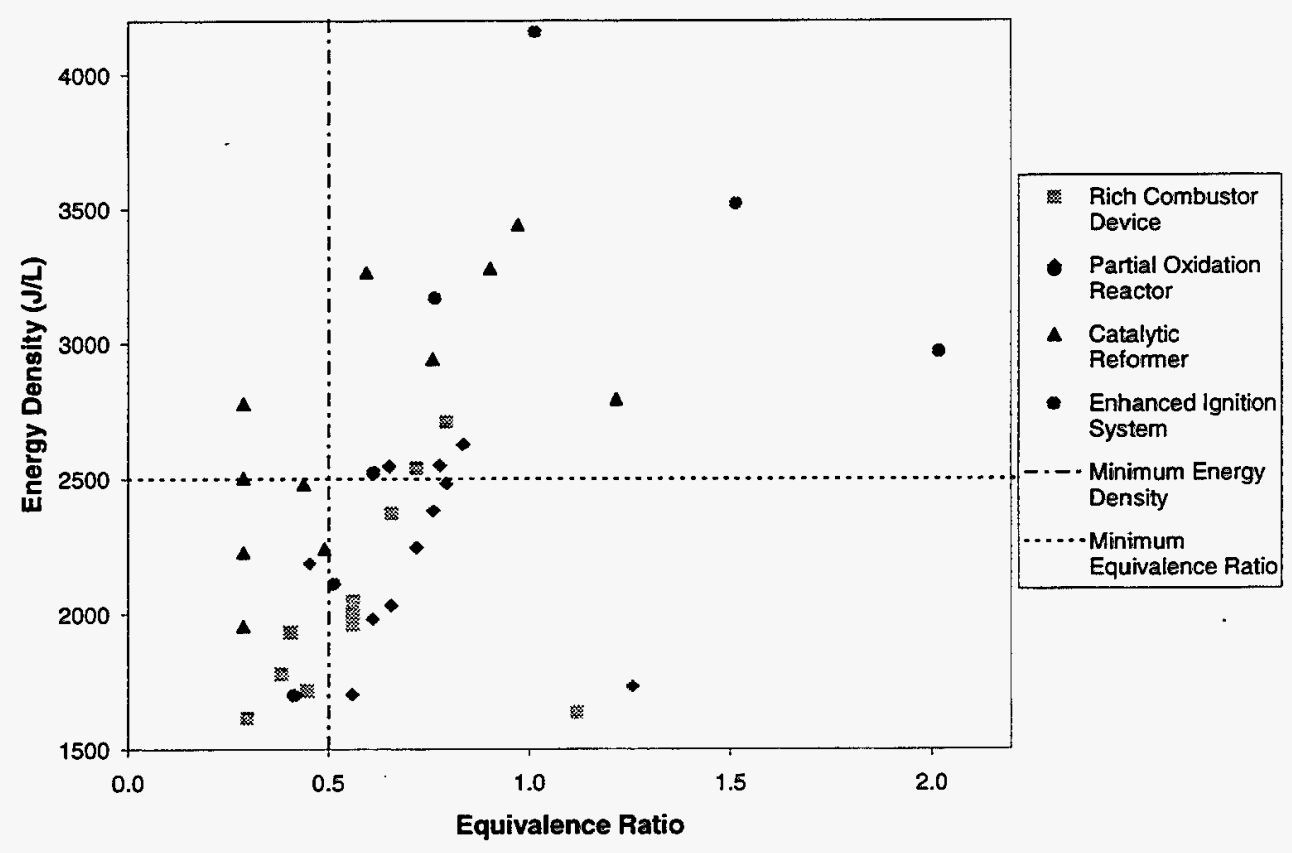

Figure 13. Cold-Start Technology Simulation Results - Full

\subsection{Secondary Comparison}

Table 11 shows how we assigned relative rankings to each technology. For each technology, we composed comments on each parameter based on information from subcontract reports and other 
technical papers, then assigned a "grade" based on these comments— the higher the score the better. Figure 14 compares each technology based on the secondary comparison parameters. We generated an average combined index and the results are displayed in Figure 15. Based on this grading procedure, we concluded that the enhanced ignition system has the greatest potential for commercialization.

\section{Table 11. Secondary Comparison of Cold-Start Technologies}

\begin{tabular}{|c|c|c|c|c|}
\hline \multicolumn{5}{|c|}{ Secondary Comparison of Cold-Start Technologies } \\
\hline & \multicolumn{2}{|c|}{ Rich Combustor Device } & \multicolumn{2}{|l|}{ Partial Oxidation Reactor } \\
\hline Parameter & Comments & Rank & Comments & Rank \\
\hline Cost & $\begin{array}{l}\text { construction relatively simple; } \\
\text { commercial components }\end{array}$ & & $\begin{array}{l}\text { simple design -common materials; } \\
\text { commercial components; heat } \\
\text { exchanger }\end{array}$ & 4 \\
\hline Durability & $\begin{array}{l}\text { few moving parts; corrosion from } \\
\text { water vapor }\end{array}$ & & $\begin{array}{l}\text { few moving parts, corrosion from } \\
\text { water vapor }\end{array}$ & 3 \\
\hline $\begin{array}{l}\text { Pre-Heat/Delay } \\
\text { Period }\end{array}$ & none & & surface ignitor must be pre-heated & 3 \\
\hline $\begin{array}{l}\text { Ease of } \\
\text { Implementation }\end{array}$ & $\begin{array}{l}\text { add-on device; additional controls, fuel } \\
\text { injectors, and ignitors }\end{array}$ & & add-on device; fueling strategy & 4 \\
\hline \multirow[t]{2}{*}{ Average Rank } & & 3.5 & & 3.5 \\
\hline & Catalytic Reformer & & Enhanced Ignition Syster & \\
\hline Parameter & Comments & Rank & Comments & Rank \\
\hline Cost & $\begin{array}{l}\text { catalyst relatively inexpensive; heating } \\
\text { elements; controls }\end{array}$ & & $\begin{array}{l}\text { commercial components; replaces } \\
\text { existing components }\end{array}$ & 4 \\
\hline Durability & $\begin{array}{l}\text { good within operating conditions; } \\
\text { catalyst material }\end{array}$ & & $\begin{array}{l}\text { intermittent high energy output; low. } \\
\text { energy used during warm operation }\end{array}$ & 3 \\
\hline $\begin{array}{l}\text { Pre-Heat/Delay } \\
\text { Period }\end{array}$ & $\begin{array}{l}\text { catalyst bed and heaters require pre- } \\
\text { heat }\end{array}$ & & none & 5 \\
\hline $\begin{array}{l}\text { Ease of } \\
\text { Implementation }\end{array}$ & some problems with reaction control & & $\begin{array}{l}\text { similar to existing system; additional } \\
\text { controls, mostly software }\end{array}$ & 4 \\
\hline Average Rank & & 3 & & 4 \\
\hline
\end{tabular}

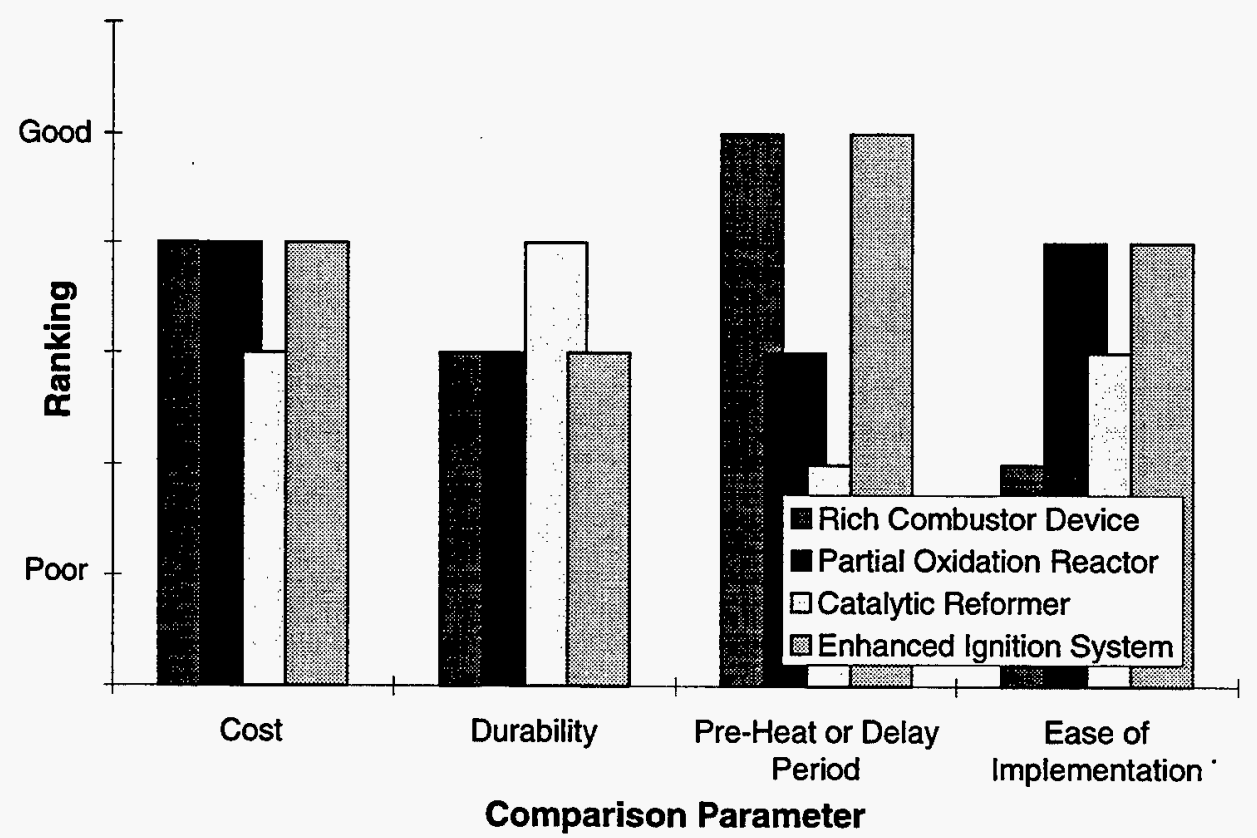

Figure 14. Secondary Comparison of Cold-Start Technologies 


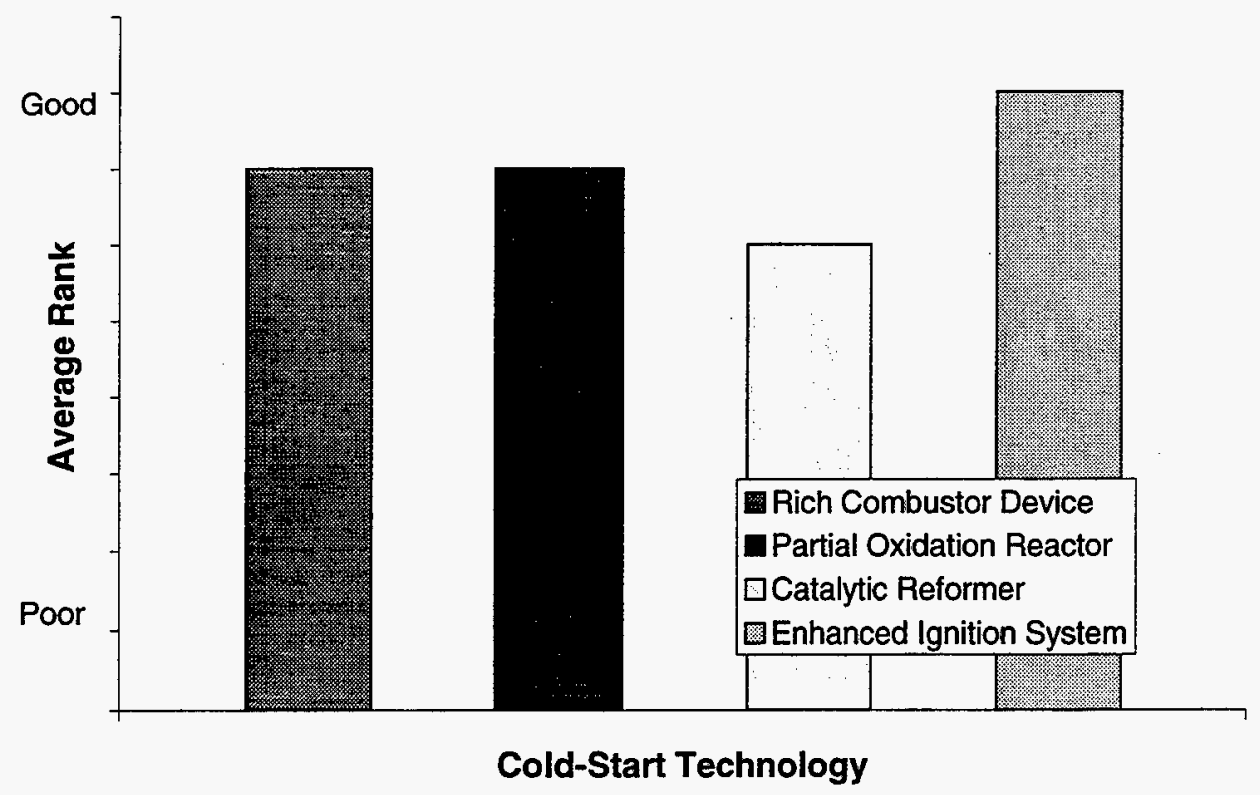

Figure 15. Secondary Comparison of Cold-Start Technologies - Average Combined Index

\subsection{Summary, Conclusions, and Recommendations}

We used computer simulation to determine VPER and energy densities for various fuel blends and cold-start technologies (a rich combustor device, a partial oxidation reactor, a catalytic reformer, and an enhanced ignition system) over a range of operating conditions. The averaged performance predictions were compared to a set of acceptance criteria. To be acceptable, a coldstart approach must provide a VPER greater than 0.50 and the energy density greater than 2500 $\mathrm{J} / \mathrm{L}$. Only two pseudo-gasoline blends and two cold-start technologies were able to satisfy these criteria. Our analysis showed that fuel blends alone are unlikely to provide acceptable cold-start performance at $-25^{\circ} \mathrm{C}$, which means that some type of cold-start assistance technology will be necessary. Based on the simulation results, the catalytic reformer and the enhanced ignition system are good candidates for cold-start assistance. In addition, we compared the cold-start technologies based on a set of secondary parameters related to commercialization. The enhanced ignition system ranked highest in this comparison.

Based on the our analysis and conclusions, we determined that the enhanced ignition system has the best potential for success out of the four technologies evaluated. Further investigation could be performed to further evaluate the commercialization of this technology. In addition, the optimization of this system offers many avenues for further research and development.

\subsection{Acknowledgments}

We gratefully acknowledge the U.S. Department of Energy (DOE) and DOE Program Manager John Garbak for providing funding for this activity. In addition, thanks are due each of the subcontract principal investigators-Jeffrey Hodgson, University of Tennessee (rich combustor 
device); Peter Loftus, Arthur D. Little, Inc. (partial oxidation reactor); Scott Cowley, Colorado School of Mines (catalytic reformer); and David Gardiner, Thermotech Engineering (enhanced ignition system)-for their assistance in furthering the development and our understanding of alcohol cold-start technologies.

\subsection{References}

1. Kelly, K.J.; Bailey, B.K.; Coburn, T.; Clark, W.; Lissiuk, P. (1996). "Federal Test Procedure Emissions Test Results from Ethanol Variable-Fuel Vehicle Chevrolet Luminas." SAE Publication 961092, Warrendale, PA: Society of Automotive Engineers.

2. Kelly, K.J.; Bailey, B.K.; Coburn, T.; Clark, W.; Eudy, L.; Lissiuk, P. (1996). "FTP Emissions Test Results from Flexible-Fuel Methanol Dodge Spirits and Ford Econoline Vans." SAE Publication 961090, Warrendale, PA: Society of Automotive Engineers.

3. Heywood, J. (1988). Internal Combustion Engine Fundamentals. New York: McGraw-Hill.

4. Zabetakis, M. (1965). "Flammability Characteristics of Combustible Gases and Vapors." U.S. Department of the Interior, Bureau of Mines; Bulletin 627.

5. Hodgson, J.; Irick, D.K. (1997). Investigation and Demonstration of a Rich Combustor ColdStart Device for Alcohol-Fueled Engines. Draft final report on NREL Subcontract XCF-514050-03; in press.

6. Loftus, P. (1997). Partial Oxidation for Improved Cold-Start in Alcohol Fueled Engines: Phase II Topical Report. Draft final report on NREL Subcontract YCC-5-14050-01; in press.

7. Kito, T.; Cowley, S.W. (1997). Generation of Ethyl Ether in an Ethanol Vehicle System for Cold Start Assistance. Final report on NREL Subcontract XCF-5-14380-01; March 1997.

8. Gardiner, D. (1996). "Experimental Studies Aimed at Lowering the Electrical Energy Requirements of a Plasma Jet Ignition System for M100 Fuelled Engines." SAE Publication 961989, Warrendale, PA: Society for Automotive Engineers.

9. Gardiner, D.; Mallory, R.; Todesco, M. (1997). Fabrication and Testing of an Enhanced Ignition System to Reduce Cold-Start Emissions in an Ethanol (E85) Light-Duty Truck Engine. Final Report on NREL Subcontract ACI-6-16602-01; NREL/SR-540-22967. 


\title{
Modeling and Simulation of Cold Start in Alcohol- Fueled Engines
}

\author{
Task 1: Review of Industry and Literature Resources \\ FINAL DRAFT
}

\author{
Prepared By \\ Anthony J. Markel \\ National Renewable Energy Laboratory
}

June 12,1997 


\section{Table of Contents}

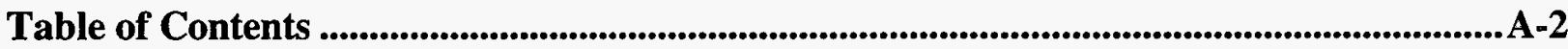

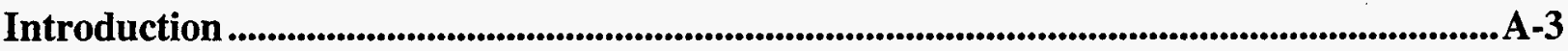

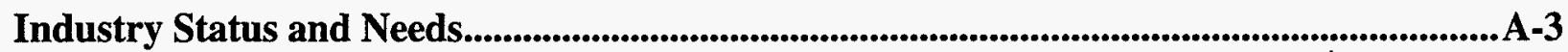

Problems Encountered During Cold Starting ......................................................................................A-4

Cold-Start Assistance Methods and Devices..................................................................................5-5

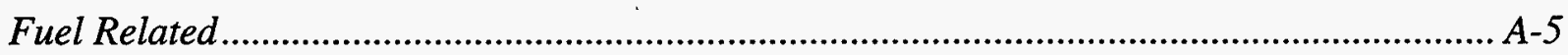

Engine Related ............................................................................................................... A-7

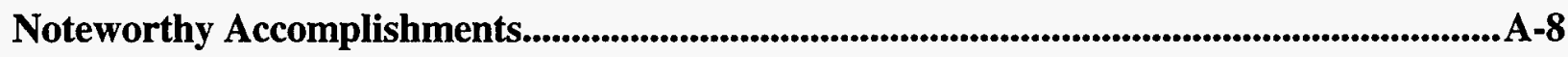

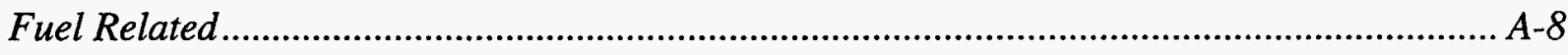

Engine Related ......................................................................................................... A-9

Vapor Pressure and Fuel Flammability .................................................................................................A-9

Engine Modeling................................................................................................................................A-13

Model Types and Levels of Detail....................................................................................... A-13

Current State of Engine Models................................................................................ A-14

Summary and Direction for Project Completion ......................................................................A-14

References Cited ...........................................................................................................................................A-16

Bibliography .....................................................................................................................................A-18 


\section{Introduction}

The consumption of foreign oil for transportation purposes in the United States continues to rise. Our dependence on petroleum products not only leaves us vulnerable to supply distributions, but also contributes to poor air quality. If we are to curb this dependence, we must develop alternative fuels that exhibit characteristics similar to and better than those of gasoline and diesel fuel. A major stumbling block for the use of alternative fuels is the development of technologies that will take full advantage of the fuels' positive aspects and compensate for their demerits. This presents a complex problem and a roadblock for the implementation and expansion of alternative fuels into the marketplace.

This project, which is focused on cold starting in alcohol-fueled engines, takes a first step toward removing one of those roadblocks. The use of alcohol fuels, such as methanol and ethanol, is desirable. They have low evaporative emission rates and their products of combustion have low atmospheric reactivities. They can also be derived from renewable and domestic resources. However, they are also extremely difficult, if not impossible, to start at low temperatures without assistance in typical spark ignition engines. This difficulty results from the chemical properties of methanol and ethanol, which have lower vapor pressures, higher heats of vaporization, and lower energy densities in comparison to gasoline. These deficiencies may be overcome through the development of innovative technologies for cold-start assistance.

As interest grows in improving the feasibility of alcohol fuel usage, so does the number of innovative technologies introduced. The objective of this project is to provide a tool that will assist in the evaluation of innovative cold-start technologies for use with alcohol-fueled engines. A tool that can analyze a variety of technologies on common ground will provide direction and insight for further investigation and will reduce our dependence on costly trial and error experimental testing. However, it should be noted that the purpose is to provide guidance rather than exact solutions to the problems facing alcohol fuels.

Before starting such a project, it is necessary to conduct a thorough examination of the resources and information available. This document summarizes the results of the initial research and will set the direction for the rest of the project based on the information collected. An assessment of the industry status and basic needs will be covered, followed by a summary of the typical problems encountered during the cold starting of alcohol-fueled engines. Next is a brief description of general approaches to solving these problems. Various investigators have made significant progress toward solving the cold-start problems and their activities are summarized. Numerous researchers agree that the delivery of a flammable mixture within the cylinder at the right moment is key. Mixture flammability will be covered in further detail. In addition, as this project presents a modeling approach to cold-start research, a review of modeling classifications and current highlights in this area is presented. Finally, a brief summary is provided, along with a recommended direction for the project.

\section{Industry Status and Needs}

As a result of recent legislation, the use of alcohol-fueled vehicles is growing. However, the vehicles remain a niche market primarily because of their limitations when compared to gasoline engines. Current gasoline engines operate using optimized vehicle and engine specific data stored in the engine controller. With similar improvements geared toward alcohol fuels, they may become much more acceptable and prominent. The necessary improvements will likely result from work in modeling and simulation in conjunction with engineering and design. 
First, what is modeling and simulation and what does it offer? A particular engine process or action can typically be modeled with mathematical expressions. When these individual models are connected to describe a large interacting system that is evaluated during a typical situation or process, it constitutes a simulation. Models allow the developer to evaluate a variety of cases in a fraction of the time required for actual hardware testing.

It is not new for researchers to create models for engines and perform simulations with these models to gain insight into the operation of an engine. However, in the area of cold starting, the intensity of research drops dramatically. Modeling of the cold-start phase of engine operation involves highly complex, transient, non-ideal, unsteady situations. Thus the bulk of reporting on modeling and simulation associated with engines deals only with steady-state, fully warmed, ideal cases. There is certainly a need, then, for further work in the area of modeling and simulation as applied to the cold-start phase in engines.

On the other hand, from the engineering, design and testing standpoint, there has been a vast amount of activity. Experiments have typically focused on creating a device that will assist the engine during the cold-start phase. These devices range from high-speed starters to on-board fuel reformers. However, even with the extensive experimentation as support, there is little agreement as to the ultimate solution for cold starting of alcohol-fueled vehicles. It is apparent that engine-specific and experimental design variations play a significant role in determining the leading technology. To determine the most viable technology, then, a standard set of acceptable conditions and constraints must be devised. Otherwise, each specific case will need to be investigated independently, which is extremely costly.

This emphasizes the need for models and simulation. With a reasonably flexible model, numerous case studies can be performed in a fraction of the time and for a fraction of the cost required for experimentation. Although models will not provide specific answers, they will provide the guidance for experimentation that is needed.

\section{Problems Encountered During Cold Starting}

For an alcohol-fueled vehicle to cold start successfully, a sufficient amount of a combustible mixture of air and fuel must be supplied to and be present in the cylinder at the time of an ignition event.[Dasch et al., 1991; Gardiner et al., 1987; Iwai et al., 1988a; Iwai et al., 1988b; Nakajima, et al., 1978; Shayler et al., 1989] Many factors affect a cold-cranking engine. Factors that prevent such conditions from occurring, thus, prevent the engine from starting.

The level of charge and strength of the battery system is a typical problem. Cold ambient temperatures reduce the charge capacity of standard batteries such that they have insufficient power to crank the engine at the desired speeds. Gardiner et al. [1993] determined that at $-30^{\circ} \mathrm{C}$, two $12-\mathrm{V}$ batteries with 525 cold-cranking amps of power connected in parallel could produce cranking speeds of $150 \mathrm{rpm}$. When connected in series, cranking speeds of $250 \mathrm{rpm}$ were achieved. Low battery levels can also affect the ignition systems. They may not be able to provide sufficient energy to generate a spark and ignite the mixture.

Fuel condensation in the cold intake manifold is a major problem in alcohol-fueled engines.[Maxwell et al. 1993a; Nebolon et al., 1982; Shayler et al., 1994] The manifold and associated engine components act as an extremely large heat sink, pulling heat from the vaporized or warmed methanol into the cold piping components. Until the engine reaches typical operating temperatures, fuel condensation in the manifold will cause fuel transport delays during cold starting. 
The low vapor pressures associated with alcohol fuels at low temperatures prevent high evaporative emissions, however, they also hinder cold startability. At $-23^{\circ} \mathrm{C}\left(-10^{\circ} \mathrm{F}\right)$ the vapor pressure of methanol is $0.83 \mathrm{kPa}(0.12 \mathrm{psia})$. Ethanol has a vapor pressure of $0.269 \mathrm{kPa}(0.039$ psia) at $-23^{\circ} \mathrm{C}\left(-10^{\circ} \mathrm{F}\right)$.[Obert, 1973] In contrast, gasoline is a highly complex mixture of light and heavy hydrocarbon compounds. The light fractions such as butane and pentane have high vapor pressures. The vapor pressures of butane and pentane at $0^{\circ} \mathrm{C}\left(32^{\circ} \mathrm{F}\right)$ are $103 \mathrm{kPa}(14.94$ psia) and $24.5 \mathrm{kPa}$ (3.55 psia), respectively.[Lide, 1995] At low temperatures, the light fractions are more likely to form vapor and promote combustion.

In addition to their low vapor pressures, methanol and ethanol require higher volume percents in air to produce a flammable mixture than gasoline and some of its components. According to Zabetakis [1965], methanol is flammable from 6.7 to 36 volume percent in air at $25^{\circ} \mathrm{C}$ and 1 atm. Likewise, ethanol is flammable from 3.3 to 19 volume percent in air. For comparison, a typical gasoline is combustible from 1.3 to 7.1 volume percent in air. Its light components, butane and pentane, have flammable ranges of 1.8 to 8.4 and 1.4 to 7.8 volume percent in air, respectively. Methanol and ethanol, therefore, require a larger volume of fuel vapor in air to produce a flammable mixture while they are also less likely to form vapor at low temperatures than gasoline and its light components.

The electrical conductivity of methanol also presents a problem during cold starts. It is possible for liquid methanol to bridge the gap of the spark plug electrodes if the spark energy is insufficient to vaporize the methanol. This short circuiting of the ignition system results in a misfire and unburned fuel in the emissions stream.[Dasch et al., 1991]

Alcohol fuels also pose problems with material compatibility and durability. Morita et al.[1996] showed that methanol reduced the life of injectors as a result of corrosion and deposits on the injector tips.

Cold starting in engines, in general, must overcome the excessively high frictional losses resulting from oil viscosity and the detrimental effects of blowby past the cylinder rings.[Haahtela and Decker, 1989] At low ambient temperatures, the lubricant in the engine is highly viscous and will provide resistance to motion of the engine components. In addition, because the rings, piston, and cylinder walls are cold, contracted, and not coated with oil, air and fuel inducted is allowed to leak from the cylinder.[Gardiner and Bardon, 1986] At low temperatures, this presents a problem -- as the cylinder motion attempts to compress the captured gases, the gases are able to escape past the rings and into the crankcase. As a result, the incylinder compression temperatures and pressures will be lower.

\section{Cold-Start Assistance Methods and Devices}

Although numerous problems hamper the cold starting of engines, specifically those fueled with alcohol fuels, many solutions to these problems have been suggested and investigated. These cold-start assistance methods, in general, can be classified into two categories: those related to the fuel and those dealing with the engine and its components.

\section{Fuel Related}

Major problems with the use of alcohols to fuel spark ignition engines include their high heat of vaporization, low vapor pressure, higher range of flammability, and low energy density. Several methods and technologies attempt to rectify such demerits.

Various methods to increase the amount of vapor available for combustion exist. In the simplest method, the fuel or the air flowing to the engine is heated either via electrical heating or 
direct combustion heating. Such attempts have provided little improvement. Any vapor that is generated in this manner generally will recondense as it contacts the cold intake manifold or other engine components.[Nebolon et al., 1982]

Fuel droplet size and atomization improvement has been investigated to see if this may help in cold starting. Browning [1983] has shown that by providing a finely atomized spray to the intake manifold, it is more likely that the fuel droplets will remain suspended in the air and reach the cylinder. Browning and Raghuraman [1984] determined that if droplets of less than 30 $\mu \mathrm{m}$ in diameter could be provided to the intake manifold, they were more likely to reach the cylinder and provide combustion at temperatures as low as $3^{\circ} \mathrm{C}$ in a carbureted engine.

In an effort to improve the vapor pressure and flammability of alcohol fuels, most of the research has been conducted in the area of fuel blending. The primary alcohol fuel is typically blended with either a single component primer fuel such as butane, pentane, or dimethyl ether, or is blended with a multi-component fuel such as winter-grade gasoline. The purpose of the blending is to provide a component that will vaporize at low temperatures and provide the vapor air mixture required for combustion to initiate. A mixture of $85 \%$ methanol and $15 \%$ gasoline (M85) is quite common, and extensive experiments have been conducted with this and other similar compositions. In general, such a mixture will provide minimum starting temperatures in the range of $-20^{\circ}$ to $-30^{\circ} \mathrm{C}$. However, to achieve such starts enough fuel must be provided so that the gasoline concentration or primer component alone is sufficient to promote ignition.[Gardiner et al., 1993; Petterson and Sjöström, 1991b] This results in excessive fueling in the initial cranking cycles and in high unburned hydrocarbon emissions. Such a fuel blending approach also causes problems with excessive vapor pressure during warm operation. Fuel blending provides a simple method for achieving cold starts, although it requires over-fueling and results in unfavorable emissions levels.

A more complicated, but possibly more effective, method of cold starting alcohol engines is to use an on-board device to reform the primary alcohol fuel into a gaseous mixture. Using a gaseous mixture eliminates the problem of wall condensation and compensates for the slow equilibrium evaporation rates of alcohols. Several approaches exist for reforming alcohol fuels.

Dehydration will produce dimethyl ether and diethyl ether from methanol and ethanol, respectively. For methanol, this process requires approximately $323 \mathrm{~W}-\mathrm{hr} / \mathrm{kg}$.[Karpuk and Cowley, 1988] Dehydration is typically performed by passing vaporized fuel over a catalyst bed heated electrically or with hot exhaust gases. Using a fluorinated g-alumina catalyst material, Karpuk and Cowley were able to achieve 50\% conversion of methanol at an operating temperature of $250^{\circ} \mathrm{C}$.

The alcohol fuel can also be dissociated into hydrogen and carbon monoxide using a variety of methods. Similar to the dehydration method, vaporized methanol or ethanol can be passed through a heated catalyst bed to produce a gaseous mixture. This reaction requires 1227 $\mathrm{W}-\mathrm{hr} / \mathrm{kg}$ for methanol making it more energy intensive than the dehydration process.[Karpuk and Cowley, 1988] Again the catalyst bed can be heated electrically, with exhaust energy, or through direct combustion heating.

Another method of alcohol dissociation involves the combustion of a rich mixture of fuel and air to produce hydrogen and carbon monoxide along with other combustion products. The rich mixture, typically with an equivalence ratio of approximately 2.0 , is ignited with a glow plug, spark plug, or other similar ignition device. The ignition device may require additional 
energy with this approach. However, a flammable mixture is produced quickly while the catalyst material requires time for preheating before it will operate properly.

Alcohols can also be dissociated through a process similar to the electrolysis of water. Sethuraman et al. [1994] investigated the dissociation of methanol using a submerged electric arc. Although the system was able to produce the desired hydrogen and carbon monoxide mixture, the energy efficiency of the design was only $18 \%$.

Each of these technologies has the principal goal of taking a fuel that would not be able to initiate combustion in a cold-cranking engine and producing a composition that is more likely to ignite because of its chemical properties. It must also be noted, however, that changing the chemical composition of the fuel may also hinder the combustion process. The gaseous mixture that is typically produced is at an elevated temperature and has a reduced energy density. As a result, it may be difficult to induct enough fuel and air into the cylinder to provide sufficient combustion energy to sustain engine rotation, because of the volumetric efficiency and high frictional losses of the engine. In addition, hydrogen and dimethyl ether each have high laminar flames speeds that may negatively affect combustion.

\section{Engine Related}

The cranking speed of the engine has been shown to significantly affect the minimum start temperatures of a cold engine.[Gardiner and Bardon, 1986] At cold temperatures, cranking speed can be dramatically reduced because of low battery energy levels and the high friction losses caused by high lubricant viscosity. If cranking speeds are increased, peak cylinder temperatures will increase, the time for blowby is decreased, turbulence levels may increase, and the time for evaporation is decreased. Thus, there should be an optimum cold-cranking speed. It seems that this is in the range of 200 to $400 \mathrm{rpm}$ although it depends somewhat on the specific engine geometry.

A second engine-related modification for cold starting is improvement of the ignition system. This approach attempts to provide enough energy through the ignition event to generate a combustible mixture in the cylinder when a flammable mixture cannot be inducted. The first technique is to extend the duration of the spark. Bruetsch [1989] investigated this using 3 to 6 times the normal duration and achieved starts as low as $-7^{\circ} \mathrm{C}$ using neat methanol. However, the large energy demand quickly drained the battery.

Gardiner et al. [1993; 1995] have been more successful in the development of a plasma jet ignitor. In this system, the ignitor is modified such that one electrode is recessed within a ceramic insulator. A fuel and air vapor mixture enters this cavity and is ignited by the spark discharge. The plasma that is formed expands rapidly, extending into the cylinder approximately $1 \mathrm{~cm}$ to initiate combustion throughout the rest of the cylinder. In combination with an exhaust charged cycle (ECC) modification that promptly recycles exhaust products, this system provided engine starts as low as $-30^{\circ} \mathrm{C}$ in 5 seconds (s) with neat methanol. The ignition system requires more energy than a typical spark ignition system, but the modifications for use were minimal.

The exhaust charged cycle used in the previous example is similar to a standard exhaust gas recirculation (EGR) system in that exhaust products are brought back into the cylinder. However, with this system the exhaust is inducted into the cylinders by opening the exhaust valve rather than directing the gases to the intake manifold (as is the case in a typical EGR system). During initial combustion cycles, the exhaust products will contain formaldehyde and other unburned hydrocarbons. Recirculation of the exhaust products may result in charge heating, which helps to vaporize liquid fuel. The process may also contribute to an increase in 
cylinder turbulence levels. Gardiner et al. [1991a; 1993] attribute the observed consistency in combustion events to this system.

The direct injection engine is a more radical engine modification that has shown promising cold-start results. With this concept, fuel is injected directly into the cylinder near the end of compression and is immediately ignited. In the typical spark ignition engine, a homogeneous mixture is prepared in the manifold prior to induction into the cylinder. In contrast, the stratified-charge concept results in a flammable mixture near the ignition source and a non-homogeneous mixture throughout the cylinder. The design allows unthrottled operation, which results in better fuel economy and higher compression ratios. Siewert and Groff [1987] obtained starts in $3 \mathrm{~s}$ on a variety of fuels at ambient temperatures of $-29^{\circ} \mathrm{C}$ using the directinjected stratified-charge concept. Jorgenson [1988] noted that this engine was nearly "fuel independent." It should also be mentioned that a unique AC ignition system was used that provided a maximum frequency of $4000 \mathrm{~Hz}$, a current of $5 \mathrm{amps}$, and a voltage of $25 \mathrm{kV}$. This ignition system resulted in an estimated supplied energy rate of $65 \mathrm{~J} / \mathrm{s}$ from the power source, which is greater than the typical spark ignition system.[Jorgenson, 1988]

\section{Noteworthy Accomplishments}

Of the various technologies and methods for cold starting introduced thus far, a few have shown promise. These, which can again be broken down into those related to the fuel and those that involve engine modifications, will be described further, along with some performance information.

\section{Fuel Related}

Hodgson and Irick [1996] (University of Tennessee) have designed and tested a rich combustor device for cold starting of methanol engines. Their system adapts to the intake system of the engine and provides a stream of reformed methanol to the engine. The device injects liquid methanol into the intake air stream to produce a rich mixture (approximately 1.5 to 2.0 equivalence ratio), which is ignited with a specially designed spark device. The mixture partially oxidizes and produces a gaseous stream with high levels of $\mathrm{CO}$ and $\mathrm{H}_{2}$. The stream is then quenched with additional injected methanol and combined with supplemental air before it reaches the cylinder. The quenching step lowers the temperature of the mixture and improves the energy density of the charge. The additional air is necessary for complete combustion to occur in the cylinder. This device has produced starts as low as $-25^{\circ} \mathrm{C}$ in $26 \mathrm{~s}$. Problems have been encountered with backfires, achieving a smooth idle speed quickly, and transition to the primary fuel.

Using a similar concept, Nishimura et al. [1994] have developed what they call a partial oxidation reactor, which they combine with an ultrasonic atomizer. The atomizer produces an extremely fine mist of fuel, which is again mixed with insufficient air and then ignited using a glow plug in this case. Similar products are produced and are combined with additional air and fuel before induction into the cylinder. This device has also produced successful starts and seems feasible.

Cowley (Colorado School of Mines) has been working on a system to catalytically reform the alcohol fuel to produce a gaseous primer such as dimethyl ether. Much of his work has emphasized evaluation of catalyst materials. As shown by the wealth of resources summarized by Petterson and Sjöström [1991a], catalytic reforming of alcohols is not new. Major problems with this system are the energy requirements and the timing of those requirements. The catalyst 
must be heated to a specific operating temperature before it is able to reform the fuel. In addition, the fuel must be vaporized before introduction to the catalyst. Thus, it is energy intensive. Karpuk and Cowley [1988], Kito et al. [1996], Cowley and Gebhard [1983] describe two approaches, one in which the catalyst and fuel are heated using the excess exhaust heat, and a second in which the heat is supplied with an electric heater. With both methods, problems surface in control of the reaction and the time required for preheating.

Fuel blending may be one of the simplest approaches as long as operation on neat methanol is not a requirement. Gardiner et al. [1987] has shown that if methanol is blended with butane or pentane, cold startability is dramatically improved. These priming components increase the vapor pressure of the mixture and improve its flammability range. With $10 \%$ butane in methanol, starts were obtained at $-18.5^{\circ} \mathrm{C}$ with $30 \mathrm{~s}$ of cranking. With pentane, Mitchell [1984] has demonstrated that a mixture of $9 \%$ pentane in methanol will result in a minimum start temperature of $-21.5^{\circ} \mathrm{C}$ with $30 \mathrm{~s}$ of cranking. However, it should be noted that blending a high volatility component into the alcohol fuel increases the evaporative emissions and the exhaust emissions.

\section{Engine Related}

In the area of ignition system development, Gardiner et al. [1993; 1995] have completed the most research with the most success. The plasma jet ignition system mentioned above attempts to compensate for the inability to provide a flammable mixture to the cylinder by providing the energy necessary to result in favorable conditions for combustion. The plasma plume created moves into the chamber and disperses its energy, resulting in localized ignition and flame propagation throughout the rest of the cylinder. Although the device may require more energy than the standard ignition system, it also requires only minimal modifications for use. During their testing, either the battery was not cooled to the engine test conditions or additional battery power was supplied so that the available energy was not the limiting factor during ignitor development. One concern with the use of this device was its durability. The high energy levels at which it operates deteriorate the ignitor materials. Further research and development may provide insight into improvements in this area.

Other impressive results resulting from engine modifications come from the work of Siewert and Groff [1987] in the development of a direct-injection stratified-charge engine. The concept was explained above. Although the engine requires that it is designed specifically for direct injection rather than modifying an existing system, it proved successful. The engine was able to start at $-29^{\circ} \mathrm{C}$ (the limit temperature of the test apparatus) using a variety of fuels including methanol, ethanol, gasoline, and diesel fuel. Jorgenson [1988] attempted to explain the success of this engine design. He concluded that the success was not entirely attributed to compression heating but more likely the result of spark vaporization of the injected fuel. The ignition system provided energy levels greater than that of a normal ignition system. In addition, the fuel continued to be injected after ignition thus feeding the combustion process. The combination of the increased energy level and direct injection system most likely helped to vaporize the liquid, promote ignition, and sustain combustion.

\section{Vapor Pressure and Fuel Flammability}

It is implied numerous times in the literature that in order for combustion to occur in an engine cylinder, the presence of the proper vapor phase mixture of fuel and air must coincide with an ignition event. While many other factors are involved it is clear that if the fuel and air 
vapor mixture is too rich or too lean, it is highly unlikely that ignition will occur. The generation of the proper fuel and air mixture is dependent on both the flammability range and the vapor pressure characteristics of the fuel.

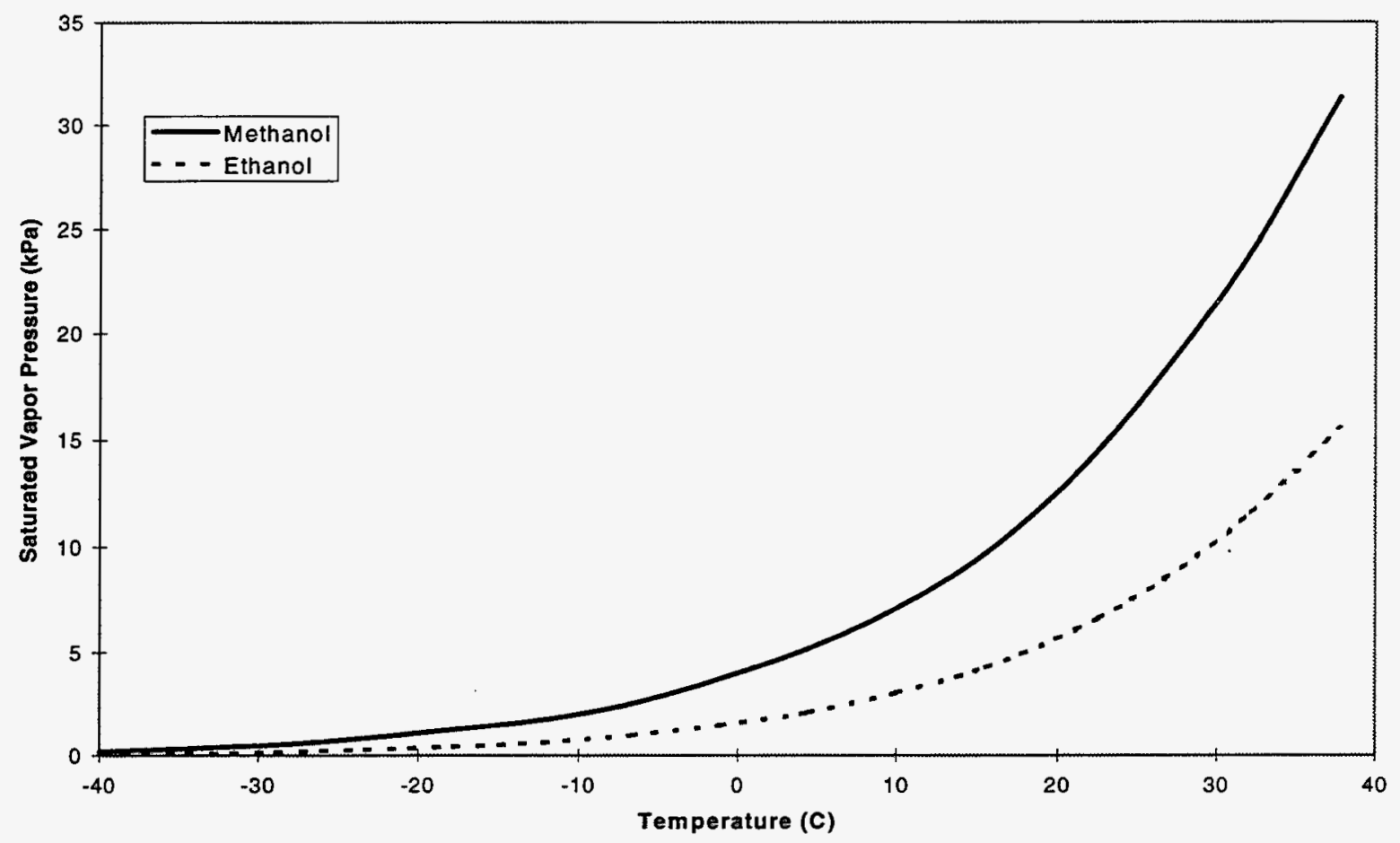

Figure 1 Vapor Pressures of Alcohol Fuels at Low Temperatures

For pure substances, the ability to generate a vapor composition within its flammable range is directly related to the vapor pressure of the substance. Vapor pressure is defined as the pressure at which a liquid will exist in equilibrium contact with its vapor at a specified temperature.[Vaivads et al., 1993] It is a function of temperature only for pure substances. The vapor pressure curves for pure methanol and ethanol at low temperatures derived from data tabulated by Obert [1973] are shown in Figure 1. These can also be predicted using the following expression as a function of temperature.[Obert, 1973]

$$
\log P=A+\frac{B}{T}+\frac{C}{T^{2}}
$$

where $A, B$, and $C$ are empirical component-specific constants.

When the flammability of mixtures is considered, the problem becomes more complicated. Not only is the range of flammability affected, but the vapor pressure is both a function of temperature and fraction vaporized of each component.[Vaivads et al., 1993] The vapor pressures of specific components in a binary mixture can be predicted from Raoult's Law as described by Vaivads et al. [1993],

$$
P_{t}=\gamma_{a} \chi_{a} P_{a_{s a}}+\gamma_{b} \chi_{b} P_{b_{s a t}}
$$




$$
\begin{aligned}
& \text { where } 0<\gamma_{i}<1.0 \text { to account for non-ideality, } \\
& \qquad \begin{array}{c}
P_{i_{s u t}}=\text { saturation pressure of } i, \\
\chi_{i} \text { is the mole fraction of } i
\end{array}
\end{aligned}
$$

For more complex mixtures, prediction is difficult. Vaivads et al. provide a method of predicting the vapor pressure of gasoline and methanol mixtures based on Raoult's Law and gasoline distillation curves.

As mentioned above, the vapor pressure is a function of temperature. The flammability range of a substance is related to vapor pressure and is therefore also affected by temperature. Zabetakis [1965] has compiled an extensive list of the lean and rich flammability limits of a variety of compounds at $25^{\circ} \mathrm{C}$ and $1 \mathrm{~atm}$. These can be adjusted with a modified BurgessWheeler Law for other temperatures. [Zabetakis, 1965]

For lean limits:

$$
X_{L_{T}}=X_{L_{25}} 1-\frac{0.75}{\Delta H_{C}}(T-25) .
$$

where $X_{L_{T}}$ is the lower flammability limit at temperature T,

$X_{L_{25}}$ is the lower flammability limit at $25^{\circ} \mathrm{C}$

and $\Delta H_{c}$ is the heat of combustion.

For rich limits:

$$
X_{R_{T}}=X_{R_{25}} 1+\frac{0.75}{\Delta H_{C}}(T-25) .
$$

Note that the flammability limits reported by Zabetakis have been compiled from multiple sources and that the accuracy of the limits reported depend on the type of ignition source and the energy level used. However, this is the most complete set of data available.

The concentration and the flammability limits of each constituent affect the flammability of the entire mixture. A first approximation at determining the overall mixture flammability can be found by applying the Le Chatelier mixing principle as demonstrated by Zabetakis [1965]. The lean limit can be approximated by,

$$
X_{L}=\frac{1}{\sum X_{i} / X_{L_{i}}}
$$

where $X_{i}$ is the actual mole fraction of $i$ and

$X_{L_{i}}$ is the independent lean limit mole fraction of $i$.

It is unclear from the literature if a similar expression can be derived for the rich limits of a mixture.

Evaluation of detailed mixture properties presents a very complicated problem, but there maybe a simpler way to approach the fuel flammability determination. For example, several 
authors discuss what is referred to as the vapor phase equivalence ratio (VPER). This can be expressed as follows,

$$
V P E R=\frac{\text { mass of fuel in vapor phase } / \text { mass of air }}{(\text { mass of fuel/mass of air })_{\text {stoichiomeric }}}
$$

It was shown by Vaivads et al. [1993] that for M20-M85 mixtures, VPER's in the range from 0.58 to 2.8 typically provide a combustion event over the range of mixture compositions. It is interesting to note that these values for the lean and rich limits were surprisingly constant across the entire range of fuel compositions.

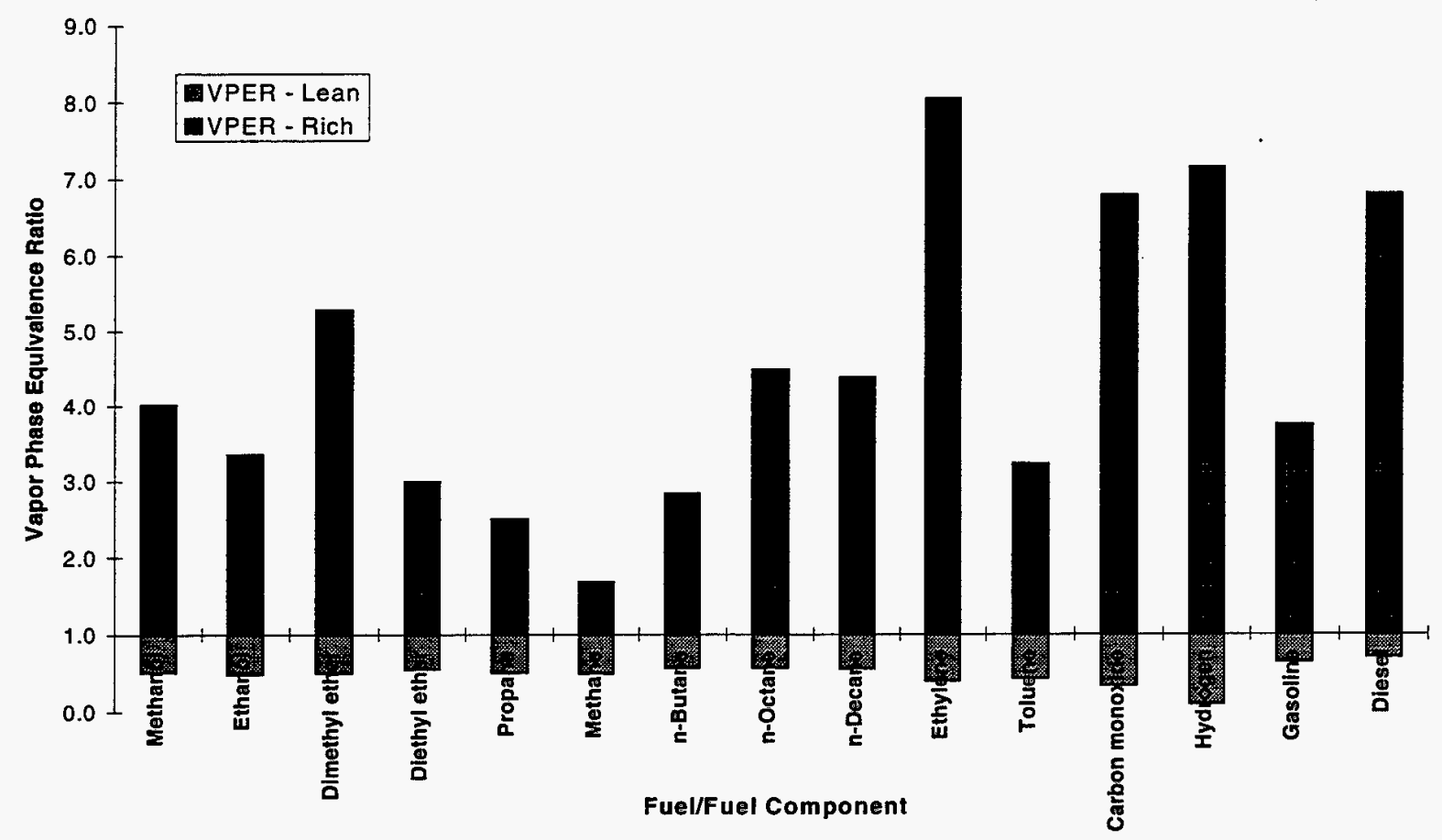

Figure 2: Vapor Phase Equivalence Ratio of Various Fuels and Fuel Components

It can be assumed that if a VPER equal to 1.0 (stoichiometric) is present at the time of an ignition event supplying sufficient energy, combustion will occur. A lean limit (less than 1.0) and a rich limit (greater than 1.0) will also exist. Outside of these limits, it is unlikely that the mixture will ignite. It is unclear as to whether the limits for all fuels are similar to those presented by Vaivads et al. [1993]. Figure 2 shows the lean and rich VPER's of a variety of fuels and fuel components based on flammability limits reported by Zabetakis. From this graph, it seems that the lower limits are fairly constant while the upper limits fluctuate. Note that these values are greatly affected by the flammability limit values used and the estimated molecular weights (in the case of gasoline and diesel fuel).

The VPER values presented in Figure 2 were calculated using eqn. 7 shown below.

$$
V P E R=\frac{\frac{L}{1-L} * \frac{M W_{\text {fuel }}}{M W_{\text {air }}}}{(F / A)_{s}}
$$


where $L$ is the lean or rich flammability limit volume fraction, $M W$ is the molecular weight

and $(F / A)_{S}$ is the stoichiometric fuel-air ratio.

Reid Vapor Pressure (RVP) has been used in the past to indicate the volatility of a fuel. The RVP is determined by measuring the vapor pressure in an enclosed container under specified conditions. It has been shown, however, that this is not the best indicator of flammability and cold startability.[Gardiner et al., 1987; Kirwin and Brinkman, 1991] For example, dimethyl ether has a very high vapor pressure and when mixed with methanol does indeed improve cold startability. However, when higher percentages of dimethyl ether are used as a priming agent, cold startability does not improve and is at times diminished. A much better correlation exists between VPER and cold startability than between RVP and cold startability.

\section{Engine Modeling}

Mathematical modeling of engine systems is not a new concept, although it is one generating increased interest with lots of room to grow. Models vary in complexity from simple ideal air cycle analysis to highly detailed and time-consuming multi-dimensional models. First, the different types and levels of complexity of models are described, followed by a short description of a few highlighted models.

\section{Model Types and Levels of Detail}

There seems to be two general approaches to modeling of engines. The first approach is based on thermodynamics; the second is based primarily on tabulated empirical data. The thermodynamic approach can range from very simple to extremely complex in structure, depending on the desired results. A large amount of computing time may be required to evaluate individual events. Although, the more empirical approach may require more preparation time to collect the required data, the models ease of operation and flexibility offer advantages.

The typical thermodynamic model for a spark ignition engine divides the combustion chamber into two zones. One contains the unburned fuel and air mixture; the second is composed of combustion products. The progression of the conversion of the mixture from unburned to burned composition defines the temperature and pressure changes within the cylinder, and as a result, the piston motion and engine speed. The intake and exhaust processes can also be modeled with expressions defining a plenum chamber that is filled and emptied as needed or with more detailed gas dynamic equations detailing a continuous gas exchange process. Most models of this type have been used for steady-state analysis although a few attempt to handle transient cases. Although these models are primarily thermodynamic in nature, empirical engine data is necessary to develop and support the thermodynamic relationships.

In comparison, the basic idea behind the empirical approach is that if the steady-state engine performance data is available, a transient case can be approximated with a series of extremely brief steady-state steps. This type of model typically uses mean values for engine inputs and outputs and is unable to predict individual cycle events. They do, however, provide a good overall picture of the engine operation. Recently, this type of model has been applied to the area of control strategy development. For this application, computational speed is important while the specific cycle to cycle events are less important. 


\section{Current State of Engine Models}

Many models have been created, each with its own advantages and disadvantages. A brief description of some of the most appealing ones follows. This is a small sample of engine modeling activities and is not intended to be comprehensive.

Assanis (University of Michigan) has created thermodynamic simulations for both spark ignition and compression ignition engines. Separate simulation packages exist for each type of engine. The purpose of these models is to look at the effects of a variety of variables on cycle performance. Input parameters such as engine speed, valve and ignition event timings, and manifold pressures are specified. The model returns both cycle-averaged and crank-angle-based engine outputs.

GT-Power from Gamma Technologies, Inc. and Wave from Ricardo N.A., Inc. are also thermodynamically based models similar to those developed by Assanis, but they include more detailed handling of manifold and in-cylinder gas dynamics. They require more computing time and power but also provide more detailed results.

On the other hand, Weeks (Simcar.com) and Moskwa (University of Wisconsin Madison) and Rizzoni (The Ohio State University) have created models that are more empirical in nature. These models typically do not predict individual cylinder events. Instead, the results provided are averaged over several cycles of operation and are thus referred to as "mean value" models. Rizzoni is in the process of adding more detailed cylinder event and cycle specific information to his models. These are useful packages for control strategy development because minimal computing time is required for the analysis of a variety of cases.

Two models that are specific to the cold-starting process have been uncovered. The first was created by Shaylor (University of Nottingham) for comparison of various engine modifications on cold startability. A wealth of experimental data was collected from engine tests on various engine builds. The data was compiled and an evaluation was performed with a computer model. This analysis dealt only with engine configuration effects on cold starting and did not consider the effects of fuel composition. The second was created by Hodgson and Irick [1996] (University of Tennessee) in conjunction with their development of a rich combustor device. This model helped them to evaluate the chemistry of the rich combustor device and to predict the operation of the engine on the combustor products. As with nearly every simulation that has been developed, combustion is assumed to occur without analysis of its likelihood.

\section{Summary and Direction for Project Completion}

The resources collected, reviewed, and summarized provide a stable base of knowledge to build on to complete this project. The goal is to provide an evaluation tool that will provide input as to which technologies for cold starting of alcohol-fueled engines offer the most promise and should be developed further. This is a challenging goal with a variety of obstacles to overcome along the way.

First, the type of engine model to be used must be chosen. This project will need both the simplicity of "mean value"-based models and the cyclic analysis of the more detailed thermodynamic models. A model that combines aspects from each of these types will be required, and accounting for both fuel dynamics and engine modifications within a single model will be complex.

Determining the criteria that each technology must satisfy is a second obstacle that needs to be tackled. The time to start and the minimum temperature at which the engine will start 
should be included in these standards. The energy requirements to achieve a start must also be considered. Consumers are unwilling to sacrifice convenience even at $-30^{\circ} \mathrm{C}$. It is likely that each technology will need to meet size constraints and be easy to install.

The approach must allow evaluation in stages and allow for process corrections as the project progresses. This literature and industry review was the first step toward providing the required background information. Next, a chemical process modeling tool, such as ASPEN Plus, will be used to perform simplified chemical modeling to simulate the intake and compression processes of an engine cycle. The model will be designed to provide detailed phase composition information at the end of compression for each of the specific technologies. The initial fueling rates and compositions required of the technologies will be determined that provide the desired vapor phase equivalence ratios. This chemical analysis provides a first cut feasibility determination. The models will provide information to map the operating environment for each technology. These maps may then be compiled and incorporated into a simplified flexible engine model similar to that of Weeks and Moskwa or Rizzoni to provide the cyclic analysis data on which the technologies can be compared. The evaluation of specific technologies for time to start and ability to idle along with energy requirements determined from cyclic engine models will provide insight into the cold startability for each technology under a variety of conditions.

In summary, it is important to stress that this endeavor is unique. Researchers have attempted to model, simulate, and investigate the operation of internal combustion engines for many years with varied success. One area in which little, if any, effort has been placed is in understanding and duplicating the process that begins when the key is turned and progresses to the point at which we are able to drive away. Once again, nearly all of the engine modeling efforts investigate the use of gasoline and diesel fuels. This project, however, will make progress in helping us to understand more about the combustion of alcohol fuels. It is the overall vision of the project that the tool that results will focus research on specific cold-start technologies and speed the introduction and use of alternative fuels. 


\section{References Cited}

Browning, L. (1983) "Alcohol Cold Starting-A Theoretical Study." 18th IECEC; Vol. 2, pp. 586591.

Browning, L.; Raghuraman, G. (1984). "A Detailed Study of Alcohol Cold Starting." Proc. VI Intl. Symp. on Alcohol Fuels Tech.; Vol. 1, pp. 63-69.

Bruetsch, R. (1989). "Cold Starting a Neat Methanol (M100) Vehicle with Long Duration Spark Ignition." EPA/AA/CTAB-89/05.

Cowley, S.W.; Gebhard, S.C. (1983). "The Catalytic Decomposition of Methanol into Synthesis Gas for Use as an Automotive Fuel." Colorado School of Mines Publication 01639153/83/7803-0041.

Dasch, C.J.; Brinkman, N.D.; Hopper, D.H. (1991). "Cold Starts Using M-85 (85\% Methanol): Coping with Low Fuel Volatility and Spark Plug Wetting." SAE Publication 910865.

Gardiner, D.; Bardon, M. (1986). "The Effect of Cranking Speed on Cold Starting Performance with Methanol Fuels." Proc. VII Intl. Symp. on Alcohol Fuels Tech.; Oct. 20-23, 1986; Paris; pp. 191-195.

Gardiner, D.P.; Caird, S.G.; Bardon, M.F. (1987). "Spark Ignition Engine Cold Starting with Methanol-Based Fuel Blends." SAE Publication 872067; SP-726.

Gardiner, D.; Rao, V.; Bardon, M.; Battista, V. (1991a). "Improving the Cold Start Combustion in Methanol Fueled Spark Ignition Engines by Means of Prompt EGR." SAE Publication 910377.

Gardiner, D.P.; Rao, V.K.; Bardon, M.F.; Dale, J.D.; Smy, P.R.; Haley, R.F., Dawe, J.R., Battista, V. (1993). "Sub-Zero Cold Starting of a Port-Injected M100 Engine Using Plasma Jet Ignition and Prompt EGR." SAE Publication 930331; SP-949.

Gardiner, D.P.; Mallory, R.W.; Rao, V.K.; Bardon, M.F.; Battista, V. (1995). "Vehicle Implementation and Cold Start Calibration of a Port Injected M100 Engine Using a Plasma Jet Ignition and Prompt EGR." SAE Publication 952375; SP-1115.

Haahtela, O.; Decker, G. (1989). "Present and Future Fuels and Lubricants in Cold Climate Operation." SAE Publication 890032.

Hodgson, J.W.; Irick, D.K. (1996). NREL Briefing: Subcontract No. XCF-5-14050-03; December 1996.

Iwai, N.; Nagai, K.; Yasuda, H.; Ayusawa, T.; Kim, Y.K. (1988a). "A Study on Cold Startability and Mixture Formation of High-Percentage Methanol Blends." SAE Publication 880044.

Iwai, N.; Nagai, K.; Yasuda, H. Ayusawa, T.; Kim, E.; Niwa, K. (1988b). "Effects of Additive Components on near Neat Methanol Fuels on the Cold Startability and Hot Weather Driveability." Proc. VIII Intl. Symp. on Alcohol Fuels Tech.; pp. 863-868.

Jorgensen, S.W. (1988). "Compression Temperatures in a Cold Cranking Engine." SAE Publication 880045.

Karpuk, M.; Cowley, S. (1988). "On Board Dimethyl Ether Generation to Assist Methanol Engine Cold Starting." SAE Publication 881678.

Kirwan, J.; Brinkman, N. (1991). "Fuel Methanol Composition Effects on Cold Starting." SAE Publication 912416; SP-889.

Kito, T.; Wittayakun, J.; Pacus, D.; Selim, S., Cowley, S.W. (1996). "The Catalytic Dissociation or Dehydration of Ethanol for On-Board Cold Start Assistance." Proc. XI Intl. Symp on Alcohol Fuels; San City, South Africa; 1996; Vol. 1, pp. 166-177. 
Lide, D.R. (1995). CRC Handbook of Chemistry and Physics. 76th edition. Boca Raton: CRC Press.

Maxwell, T.; Jones, J.C.; Shah, P.S.; Boyce, C.; Parker, H.W. (1993a). "Cold Starting Engines Fueled with Neat Methanol." Proc. X Intl. Symp. on Alcohol Fuels; November 7-10, 1993; Colorado Springs, Colorado; Vol. 2, pp. 637-648.

Mitchell, D. (1984). "The Effects of Blending Agents on the Cold Weather Operation of the Methanol Fuelled Automobiles." Proc. VI Intl. Symp. on Alcohol Fuels Tech.; Vol. 1 pp. 272-280.

Morita, K.; Hayashi, S.; Akai, M.; Iwai, N.; Inoue, S.; Otsubo, K. (1996). "Problems in Otto-type Methanol Vehicles and Solutions Thereto." Proc. XI Intl. Symp. on Alcohol Fuels; April 14-17, 1996; Sun City, South Africa; Vol. 1, pp. 262-271.

Nakajima, Y.; Saito, T.; Takagi, Y.; Katoh, K.; Iijima, T. (1978). "The Influence of Fuel Characteristics on Vaporization in the SI Engine Cylinder During Cranking At Low Temperature." SAE Publication 780612.

Nebolon, J.; Chan, K.C.; Browning, L.; Pefley, R.K. (1982). "Multi-Point Injection of Alcohol Vapour as a Cold Starting Aid for Neat Alcohol Fueled Vehicles." Proc. VIntl. Alcohol Fuels Tech. Symp.; Vol. 2, pp. 29-36.

Nishimura, J.; Hosogai, D.; Ito, T.; Iwai, N.; Akai, M. (1994). "Study of Partial Oxidation Combustor Using Ultrasonic Atomizer to Improve Cold Startability of Methanol Engine." SAE Publication 940767.

Obert, E.F. (1973). Internal Combustion Engines and Air Pollution. New York: Harper \& Row. Pettersson, L.; Sjöström, K. (1991b). "Onboard Hydrogen Generation by Methanol Decomposition for the Cold Start of Neat Methanol Engines." Int. J. Hydrogen Energy; (16:10); pp. 671-676.

Sethuraman, R.; Parker, H.W.; Maxwell, T.T.; Jones, J.C. (1994). "Submerged Electric Arc Decomposition of Methanol for Cold-Starting of Methanol-Fueled Engines." Journal of Energy Resources Technology; June, Vol. 11, pp. 155-160.

Siewert, R.; Groff, E. (1987). "Unassisted Cold Starts to -29 C and Steady-State Tests of a DirectInjection Stratified-Charge (DISC) Engine Operated on Neat Alcohols." SAE Publication 872066.

Shayler, P.; Isaacs, R.; Ma, T. (1989). "SI Engine Cold Start Behaviour and Fuel Calibration." EAEC 2nd International Conference on New Developments in Powertrain and Chassis Engineering; June 14-16, 1989; Strasbourg. Paper C382/009; pp. 51-60.

Shaylor, P.J.; Sage, J.D.; Dixon, J. (1994). "Computer Aided Evaluation of Cold Start Fuelling Strategy and Calibration Details for Spark Ignition Engines." SAE Publication 940085; P273 pp. 51-60.

Vaivads, R.; Rao, V.; Bardon, M.; Battista, V. (1993). "Volatility and Flammability of Variable Fuel Vehicle Tank Contents." SAE Publication 932776; SP-995.

Zabetakis, M. (1965). "Flammability Characteristics of Combustible Gases and Vapors." US Dept. of Interior, Bureau of Mines; Bulletin 627. 
Appendix A

\section{Bibliography \\ (Organized by Topic)}

\section{Engine Modeling}

General

Baruah, P.C. (1990). "A Simulation Model for Transient Operation of Spark-Ignition Engines." SAE Publication 900682.

Benson, R.S.; Annand, W.J.D.; Baruah, P.C. (1975). "A Simulation Model Including Intake and Exhaust Systems for a Single Cylinder Four Stroke Cycle Spark Ignition Engine." Int. J. Mech. Science; Vol. 17, pp. 97-124.

Benson, R.S. (1982) The Thermodynamics and Gas Dynamics of Internal Combustion Engines. Vol. I. Oxford Univ. Press.

Bosch, R. (1993). Automotive Handbook. 3rd edition. Stuttgart: Robert Bosch GmbH.

Ciulli, E.; Rizzoni, G.; Dawson, J. (1996). "Numerical and Experimental Study of Friction on a Single Cylinder CFR Engine." SAE Publication 960357.

Dobner, D.J. (1980). "A Mathematical Engine Model for Development of Dynamic Engine Control." SAE Publication 800054.

Dobner, D.J. (1983). "Dynamic Engine Models for Control Development." Int. J. of Vehicle Design; SP4.

Geiger, I.; Theuerkauf, H.J.; Woorman, R.J. (1990). "Real-Time Simulation of Gasoline Engines-

A Development Tool for a New Exhaust Emissions Concept." SAE Publication 901537.

Hendricks, E.; Sorenson, S.C. (1990). "Mean Value Modeling of Spark Ignition Engines." SAE Publication 900616.

Heywood, J.B. (1988). Internal Combustion Engine Fundamentals. McGraw-Hill, Inc.

Horlock, J.H.; Winterborne, D.E. (1986). The Thermodynamics and Gas Dynamics of Internal Combustion Engines. Vol. II. Oxford Univ. Press.

Obert, E.F. (1973). Internal Combustion Engines and Air Pollution. New York: Harper \& Row.

Tang, D.-L.; Sultan, M.C.; Chang, M.-F. (1989). "A Dynamic Engine Starting Model for Computer-Aided Control Systems Design." Proc. ASME Symp. on Adv. Automotive Tech.; Dec 10-15, 1989; pp. 203-222.

Taylor, C.F.; Taylor, E.S. (1961). The Internal Combustion Engine. International Textbook Company.

Weeks, R.; Moskwa, J. (1995). "Automotive Engine Modeling for Real-Time Control Using MATLAB/SIMULINK." SAE Publication 950417; SP-1080.

Zhang, H.; Widener, S. (1996). "An Integrated Engine Cycle Simulation Model with Species Tracking in Piping System." SAE Publication 960077; SP-1168.

\section{Cold Start Modeling}

Miao, H.-C.; Hewka, L.O.; Fulton, D.A. (1992). "Dynamic Modeling and Simulation of an Automotive Engine Cranking System." SAE Publication 920292; SP-910.

Patil, A.B.; Rande, N.S. (1993). "Computer Simulation of an IC Engine During Cranking by a Starting Motor." SAE Publication 930626; SP-972.

Rao, V.K.; Gardiner, D.P.; Bardon, M.F. (1994). "Effects of Gas Leakage and Crevices on Cold Starting of Engines." SAE Publication 940078. 
Shaylor, P.J.; Sage, J.D.; Dixon, J. (1994). "Computer Aided Evaluation of Cold Start Fuelling Strategy and Calibration Details for Spark Ignition Engines." SAE Publication 940085; P273 pp. 51-60.

Sultan, M.C.; Tang, D.; Chang, M.C. (1990). "An Engine and Starting System Computer Simulation." SAE Publication 900779.

\section{Alcohol Fuels}

Browning, L.; Pefley, R. (1979). "Thermokinetic Modeling of Methanol Combustion Phenomena with Application to Spark Ignition Engines." Proc. 3rd Intl. Symp. on Alcohol Fuels Tech.; Asilomar, California; May 28-31, 1979.

Mohanan, P.; Babu, M.K.G. (1991). "A Simulation Model for a Methanol Fueled Turbo Charged Multi-Cylinder Automotive Spark Ignition Engine." SAE Publications 912417; SP-889.

\section{Cold Starting with Alcohol Fuels}

Bardon, M. F.; Rao, V.; Gardiner, D. (1984). "An Experimental and Theoretical Comparison of Methanol and Gasoline Cold Starting Performance." Proc. VI Intl. Symp. on Alcohol Fuels Tech.; Vol. 1, pp. 16-22.

Browning, L. (1983) "Alcohol Cold Starting-A Theoretical Study." 18th IECEC; Vol. 2, pp. 586591.

Browning, L.; Raghuraman, G. (1984). "A Detailed Study of Alcohol Cold Starting." Proc. VI Intl. Symp. on Alcohol Fuels Tech.; Vol. 1, pp. 63-69.

\section{Cold Start Devices and Methods - Engine Related Exhaust Gas Recirculation}

Gardiner, D.; Rao, V.; Bardon, M.; Battista, V. (1991a). "Improving the Cold Start Combustion in Methanol Fueled Spark Ignition Engines by Means of Prompt EGR." SAE Publication 910377.

Gardiner, D.P.; Rao, V.K.; Bardon, M.F.; Battista, V. (1991b). "Improving the Cold Starting and Running of Spark Ignition Engines Fuelled with Neat Methanol." Proc. IX Intl. Symp. on Alcohol Fuels; Vol. 2, pp. 574-579.

Rao, V.K.; Bardon, M.F.; Gardiner, D.P. (1989). "A Method of Assisting Cold-Starts, Improving Fuel Economy and Reducing Emissions of Engines at Cold Temperatures." SAE Publication 890001.

\section{Ignition Systems}

Bruetsch, R. (1989). "Cold Starting a Neat Methanol (M100) Vehicle with Long Duration Spark Ignition." EPA/AA/CTAB-89/05.

Dasch, C.J.; Brinkman, N.D.; Hopper, D.H. (1991). "Cold Starts Using M-85 (85\% Methanol): Coping with Low Fuel Volatility and Spark Plug Wetting." SAE Publication 910865.

Gardiner, D.P.; Rao, V.K.; Bardon, M.F.; Dale, J.D.; Smy, P.R.; Haley, R.F., Dawe, J.R., Battista, V. (1993). "Sub-Zero Cold Starting of a Port-Injected M100 Engine Using Plasma Jet Ignition and Prompt EGR." SAE Publication 930331; SP-949.

Gardiner, D.P.; Mallory, R.W.; Rao, V.K.; Bardon, M.F.; Battista, V. (1995). "Vehicle Implementation and Cold Start Calibration of a Port Injected M100 Engine Using a Plasma Jet Ignition and Prompt EGR." SAE Publication 952375; SP-1115. 
Gardiner, D.P.; Mallory, R.W.; Pucher, G.R.; Todesco, M.K.; Bardon, M.F.; Battista, V. (1996). "Experimental Studies Aimed at Lowering the Electrical Energy Requirements of a Plasma Jet Ignition System for M100 Fuelled Engines." SAE Publication 961989.

\section{Cranking Speed}

Blair, D. (1988). "Effects of Cranking Speed, Finely Atomized Fuel Delivery on Minimum Cold Starting Temperature of a Methanol-Fuelled Vehicle." EPA/AA/CTAB/88-04.

Gardiner, D.; Bardon, M. (1986). "The Effect of Cranking Speed on Cold Starting Performance with Methanol Fuels." Proc. VII Intl. Symp. on Alcohol Fuels Tech.; Oct. 20-23, 1986; Paris; pp. 191-195.

\section{Cold Start Methods and Devices - Fuel Related Catalytic Reforming}

Choi, B.-C.; Ito, K.; Fujita, O. (1991). "Effective Parameters on the Start-Up Characteristics of a Catalytic Combustor Using Methanol Mixture." IX Intl. Symp. on Alcohol Fuels; Firenze, Italy; November 14, 1991; Vol. 2, pp. 372-377.

Cowley, S.W.; Gebhard, S.C. (1983). "The Catalytic Decomposition of Methanol into Synthesis Gas for Use as an Automotive Fuel." Colorado School of Mines publication 01639153/83/7803-0041.

Dippo, J.; Karpuk, M.; Cowley, S. (1991). "Design of a Methanol Dehydration Reactor for Cold Starting Methanol-Fueled Engines." Proc. IX Intl. Symp. on Alcohol Fuels; Vol. 2, pp. 580-586.

Fulton, J.; Lynch, F.; Wilson, B.; (1995). "Hydrogen for Cold Starting and Catalyst Heating in a Methanol Vehicle." SAE Publication 951956.

Karpuk, M.; Cowley, S. (1988). "On Board Dimethyl Ether Generation to Assist Methanol Engine Cold Starting." SAE Publication 881678.

Kito, T.; Wittayakun, J.; Pacus, D.; Selim, S., Cowley, S.W. (1996). "The Catalytic Dissociation or Dehydration of Ethanol for On-Board Cold Start Assistance." Proc. XI Intl. Symp. on Alcohol Fuels; San City, South Africa; 1996; Vol. 1, pp. 166-177.

Pettersson, L.; Sjöström, K. (1982). "Decomposed Methanol-An Excellent Cold Start Fuel for Spark Ignition Engines." Proc. VII Intl. Symp. on Alcohol Fuels Tech.; Vol. 2, pp. 309316.

Pettersson, L.; Sjöström, K. (1991a). "Decomposed Methanol as a Fuel - A Review." Combust Sci Tech.; Vol. 80, pp.265-303.

Yamaguchi, I.; Takashita, T.; Sakai, T.; Ayusawa, T.; Kim, K.Y. (1985). "Development Research on Dissociated Methanol Fueled Spark Ignition Engine." SAE Publication 852201.

Yoo, S.J.; Lee, C.I. (1987). "Feasibility Evaluation of Reformed Methanol Usage to Spark Ignition Engine." SAE Publication 871166.

\section{Partial Oxidation/Rich Combustion Reforming}

Hodgson, J.W.; Irick, D.K. (1996). NREL Briefing: Subcontract No. XCF-5-14050-03 December 1996.

Iwai, N.; Akai, M.; Hosogai, D.; Nishimura, J.; Saori, H. (1993). Cold Startability Improvement of Neat Methanol SI Engine by Using Ultrasonic Partial Oxidation Combustor." Proc. $X$ 
Intl. Symp. on Alcohol Fuels; November 7-10, 1993; Colorado Springs, Colorado; Vol. 2, pp. 929-939.

Nishimura, J.; Hosogai, D.; Ito, T.; Iwai, N.; Akai, M. (1994). "Study of Partial Oxidation

Combustor Using Ultrasonic Atomizer to Improve Cold Startability of Methanol Engine."

SAE Publication 940767.

Pettersson, L.; Sjöström, K. (1991b). "Onboard Hydrogen Generation by Methanol

Decomposition for the Cold Start of Neat Methanol Engines." Int. J. Hydrogen Energy;

(16:10); pp. 671-676.

Pike, M.S.; Guglielmello, T.J.; Hodgson, J.W. (1993). "Development of a Cold-Start Device for Methanol-Fueled Engines." SAE Publication 932772; SP-995.

\section{Electric Arc Decomposition}

Maxwell, T.; Jones, J.C.; Jayakaran, J.D.; Boyce, C.; Parker, H.W. (1993b). "Cold Starting Methanol Fueled Engines with Decomposed Methanol." Proc. X Intl. Symp. on Alcohol

Fuels; November 7-10, 1993; Colorado Springs, Colorado; Vol. 2, pp. 1001-1009.

Sethuraman, R.; Parker, H.W.; Maxwell, T.T.; Jones, J.C. (1994). "Submerged Electric Arc Decomposition of Methanol for Cold-Starting of Methanol-Fueled Engines." Journal of Energy Resources Technology; June, Vol. 11, pp. 155-160.

\section{Fuel Primers and Blends}

Bardon, M.; Rao, V.K.; Clark, W.; Battista, V. (1990). "Gasoline and Light Isocrackate as Primers for High Methanol Blends." ASME 90-ICE-24.

Chen, K.-C.; Dewitte, K., Cheng, W.K. (1995). "Fuel Effects and Enrichment Effects on Engine Starting and Warm-Up Behavior." SAE Publication 950065; SP-1084.

Gardiner, D.P.; Caird, S.G.; Bardon, M.F. (1987). "Spark Ignition Engine Cold Starting with Methanol-Based Fuel Blends." SAE Publication 872067; SP-726.

Iwai, N.; Nagai, K.; Yasuda, H.; Ayusawa, T.; Kim, Y.K. (1988a). "A Study on Cold Startability and Mixture Formation of High-Percentage Methanol Blends." SAE Publication 880044.

Iwai, N.; Nagai, K.; Yasuda, H. Ayusawa, T.; Kim, E.; Niwa, K. (1988b). "Effects of Additive Components on near Neat Methanol Fuels on the Cold Startability and Hot Weather Driveability." Proc. VIII Intl. Symp. on Alcohol Fuels Tech.; pp. 863-868.

Kirwan, J.; Brinkman, N. (1991). "Fuel Methanol Composition Effects on Cold Starting." SAE Publication 912416; SP-889.

Kozole, K.; Wallace, J. (1988). "The Use of Dimethyl Ether as a Starting Aid for MethanolFuelled SI Engines at Low Temperatures." SAE Publication 881677.

Lumsden, G.; Watson, H.C. (1995). "HAJI Operation in a Hydrogen-Only Mode for Emission Control at Cold Start." SAE Publication 950412.

Mitchell, D. (1984). "The Effects of Blending Agents on the Cold Weather Operation of the Methanol Fuelled Automobiles." Proc. VI Intl. Symp. on Alcohol Fuels Tech.; Vol. 1 pp. 272-280.

Fuel Atomization and Vaporization

Bruetsch, R.; Hamady, F. (1993). "Cold Starting an Alcohol-Fueled Engine with Ultrasonic Fuel Atomization." EPA/AA/TDG-93/02A. 
Dodge, L.; Naegeli, D.; Crane, M. (1992). "Improved Atomization of Methanol for LowTemperature Starting in Spark-Ignition Engines." SAE Publication 920592; SP-900.

Mitsumoto, H.; Ohta, T.; Hamai, K. (1992). "Improvement of Cold Startability Running on M85 Spark Ignition Engine." SAE Publication 920293; SP-910.

Nebolon, J.; Chan, K.C.; Browning, L.; Pefley, R.K. (1982). "Multi-Point Injection of Alcohol Vapour as a Cold Starting Aid for Neat Alcohol Fueled Vehicles." Proc. V Intl. Alcohol Fuels Tech. Symp.; Vol. 2, pp. 29-36.

\section{Cold Starting with Alcohol Fuels}

Battista, V.; Gardiner, D.P.; Bardon, M.F.; Rao, V.K. (1990a). "Review of Cold Starting Performance of Methanol and High Methanol Blends in Spark Ignition Engines: Neat Methanol." SAE Publication 902154; SP-840.

Battista, V.; Gardiner, D.P.; Bardon, M.F.; Rao, V.K. (1990b). "Review of Cold Starting Performance of the Methanol and High Methanol Blends in Spark Ignition Engines: High Methanol Blends." SAE Publication 902181; SP-840.

"Fuel and Engine Modifications Needed for Efficient Cold Starts." Automotive Engineering. Vol. 98 No. 2; Feb. 1990; pp. 69-72.

Ito, S.; Sato, A.; Ichimiya, T. (1981). "Performance of a Methanol Fueled Car." SAE Publication 811383.

Kirwin, J.E.; Brinkman, N.D. (1991). "A Cold Starting Performance Index for Wintertime Fuel Methanol." Presented at IX International Symposium on Alcohol Fuels; Florence, Italy; November 12-15, 1991.

Morita, K.; Hayashi, S.; Akai, M.; Iwai, N.; Inoue, S.; Otsubo, K. (1996). "Problems in Otto-type Methanol Vehicles and Solutions Thereto." Proc. XI Intl. Symp. on Alcohol Fuels; April 14-17, 1996; Sun City, South Africa; Vol. 1, pp. 262-271.

Rajan, S. (1979). "Factors Influencing Cold Starting of Engines Operation on Alcohol Fuel." Proc. 3rd Intl. Symp. on Alcohol Fuels Tech.; May 28-31, 1979; Asilomar, California; Vol. 2.

\section{Direct Injection Engine Technology}

Anderson, R.W.; Yang, J., Brehob, D.D.; Vallance, J.K., Whiteaker, R.M. (1996). "Understanding the Thermodynamics of Direct Injection Spark Ignition (DISI) Combustion Systems: An Analytical and Experimental Investigation." SAE Publication 962018.

Bruetsch, R.I.; Hellman, K.H. (1992). "Evaluation of Passenger Car Equipped with a Direct Injection Neat Methanol Engine." SAE Publication 920196; SP-900.

Hilger, U.; Jain, G., Pischinger, F. (1991). "Development of a DI Methanol Engine for Passenger Car Application." IX Intl. Symp. on Alcohol Fuels; Firenze, Italy; November 14, 1991; Vol. 2, pp. 479-484.

Jorgensen, S.W. (1988). "Compression Temperatures in a Cold Cranking Engine." SAE Publication 880045.

Maxwell, T.; Jones, J.C.; Shah, P.S.; Boyce, C.; Parker, H.W. (1993a). "Cold Starting Engines Fueled with Neat Methanol." Proc. X Intl. Symp. on Alcohol Fuels; November 7-10, 1993; Colorado Springs, Colorado; Vol. 2, pp. 637-648. 
Siewert, R.; Groff, E. (1987). "Unassisted Cold Starts to -29C and Steady-State Tests of a DirectInjection Stratified-Charge (DISC) Engine Operated on Neat Alcohols." SAE Publication 872066.

\section{Fuel Characteristics and Properties}

Bardon, M.; Rao, V. (1984). "Calculation of Gasoline Volatility." Journal of Institute of Energy; Sept. 1984, pp. 343-348.

Bardon, M.F.; Rao, V.K., Vaivads, R.; Evans, M.J.B. (1986). "Measured and Predicted Effect of the Extent of Evaporation on Gasoline Vapour Pressure." Journal of the Institute of Energy; Dec., Vol. 216.

Bardon, M.; Nicks, G.W.; Rao, V.K.; Vaivads, R. (1987). "A Vapour Pressure Model for Methanol/Gasoline M85 Blends." SAE Publication 870366.

Bardon, M.F.; Rao, V.K.; Battista, V. (1988). "Modelling the Flammability Hazards of Methanol/Gasoline Blends." Proc. VIII Intl. Symp. on Alcohol Fuels; Nov. 13-16, 1988; Tokyo, Japan; pp. 829-834.

Bardon, M.; Rao, V.; Battista, V. (1989). "Volatility and Flammability of Methanol/Gasoline Blends." SAE Publication 892062.

Bardon, M.; Rao, V. (1991). "Estimating Instantaneous Properties of Vaporizing Light Petroleum Fractions." Combustion and Flame; Vol. 84, pp. 427-431.

Carlson, E. (1995). "Don't Gamble with Physical Properties for Simulations." Chemical Engineering Progress; Oct. pp. 35-46.

Furey, R.; Perry, K. (1991). "Vapor Pressure Characteristics of M85 Fuels." SAE Publication $912415 ;$ SP-889.

Gauthier, J.; Bardon, M. (1990). "Laminar Flame Propagation in Mixtures of Fuel Droplets, Fuel Vapour and Air." Journal of the Institute of Energy; June 1990, pp. 83-88.

Gordon, D.J.; Murin, J.; Cruice, W.J. (1985). "Temperature Flammable Limits of Methanol Unleaded Gasoline Mixtures." SAE Publication 852107.

Lide, D.R. (1995). CRC Handbook of Chemistry and Physics. 76th edition. Boca Raton: CRC Press.

Murphy, M. (1994). "Properties of Alternative Fuels." FTA-OH-06-0060-94-1.

Nakajima, Y.; Saito, T.; Takagi, Y.; Katoh, K.; Iijima, T. (1978). "The Influence of Fuel Characteristics on Vaporization in the SI Engine Cylinder During Cranking At Low Temperature." SAE Publication 780612.

Vaivads, R.; Rao, V.; Bardon, M.; Battista, V. (1993). "Volatility and Flammability of Variable Fuel Vehicle Tank Contents." SAE Publication 932776; SP-995.

Vaivads, R.H.; Bardon, M.F.; Rao, V.K.; Battista, V. (1995). "Flammability Tests of Alcohol/Gasoline Vapours." SAE Publication 950401.

Zabetakis, M. (1965). "Flammability Characteristics of Combustible Gases and Vapors." US Dept. of Interior, Bureau of Mines; Bulletin 627.

\section{Feasibility of Alcohol Fuel Usage}

Hirota, T.; Ohta, T.; Mitsumoto, H. (1991). "R\&D Activities for Methanol S.I. Engines at Nissan." Proc. XI Intl. Sym. on Alcohol Fuels Tech.; Vol. 2, pp. 587-592. 
Ito, K. ed. (1995). "Feasibility Study on Utilization of Methanol Fuels for Automobiles. Report on the Primary Controlled Fleet Test of Otto-type M85 Methanol Vehicles." Petroleum Energy Center; Mar. 1995.

Jones, B.; Ready, K.; Bach, R.; Hansen, D.; Kaitala, E.; Larson, J.; Morales, J.; Reese, C. (1995). "A Comparative Analysis of Ethanol Versus Gasoline as a Fuel in Production FourStroke Automotive Engines." SAE Publication 952749; SP-294 pp. 95-102.

Niwa, K.; Saori, H.; Hoshino, T.; Nakano, Y. (1991). "A Feasibility Study on the Use of Methanol as an Automotive Fuel." Proc. IX Intl. Symp. on Alcohol Fuels; Vol. 2, pp. 852855.

Niwa, K.; Shigeru, I. (1995). "Advance of Technology on Methanol Fuels and Methanol Vehicles in Japan." SAE Publication 952753; P-294 pp. 141-152.

Pefley, R.K.; Browning, L.H. (1978). "Characterization and Research Investigation of Alcohol Fuels in Automobile Engines." DOE contract DE-AC03-78CS.

Pefley, R.K.; Browning, L.; Espinola, S.; Pullmna, B.; Gururangan, R., Saito, N. (1984).

"Research and Development of Neat Alcohol Usage in Automobiles." DOE/NBB-0067.

\section{Engine Cold-Start Experiments}

Grüefeld, G.; Knapp, M.; Beushausen, V.; Andresen, P.; Hentschel, W.; Manz, P. (1995). "In Cylinder Measurements and Analysis of Fundamental Cold Start and Warm-Up Phenomena in SI Engines." SAE Publication 952394.

Haahtela, O.; Decker, G. (1989). "Present and Future Fuels and Lubricants in Cold Climate Operation." SAE Publication 890032.

Shayler, P.; Isaacs, R.; Eade, D. (1991). "Improved Start Quality from Revised Cold Start Calibration Methods." Proceedings of the 3rd Aachen Colloquium on Automobile and Engine Technology; October 15-17, 1991; Aachen; pp. 237-252.

Shayler, P.; Isaacs, R.; Ma, T. (1988). "Cold Start Performance of SI Engines." Experimental Methods in Engine Research; March 9-10, 1988. IMechE Paper 481/6; pp. 85-92.

Shayler, P.; Isaacs, R.; Ma, T. (1989). "SI Engine Cold Start Behaviour and Fuel Calibration." EAEC 2nd International Conference on New Developments in Powertrain and Chassis Engineering; June 14-16, 1989; Strasbourg. Paper C382/009; pp. 51-60.

Shayler, P.; Isaacs, R.; Ma, T. (1992). "The Variation of In-cylinder Mixture Ratios During Engine Cranking at Low Ambient Temperatures." Proc. IMechE.; Vol. 206, pp. 55-62. 
Appendix $B$

Fuel Properties Analysis - M-85 RFA Fuel, Lot W-969

\begin{tabular}{cl}
\multicolumn{1}{c}{ Tests } & Results \\
\cline { 2 - 2 } Specific Gravity, 60/60 F & 0.7881 \\
API Gravity & 48.1 \\
Particulates (mg/L) & 0.05 \\
Acidity as acetic acid & 0.001 \\
Total Chlorides & 0.0001 \\
Reid Vapor Pressure & 8.8 \\
& \\
Distillation, deg F & \\
\hline IBP & 120.0 \\
$5 \%$ & 138.9 \\
$10 \%$ & 143.9 \\
$20 \%$ & 146.9 \\
$30 \%$ & 148.1 \\
$40 \%$ & 148.4 \\
$50 \%$ & 148.8 \\
$60 \%$ & 149.0 \\
$70 \%$ & 149.0 \\
$80 \%$ & 149.3 \\
$90 \%$ & 149.7 \\
$95 \%$ & 150.2 \\
EP & 358.0 \\
Loss & 0.9 \\
Residue & 1.0
\end{tabular}

Specifications Method

Report

ASTM D-4052

Report

ASTM D-1298

$0.38 \max$

ASTM D-2276

$0.003 \max$

ASTM D-1613

$0.0002 \max$

Report

ASTM D-3120

ASTM D-323

Report

ASTM D-86

138.9

143.9

148.1

148.4

148.8

149.0

149.3

149.7

358.0

1.0

\section{Composition, VOL \%}

Fischer Water, WT\%

0.061

$0.1 \max$

ASTM D-1744

Methanol

84.93

$85+/-1$

Hydrocarbon

15.07

Remainder

Chromatography

Chromatography

Note: analysis performed by Phillips Chemical Company, 06/04/97 


\section{Fuel Speciation - M-85 RFA Fuel, Lot W-969}

\begin{tabular}{|c|c|c|c|}
\hline Component & Weight \% & Component & Weight \% \\
\hline Methanol & 84.93 & 4-methyl heptane & 0.04 \\
\hline N-butane & 0.98 & 3-methyl heptane & 0.10 \\
\hline 2,2 dimethyl propane & 0.01 & 3-ethyl hexane & 0.04 \\
\hline I-pentane & 0.85 & 3-methyl-3-ethyl pentane & 0.04 \\
\hline pentene-1 & 0.03 & 1,1 dimethyl cyclohexane & 0.02 \\
\hline 2-methyl-1-butene & 0.06 & $1,2,3$ trimethyl cyclopentane & 0.01 \\
\hline n-pentane & 0.21 & n-octane & 0.07 \\
\hline trans-pentene-2 & 0.08 & ethyl benzene & 0.48 \\
\hline cis-pentene-2 & 0.05 & m-xylene & 0.82 \\
\hline 2-methyl-2-butene & 0.13 & p-xylene & 0.35 \\
\hline 2,2 dimethyl butane & 0.08 & o-xylene & 0.42 \\
\hline cyclopentene & 0.02 & 4-methyl octane & 0.03 \\
\hline 2,3 dimethyl butane & 0.25 & 2-methyl octane & 0.04 \\
\hline 2-methyl pentane & 0.79 & n-nonane & 0.02 \\
\hline 3-methyl pentane & 0.44 & 3,3 dimethyl octane & 0.08 \\
\hline 2-methyl-1-pentene & 0.03 & 1-methyl-3-ethyl benzene & 0.32 \\
\hline n-hexane & 0.20 & 1-methyl-4-ethyl benzene & 0.14 \\
\hline trans-hexene-3 & 0.02 & $1,3,5$ trimethyl benzene & 0.17 \\
\hline c7 Olefin & 0.01 & 1-methyl-2-ethyl benzene & 0.15 \\
\hline trans-hexene-2 & 0.05 & 3-methyl nonane & 0.02 \\
\hline cis-hexene-2 & 0.03 & $1,2,4$ trimethyl benzene & 0.46 \\
\hline c7 Olefin & 0.02 & 1,2,3 trimethyl benzene & 0.09 \\
\hline 2,2 methyl pentane & 0.05 & 1-methyl-3-propyl benzene & 0.07 \\
\hline methyl cyclopentane & 0.13 & $2,4,6$ trimethyl octane & 0.07 \\
\hline 2,4 dimethyl pentane & 0.14 & 1,4-dimethyl-2-ethyl benzene & 0.04 \\
\hline methyl cyclopentene & 0.05 & 1,3-dimethyl-4-ethyl benzene & 0.05 \\
\hline benzene & 0.30 & 1,2-dimethyl-4-ethyl benzene & 0.10 \\
\hline 3,3 dimethyl pentane & 0.03 & 1,2-dimethyl-3-ethyl benzene & 0.02 \\
\hline cyclohexane & 0.02 & naphthalene & 0.08 \\
\hline 2-methyl hexane & 0.38 & other & 1.86 \\
\hline 2,3 dimethyl pentane & 0.30 & Total & 100.00 \\
\hline 3-methyl hexane & 0.46 & & \\
\hline trans-1,3-dimethyl cyclopentane & 0.05 & & \\
\hline cis-1,3-dimethyl cyclopentane & 0.05 & & \\
\hline 3-ethyl pentane & 0.06 & & \\
\hline 1-heptene & 0.03 & & \\
\hline $2,2,4$ trimethyl pentane & 0.27 & & \\
\hline n-heptane & 0.31 & & \\
\hline methyl cyclohexane & 0.06 & & \\
\hline 3-ethyl cyclopentane & 0.03 & & \\
\hline 2,5 dimethyl hexane & 0.05 & & \\
\hline 2,4 dimethyl hexane & 0.08 & & \\
\hline $2,3,4$ trimethyl pentane & 0.11 & & \\
\hline toluene & 1.41 & & \\
\hline 2,3 dimethyl hexane & 0.06 & & \\
\hline 2-methyl heptane & 0.10 & & \\
\hline
\end{tabular}

Note: analysis performed by SGS Control Services, Inc., 08/28/97 


\section{Appendix C}

Table 1: Fuel Blends Simulation Results - Acurex RFA

\begin{tabular}{|c|c|c|c|c|}
\hline \multicolumn{5}{|c|}{ Fuel Blends Simulation Results - Acurex RFA } \\
\hline \multirow[t]{2}{*}{$\begin{array}{c}\text { Test } \\
\text { Condition } \\
\end{array}$} & $\begin{array}{c}\text { Overall } \\
\text { Equivalence } \\
\text { Ratio } \\
\end{array}$ & $\begin{array}{c}\text { Lqquid } \\
\text { Entrainment } \\
\text { Fraction } \\
\end{array}$ & $\begin{array}{c}\text { Vapor Phase } \\
\text { Equivalence } \\
\text { Ratio } \\
\end{array}$ & $\begin{array}{l}\text { Energy } \\
\text { Density }\end{array}$ \\
\hline & -- &.. & -- & $\mathrm{J} / \mathrm{L}$ \\
\hline \multicolumn{5}{|l|}{ Baseline } \\
\hline \multicolumn{5}{|c|}{ Overall Equivalence Ratio } \\
\hline & 1.0 & & 0.344 & 1916 \\
\hline & 2.0 & & 0.504 & 3260 \\
\hline & 4.0 & & 0.711 & 3566 \\
\hline & 5.0 & & 0.788 & 3243 \\
\hline & 6.0 & & 0.854 & 2948 \\
\hline \multicolumn{5}{|c|}{ Liquid Entrainment Fraction } \\
\hline & & 0.00 & 0.619 & 2494 \\
\hline & & 0.10 & 0.619 & 3473 \\
\hline & & 0.30 & 0.619 & 3620 \\
\hline & & 0.40 & 0.619 & 3326 \\
\hline & & 0.50 & 0.619 & 3048 \\
\hline \multicolumn{5}{|c|}{ Average Results } \\
\hline \multicolumn{5}{|c|}{ Operating Condition Notes: Ambient Temp.: $-25^{\circ} \mathrm{C}$} \\
\hline
\end{tabular}

\section{Table 2: Fuel Blends Simulation Results - M85 RFA}

\begin{tabular}{|c|c|c|c|c|}
\hline \multicolumn{6}{|c|}{ Fuel Blends Simulation Results - M85 RFA } \\
\hline $\begin{array}{c}\text { Test } \\
\text { Condition }\end{array}$ & $\begin{array}{c}\text { Overall } \\
\text { Equivalence } \\
\text { Ratio }\end{array}$ & $\begin{array}{c}\text { Liquid } \\
\text { Entrainment } \\
\text { Fraction }\end{array}$ & $\begin{array}{c}\text { Vapor Phase } \\
\text { Equivalence } \\
\text { Ratio }\end{array}$ & $\begin{array}{c}\text { Energy } \\
\text { Density }\end{array}$ \\
\hline & - & -- & -- & $\mathrm{J} / \mathrm{L}$ \\
\hline
\end{tabular}

Baseline Overall Equivalence Ratio

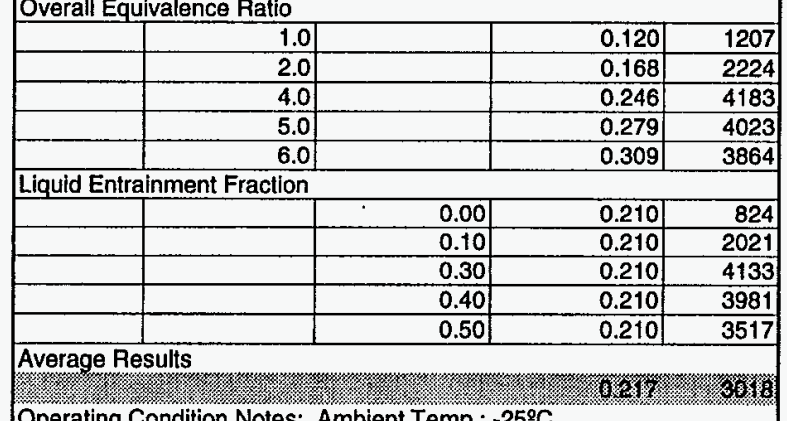

Operating Condition Notes: Ambient Temp.: $-25^{\circ} \mathrm{C}$
Table 3: Fuel Blends Simulation Results - E85 RFA

\begin{tabular}{|c|c|c|c|c|}
\hline \multicolumn{5}{|c|}{ Fuel Blends Simulation Results - E85 RFA } \\
\hline \multirow[t]{2}{*}{\begin{tabular}{|c|}
$\begin{array}{c}\text { Test } \\
\text { Condition }\end{array}$ \\
\end{tabular}} & $\begin{array}{c}\text { Overall } \\
\text { Equivalence } \\
\text { Ratio }\end{array}$ & $\begin{array}{l}\text { Lquild } \\
\text { Entrainment } \\
\text { Fraction }\end{array}$ & $\begin{array}{l}\text { Vapor Phase } \\
\text { Equivalence } \\
\text { Ratio }\end{array}$ & $\begin{array}{l}\text { Energy } \\
\text { Density }\end{array}$ \\
\hline & --- & $-\cdot$ & $-\cdots$ & $\mathrm{J} / \mathrm{L}$ \\
\hline \multicolumn{5}{|l|}{ Baseline } \\
\hline \multicolumn{5}{|c|}{ Overall Equivalence Ratio } \\
\hline & 1.0 & & 0.08 & 1039 \\
\hline & 2.0 & & 0.104 & 1951 \\
\hline & 4.0 & & 0.141 & 3742 \\
\hline & 5.0 & & 0.157 & 3908 \\
\hline & 6.0 & & 0.171 & 3624 \\
\hline \multicolumn{5}{|c|}{ Liquid Entrainment Fraction } \\
\hline & & 0.00 & 0.124 & 454 \\
\hline & & 0.10 & 0.124 & 1652 \\
\hline & & 0.30 & 0.124 & 4050 \\
\hline & & 0.40 & 0.124 & 3715 \\
\hline & & 0.50 & 0.124 & 3360 \\
\hline
\end{tabular}

Table 4: Fuel Blends Simulation Results - M100

\begin{tabular}{|c|c|c|c|c|}
\hline \multicolumn{5}{|c|}{ Fuel Blends Simulation Results - Neat Methanol } \\
\hline \multirow[t]{2}{*}{$\begin{array}{c}\begin{array}{c}\text { Test } \\
\text { Condition }\end{array} \\
\end{array}$} & $\begin{array}{c}\text { Overall } \\
\text { Equivalence } \\
\text { Ratlo } \\
\end{array}$ & $\begin{array}{c}\text { Llquid } \\
\text { Entralnment } \\
\text { Fraction }\end{array}$ & $\begin{array}{l}\text { Vapor Phase } \\
\text { Equivalence } \\
\text { Ratio }\end{array}$ & $\begin{array}{l}\text { Energy } \\
\text { Density }\end{array}$ \\
\hline & $=$ & -- & 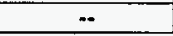 & $\mathrm{J} / \mathrm{L}$ \\
\hline \multicolumn{5}{|l|}{ Baseline } \\
\hline \multicolumn{5}{|c|}{ Overall Equivalence Ratio } \\
\hline \multicolumn{5}{|c|}{\begin{tabular}{|r|r|} 
& 1.0 \\
\end{tabular}} \\
\hline \multicolumn{5}{|c|}{0.047} \\
\hline \multicolumn{5}{|c|}{0.047} \\
\hline \multicolumn{5}{|c|}{\begin{tabular}{|r|}
5.0 \\
\end{tabular}} \\
\hline & & & 0.047 & 3970 \\
\hline \multicolumn{5}{|c|}{\begin{tabular}{|l|} 
\\
Liquid Entrainment Fraction \\
\end{tabular}} \\
\hline \multicolumn{5}{|c|}{ 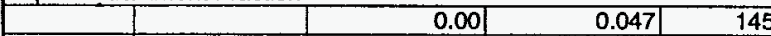 } \\
\hline & & 0.10 & 0.047 & 1428 \\
\hline & & 0.30 & 0.047 & 3994 \\
\hline & & 0.40 & 0.047 & 3999 \\
\hline & & 0.50 & 0.047 & 3701 \\
\hline \multicolumn{5}{|c|}{ Average Results } \\
\hline \multicolumn{5}{|c|}{ Operating Condition Notes: Ambient Temp.: $-25^{\circ} \mathrm{C}$} \\
\hline
\end{tabular}


Table 5: Fuel Blends Simulation Results - E100

\begin{tabular}{|c|c|c|c|c|}
\hline \multicolumn{5}{|c|}{ Fuel Blends Simulation Results - Neat Ethanol } \\
\hline \multirow[t]{2}{*}{$\begin{array}{c}\text { Test } \\
\text { Condition }\end{array}$} & $\begin{array}{c}\text { Overall } \\
\text { Equivalence } \\
\text { Ratio }\end{array}$ & $\begin{array}{c}\text { Liquid } \\
\text { Entrainment } \\
\text { Fraction }\end{array}$ & $\begin{array}{c}\text { Vapor Phase } \\
\text { Equivalence } \\
\text { Ratio }\end{array}$ & $\begin{array}{l}\text { Energy } \\
\text { Density }\end{array}$ \\
\hline & -. & +- &.- & $J / L$ \\
\hline \multicolumn{5}{|l|}{ Baseline } \\
\hline \multicolumn{5}{|c|}{ Overall Equivalence Ratio } \\
\hline & 1.0 & & 0.031 & 884 \\
\hline & 2.0 & & 0.031 & 1728 \\
\hline & 4.0 & & 0.031 & 3409 \\
\hline & 5.0 & & 0.031 & 4105 \\
\hline & 6.0 & & 0.031 & 3835 \\
\hline \multicolumn{5}{|c|}{ Liquid Entrainment Fraction } \\
\hline & & 0.00 & 0.031 & 66 \\
\hline & & 0.10 & 0.031 & 1321 \\
\hline & & 0.30 & 0.031 & 3831 \\
\hline & & 0.40 & 0.031 & 3853 \\
\hline & & 0.50 & 0.031 & 3498 \\
\hline \multicolumn{5}{|c|}{ Average Results } \\
\hline
\end{tabular}

Table 6: Fuel Blends Simulation Results - Winter Blend

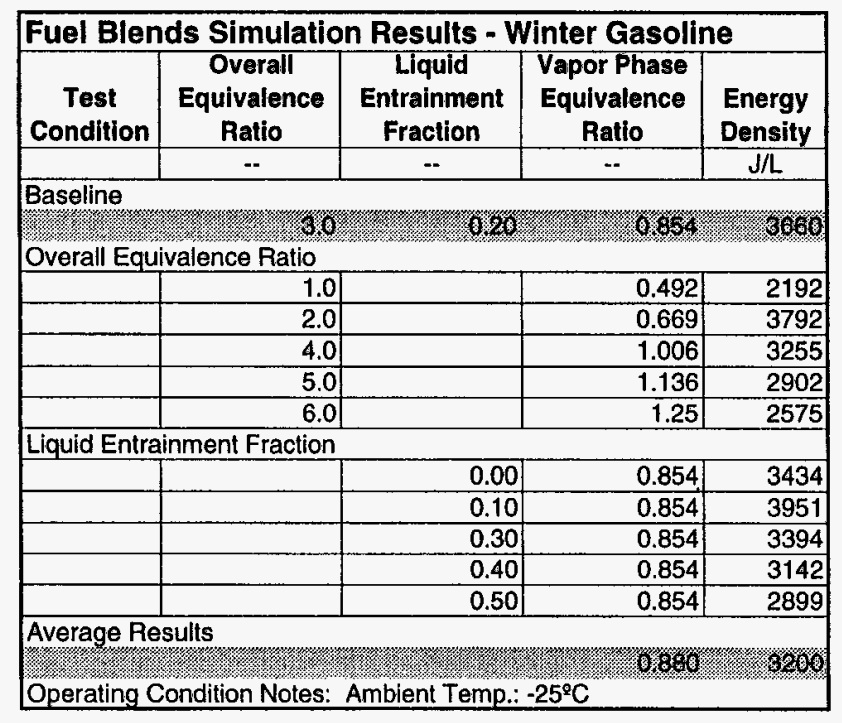

Table 7: Fuel Blends Simulation Results - M85 Winter

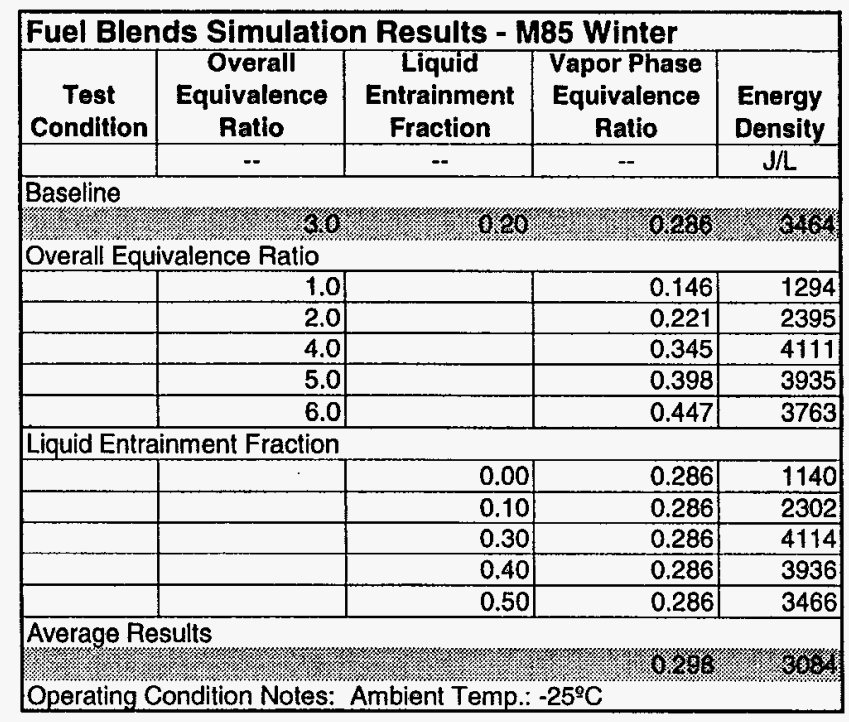

Table 8: Fuel Blends Simulation Results - E85 Winter

\begin{tabular}{|c|c|c|c|c|}
\hline \multicolumn{5}{|c|}{ Fuel Blends Simulation Results - E85 Winter } \\
\hline \multirow[t]{2}{*}{$\begin{array}{c}\text { Test } \\
\text { Condition }\end{array}$} & $\begin{array}{c}\text { Overall } \\
\text { Equivalence } \\
\text { Ratio }\end{array}$ & $\begin{array}{c}\text { Liquid } \\
\text { Entrainment } \\
\text { Fraction }\end{array}$ & $\begin{array}{l}\text { Vapor Phase } \\
\text { Equivalence } \\
\text { Ratio }\end{array}$ & $\begin{array}{l}\text { Energy } \\
\text { Density }\end{array}$ \\
\hline & -- & -- & -- & $\mathrm{J} / \mathrm{L}$ \\
\hline \multicolumn{5}{|l|}{ Baseline } \\
\hline \multicolumn{5}{|c|}{ Overall Equivalence Ratio } \\
\hline & 1.0 & & 0.09 & 1065 \\
\hline & 2.0 & & 0.126 & 2012 \\
\hline & 4.0 & & 0.186 & 3867 \\
\hline & 5.0 & & 0.212 & 3818 \\
\hline & 6.0 & & 0.238 & 3524 \\
\hline \multicolumn{5}{|c|}{ Liquid Entrainment Fraction } \\
\hline & & 0.00 & 0.157 & 594 \\
\hline & & 0.10 & 0.157 & 1770 \\
\hline & & 0.30 & 0.157 & 4056 \\
\hline & & 0.40 & 0.157 & 3657 \\
\hline & & 0.50 & 0.157 & 3303 \\
\hline \multicolumn{5}{|c|}{ Average Results } \\
\hline \multicolumn{5}{|c|}{ Operating Condition Notes: Ambient Temp.: $-25^{\circ} \mathrm{C}$} \\
\hline
\end{tabular}


Table 9: Fuel Blends Simulation Results - E60 Winter

\begin{tabular}{|c|c|c|c|c|}
\hline \multicolumn{5}{|c|}{ Fuel Blends Simulation Results - E60 Winter } \\
\hline \multirow[t]{2}{*}{$\begin{array}{c}\text { Test } \\
\text { Condition }\end{array}$} & $\begin{array}{c}\text { Overall } \\
\text { Equivalence } \\
\text { Ratio }\end{array}$ & $\begin{array}{c}\text { Liquid } \\
\text { Entrainment } \\
\text { Fraction }\end{array}$ & $\begin{array}{c}\text { Vapor Phase } \\
\text { Equivalence } \\
\text { Ratio }\end{array}$ & $\begin{array}{l}\text { Energy } \\
\text { Density }\end{array}$ \\
\hline & -- & -- & 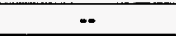 & $\mathrm{J} / \mathrm{L}$ \\
\hline \multicolumn{5}{|l|}{ Baseline } \\
\hline \multicolumn{5}{|c|}{ Overall Equivalence Ratio } \\
\hline & 1.0 & & 0.18 & 1357 \\
\hline & 2.0 & & 0.273 & 2484 \\
\hline & 4.0 & & 0.417 & 3832 \\
\hline & 5.0 & & 0.479 & 3484 \\
\hline & 6.0 & & 0.537 & 3171 \\
\hline \multicolumn{5}{|c|}{ Liquid Entrainment Fraction } \\
\hline & & 0.00 & 0.349 & 1391 \\
\hline & & 0.10 & 0.349 & 2471 \\
\hline & & 0.30 & 0.349 & 3817 \\
\hline & & 0.40 & 0.349 & 3449 \\
\hline & & 0.50 & 0.349 & 3113 \\
\hline \multicolumn{5}{|c|}{ Average Results } \\
\hline
\end{tabular}




\section{REPORT DOCUMENTATION PAGE}

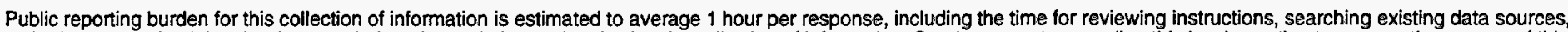

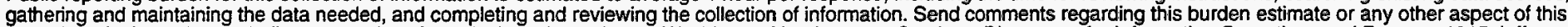

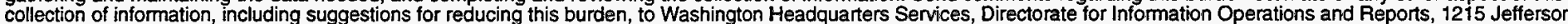

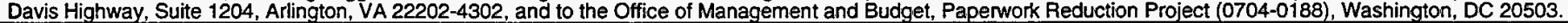
1. AGENCY USE ONLY (Leave blank)
2. REPORT DATE
3. REPORT TYPE AND DATES COVERED
May 1998
Technical report

4. TITLE AND SUBTITLE

5. FUNDING NUMBERS

Modeling and Cold Start in Alcohol-Fueled Engines

(C) N/A

(TA) FU702130

6. AUTHOR(S)

A. J. Markel and B. K. Bailey

7. PERFORMING ORGANIZATION NAME(S) AND ADDRESS(ES)

8. PERFORMING ORGANIZATION REPORT NUMBER

National Renewable Energy Laboratory

1617 Cole Blvd.

NRELTP-540-24180

Golden, CO 80401

9. SPONSORING/MONITORING AGENCY NAME(S) AND ADDRESS(ES)

10. SPONSORING/MONITORING

AGENCY REPORT NUMBER

U.S. Department of Energy

1000 Independence Ave., SW

Washington, DC 20585

\section{SUPPLEMENTARY NOTES}

\section{2a. DISTRIBUTION/AVAILABILITY STATEMENT}

National Technical Information Service

U.S. Department of Commerce

5285 Port Royal Road

Springfield, VA 22161 12b. DISTRIBUTION CODE

UC-1504

13. ABSTRACT (Maximum 200 words) Neat alcohol fuels offer several benefits over conventional gasoline in automotive applications. However, their low vapor pressure and high heat of vaporization make it difficult to produce a flammable vapor composition from a neat alcohol fuel during a start under cold ambient conditions. Various methods have been introduced to compensate for this deficiency. In this study, we applied computer modeling and simulation to evaluate the potential of four cold-start technologies for engines fueled by near-neat alcohol. The four technologies were a rich combustor device, a partial oxidation reactor, a catalytic reformer, and an enhanced ignition system. We ranked the competing technologies by their ability to meet two primary criteria for cold starting an engine at $-25^{\circ} \mathrm{C}$ and also by several secondary parameters related to commercialization. Our analysis results suggest that of the four technologies evaluated, the enhanced ignition system is the best option for further development.

\section{SUBJECT TERMS}

Alternative fuels, alcohol fuels, modeling technologies, cold starts
15. NUMBER OF PAGES 50

16. PRICE CODE

\section{SECURITY CLASSIFICATION OF REPORT}

18. SECURITY CLASSIFICATION OF THIS PAGE

\section{SECURITY CLASSIFICATION OF ABSTRACT}

20. LIMITATION OF ABSTRACT
Standard Form 298 (Rev, 2-89 Prescribed by ANS1 Std. 239-1 


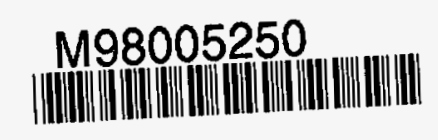

Report Number (14)NREL/TP_- $540-24180$

Publ. Date (11)

Sponsor Code (18)

199805

UC Category (19)

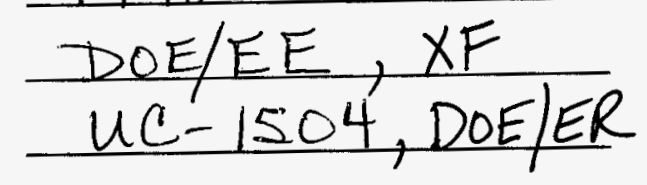

19980622073 